UNIVERSIDADE DE SÃO PAULO

CENTRO DE ENERGIA NUCLEAR NA AGRICULTURA

GRAZIELA CRISTINA ROSSI DE MOURA ANDRADE

Análises multirresíduos de agrotóxicos em tomate (Lycopersicon esculentum Mill) utilizando CG-EM e monitoramento

Piracicaba 
GRAZIELA CRISTINA ROSSI DE MOURA ANDRADE

\section{Análises multirresíduos de agrotóxicos em tomate (Lycopersicon esculentum Mill) utilizando CG-EM e monitoramento}

Dissertação apresentada ao Centro de Energia Nuclear na Agricultura da Universidade de São Paulo para obtenção do título de Mestre em Ciências.

Área de Concentração: Química na Agricultura e no Ambiente

Orientador: Prof. Dr. Valdemar Luiz Tornisielo 
AUTORIZO A DIVULGAÇÃO TOTAL OU PARCIAL DESTE TRABALHO, POR QUALQUER MEIO CONVENCIONAL OU ELETRÔNICO, PARA FINS DE ESTUDO E PESQUISA, DESDE QUE CITADA A FONTE.

Dados Internacionais de Catalogação na Publicação (CIP) Seção Técnica de Biblioteca - CENA/USP

Moura Andrade, Graziela Cristina Rossi de

Análises multirresíduos de agrotóxicos em tomate (Lycopersicon esculentum Mill) utilizando o CG-EM e monitoramento / Graziela Cristina Rossi de Moura Andrade; orientador Valdemar Luiz Tornisielo. - - Piracicaba, 2009.

115 p.: fig.

Dissertação (Mestrado - Programa de Pós-Graduação em Ciências. Área de Concentração: Química na Agricultura e no Ambiente) - Centro de Energia Nuclear na Agricultura da Universidade de São Paulo.

1. Análise de alimentos 2. Cromatografia gasosa capilar 3. Espectrometria de massas 4. Inseticidas I. Título

CDU 635.64:632.95.028 
Aos meus pais, José Carlos (in memoriam)e Rosa, pelo carinho e pelo imensurável amor que me dedicaram, e pelo exemplo de que palavras amáveis não custam nada e conseguem muito.....

Ao meu marido Daniel, pelo apoio, amore por me ajudar a compreender que na plenitude da felicidade, cada dia é uma vida inteira..... 


\section{AGRADECIMENTOS}

Ao Prof. Dr. Valdemar Luiz Tornisielo, pela paciência, atenção e apoio durante o desenvolvimento deste trabalho.

À Fundação de Amparo à Pesquisa do Estado de São Paulo pela concessão da bolsa de mestrado e pelo apoio financeiro para a concretização desta pesquisa.

À Dra . Rosana Maria Oliveira Freguglia, pela atenção e ensinamentos sobre cromatografia tão fundamentais para a realização deste trabalho.

À amiga Carla Crispino Kamogawa, pelo incentivo e apoio.

Aos queridos amigos do Laboratório de Ecotoxicologia: Nádia, Giuliane,

Cidinha, Neide, Marília, Manoela, Rafael, Franz, Aderbal, Paulo, Priscilla e Marcela pelo agradável convívio e apoio.

À Dra . Lucimara Blumer, pelo auxílio nas análises estatísticas.

Ao Dr. Sady Aléxis Chavauty, pela apresentação ao método QuEChERS e pelas correções e elogios.

Aos técnicos do Laboratório de Ecotoxicologia: Dorelli, Rodrigo, Rosangela e Silvânia, pelo auxílio prestado à realização deste trabalho.

Ao pesquisador Dr. Jorge José do Vale Oliveira, do Ital - Campinas, pela colaboração na fase inicial deste projeto.

À pesquisadora Dr ${ }^{\mathrm{a}}$. Regina Prado Zanes Furlani, pela elucidação de dúvidas sobre o método e pela atenção e carinho. 
À todos os funcionários da Bioagri Laboratórios Ltda, pelas dicas nas análises cromatográficas, em especial ao Max pela ajuda prestada.

À todos os funcionários do Cena/USP, que participaram de forma direta ou indireta neste trabalho.

À todos os funcionários da Biblioteca, em especial à Marilia Ribeiro Garcia Henyei pela gentileza e atenção na correção deste trabalho.

À minha eterna orientadora $\mathrm{Dr}^{\mathrm{a}}$. Maria Josefa dos Santos Yabe, da Universidade Estadual de Londrina, pelo apoio e exemplo...

Ao Gilmar R. Souza da Thermo Scientific pela ajuda nas análises cromatográficas.

À Cláudia do Varejão Benjamim e Ronaldo e Claudete do Varejão Vale Verde pela disponibilização das amostras e pela gentileza.

À toda minha família e amigos, principalmente às minhas irmãs Gi e Ani, e a cada um que de alguma forma torceu por mim e assim ajudou-me a fortalecer e concretizar esse sonho.

A Deus, que tanto me ajudou, dando-me saúde, paciência, entendimento e dirigindo meus caminhos, muitas vezes colocando pessoas especiais em minha vida. 
"Reparta o seu conhecimento. É uma forma de alcançar a imortalidade."

Dalai Lama

"Comece fazendo o que é necessário, depois o que é possivel, em breve estarás fazendo o impossivel."

São Francisco de Assis 


\section{RESUMO}

MOURA-ANDRADE, G. C. R. Análises multirresiduos de agrotóxicos em tomate (Lycopersicon esculentum Mill) utilizando CG-EM e monitoramento. 2009. 115 f. Dissertação (Mestrado) - Centro de Energia Nuclear na Agricultura, Universidade de São Paulo, Piracicaba, 2009.

A preocupação com os danos provocados à saúde do trabalhador rural e ao meio ambiente devido ao uso indiscriminado de agrotóxicos tem aumentado nos últimos anos. O uso generalizado e intensivo destas substâncias tem gerado diversos problemas relacionados à saúde pública e ao desequilíbrio ambiental, incluindo: intoxicações de agricultores, contaminação de alimentos, água e solos. O tomate é hoje, uma hortaliça bastante conhecida e de elevado consumo no mundo. Sua cultura é bastante afetada por quebras de rendimento e depreciação da qualidade de matéria- prima, em razão da ocorrência de doenças, pragas e estresses abióticos. Apesar da preocupação com o monitoramento dos resíduos de agrotóxicos nos alimentos, poucas metodologias analíticas podem alcançar resultados de alta qualidade simultaneamente para uma gama extensiva de agrotóxicos. No presente estudo, foi desenvolvida e validada a metodologia de análise de multirresiduos QuEChERS (quick, easy, cheap, effective, rugged, and safe) para quantificação de resíduos de agrotóxicos em tomate. Este método provê resultados de forma rápida, fácil, com custo acessivel e com alta qualidade. Foram analisados agrotóxicos utilizados principalmente no controle de insetos, sendo: buprofezina, carbofurano, a-endossulfam, $\beta$-endossulfam, sulfato de endossulfam e monocrotofós. Para isso, realizou-se a fortificação do tomate, previamente homogeneizado, com soluções contendo os agrotóxicos em 3 níveis de fortificação $(0,0625 ; 0,25$ e 1,00 mg/Kg). A purificação dos extratos foi realizada através de clean-up dispersivo, e em seguida os extratos foram analisados por CG-EM modo SIM. Neste estudo avaliaram-se os seguintes parâmetros de validação do método: linearidade da curva analítica, sensibilidade, limite de detecção (LD), limite de quantificação (LQ), o efeito matriz, bem como a precisão e a exatidão (em 
termos de percentual de recuperação). A faixa linear de concentração das curvas analiticas situou-se entre 0,25 a 4,0 ng. $\mu \mathrm{L}^{-1}$ com valores de $\mathrm{r}^{2}$ maiores que 0,99 (na matriz). A técnica CG-EM modo SIM promoveu a quantificação (critérios de recuperação entre 70 e 120\% e valores de CV\% menores que 20\%) de todos os agrotóxicos estudados. Portanto, conclui-se que o método mostrou-se adequado às análises multirresíduos dos agrotóxicos em tomate, apresentando sensibilidade e seletividade adequadas, e todos os parâmetros de validação encontram-se de acordo com os limites sugeridos para validação de métodos cromatográficos. Foram coletadas amostras ( $n=33)$ em varejões na cidade de Piracicaba e os níveis residuais de agrotóxicos apresentaram-se abaixo dos limites de detecção para os produtos analisados. Os produtos acefato, deltametrina, difenoconazole e fenpropatrina foram avaliados no sistema CG-EM e não apresentaram sensibilidade e seletividade nas condições cromatográficas aplicadas. A implementação de novos métodos cromatográficos para análise de resíduos de agrotóxicos em alimentos devem ser fomentados para contribuir com o monitoramento eficiente, visando avaliar a qualidade e segurança dos alimentos consumidos pela população, caracterizar as fontes de contaminação e proporcionar uma avaliação quanto ao uso inadequado e não autorizado dos agrotóxicos.

Palavras-chave: Tomate. Agrotóxicos. CG-EM modo SIM. Método QuEChERS. Análises multirresíduos. 


\section{ABSTRACT}

MOURA-ANDRADE, G. C. R. Multiresidue analysis of pesticides in tomato (Lycopersicon esculentum Mill) using GC-MS and monitoring. 2009. 115 f. Dissertação (Mestrado) - Centro de Energia Nuclear na Agricultura, Universidade de São Paulo, Piracicaba, 2009.

The concernment about the damage caused to the health of rural workers and the environment due to indiscriminate use of pesticides has increased in recent years. The commonly and intensive use of these substances has created several problems related to public health and environmental disequilibrium, including poisoning of farmers, contamination of food, water and soil. Nowadays, the tomato is a well known vegetables and high consumption in the world. Its culture is highly affected by loss of yield and depreciation of the quality of raw material, due to the occurrence of diseases, pests and abiotic stresses. Considering the concernment about the monitoring of pesticide residues in food, few analytical methods can achieve high quality results for both a wide range of pesticides. In this study, was developed and validated the methodology of multiresidue analysis QuEChERS (quick, easy, cheap, effective, rugged, and safe) for quantification of residues of pesticides in tomatoes. This method provides results quick, easy, inexpensive and high quality. Were analyzed mainly pesticides used to control insects, are: buprofezina, carbofuran, a-endossulfam, $\beta$ endossulfam, sulphate endossulfam and monocrotophos. Then, performed a spiking of tomatoes homogenized previously, with solutions containing pesticides, in 3 of fortification levels $(0.0625,0.25$ and $1.00 \mathrm{mg} / \mathrm{kg})$. The purification of the extracts was performed by dispersive clean-up, and then the extracts were analyzed by GC-MS using SIM mode. This study evaluated the following parameters for validation of the method: linearity, sensitivity, limit of detection (LOD), limit of quantification (LOQ), matrix effect, precision and accuracy (in terms of percentage of recovery). The linear range of 
concentration of the analytical curves was between 0.25 to $4.0 \mathrm{ng} \cdot \mathrm{\mu L}^{-1}$ with $\mathrm{r}^{2}$ values of greater than 0.99 (in the matrix). The technique GC-MS SIM mode promoted quantification (criteria of recovery between 70 and $120 \%$ and RSD\% values of less than 20\%) of all pesticides studied. Therefore, concluded that the method proved to be appropriate for multiresidue analysis of pesticides in tomatoes, showing sensitivity and selectivity adequate, and all parameters of validation are according with the limits suggested for validation of chromatographic methods. Samples were collected $(n=33)$ in the Piracicaba city in local market and the levels of pesticide residues were below the limits of detection for the products analyzed. The products acephate, deltamethrin, difenoconazole and fenpropathrin were evaluated in the GC-MS and showed no sensitivity and selectivity in the chromatographic conditions applied. The implementation of new chromatographic methods for analysis of pesticide residues in food should be encouraged to contribute to efficient monitoring to evaluate the quality and safety of food consumed by the population, identify the sources of contamination and provide an assessment as to the misuse and use unauthorized pesticides.

Keywords: Tomato. Pesticides. GC-MS SIM mode. QuEChERS method. Multiresidue analysis. 


\section{LISTA DE ILUSTRAÇÕES}

Figura 1 - Seção transversal do fruto do tomateiro. 26

Figura 2 - Maiores produtores mundiais de tomate em 2007 (FAO, 2009c) . 30

Figura 3 - Cartograma da produção de tomate (em toneladas) no Brasil, na safra de 2007

Figura 4 - Quantidade produzida em tonelada no ano de 2007 para a cultura de tomate nos estados brasileiros 32

Figura 5 - Ilustração simplificada da causa do efeito de matriz no aumento de resposta cromatográfica; C - número de moléculas do analito injetadas; X e Y - números de sítios ativos livres para adsorção de moléculas no injetor; • moléculas do analito na amostra injetada; - porção das moléculas do analito adsorvidas no liner; moléculas de componentes da matriz na amostra injetada; $\Delta$ porção dos componentes da matriz adsorvidos no liner; (C-X) < (C-Y).

Figura 6 - Ilustração dos passos analiticos para realização do método QuEChERS nas análises da matriz tomate 78

Figura 7 - Representação esquemática do método de análise de resíduos de agrotóxicos em tomate, utilizando método QuEChERS

Figura 8 - Cromatograma total obtido por CG-EM modo SIM, para extrato "branco" de tomate

Figura 9 - Cromatograma dos agrotóxicos analisados por CG-EM modo SIM, quando em soluções analíticas $1,0 \mathrm{ng} \cdot \mu \mathrm{L}^{-1}$ preparadas em a) solvente orgânico (tolueno); b) extrato "branco" fortificado da matriz (tomate)

Figura 10 - Recuperações obtidas para os agrotóxicos nos três diferentes níveis de fortificação $(0,06 ; 0,25$ e 1,00 mg/kg)

Figura 11 - Cromatograma obtido por CG-EM modo SIM para tomate fortificado ao nivel de (a) 0,06 (b) 0,25 e (c) 1,00 mg/ $\mathrm{kg}$ 93

Figura 12 - Comparação visual entre as inclinações das curvas analíticas preparadas em tolueno e em matriz de tomate 
Figura 13 - Fórmula estrutural do acefato .......................................... 110

Figura 14 - Fórmula estrutural da buprofezina................................... 111

Figura 15 - Fórmula estrutural do carbofurano .................................... 112

Figura 16 - Fórmula estrutural da deltametrina .................................. 112

Figura 17 - Fórmula estrutural do difenoconazol ................................ 113

Figura 18 - Fórmula estrutural do $\alpha, \beta$ endossulfam e endossulfam

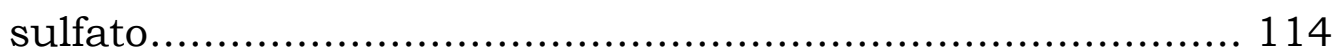

Figura 19 - Fórmula estrutural da fenpropatrina................................. 115

Figura 20 - Fórmula estrutural do monocrotofós ................................. 115 


\section{LISTA DE TABELAS}

Tabela 1 - Composição centesimal do tomate (Lycopersicum esculentum Mill ) cru (em cada $100 \mathrm{~g})$ 28

Tabela 2 - Classes toxicológicas dos agrotóxicos e respectivas cores obrigatórias nos rótulos das formulações

Tabela 3 - Casos de intoxicação por agrotóxicos de uso agrícola no Brasil em 2003, segundo circunstâncias e evolução.

Tabela 4 - Recentes publicações de análises multirresíduos utilizando o método QuEChERS em diferentes matrizes

Tabela 5 - Agrotóxicos analisados por CG-EM modo SIM, com informações de pureza, classe, fornecedor, grupo químico e fórmula molecular .72

Tabela 6 - Agrotóxicos analisados por CG-EM, modo de aquisição SIM, valores de $t_{R}$, massa molar e íons monitorados .84

Tabela 7 - Média das Áreas das injeções e CV para as soluções de 0,05; 0,10; 0,$15 ; 0,25 ; 0,30$ e 0,50 ng. $\mu \mathrm{L}^{-1}$ dos agrotóxicos analisados por CGEM modo SIM 86

Tabela 8 - Estimativa dos coeficientes linear (s) e angular (S) das curvas analíticas, limites de detecção (LD) e quantificação (LQ) e LMR.. 87

Tabela 9 - Parâmetros das curvas analíticas, obtidos para os agrotóxicos analisados por CG-EM modo SIM, a partir das soluções 0,25; 0,$50 ; 1,00 ; 2,00 ; 3,00$ e 4,00 ng. $\mu \mathrm{L}^{-1}$ em tolueno e na matriz .....88

Tabela 10 - Porcentagem de recuperação (Rec\%), desvio padrão e coeficiente de variação (CV\%) obtido após três extrações dos agrotóxicos em tomate

Tabela 11 - Média dos percentuais de recuperação $\left(R_{M}\right)$ e coeficiente de variação $\left(\mathrm{CV}_{\mathrm{M}}\right)$, obtidos a partir da extração com acetonitrila do tomate fortificado, aos niveis de 0,0625;0,25 e 1,00 mg/Kg dos agrotóxicos analisados por CG-EM modo SIM. 92 
Tabela 12 - Resultado dos efeitos de matriz pela variação dos coeficientes angulares das curvas em solvente e matriz, e dos testes de $\mathrm{F}$ e $\mathrm{t}$ ao nivel de $95 \%$ de confiança ............................................. 97 


\section{LISTA DE SIGLAS}

ANVISA Agência Nacional de Vigilância Sanitária

APCI Atmospheric Pressure Chemical Ionization (Ionização química à pressão atmosférica)

API Atmospheric Pressure Ionization (Ionização à pressão atmosférica)

APPI Atmospheric Pressure Photoionization (Fotoionização à pressão atmosférica)

CEAGESP Companhia de Entrepostos e Armazéns Gerais de São Paulo

CG Cromatografia Gasosa

CG-EM Cromatografia Gasosa acoplada a Espectrometria de Massas

CI Chemical Ionization (Ionização Química)

CL Cromatografia Liquida

CV Coeficiente de Variação

$\mathrm{DL}_{50} \quad$ Dose Média Letal via oral

dSPE Dispersive Solid-Phase Extraction (Extração em fase sólida dispersiva)

ECD Electron Capture Detector (Detector de captura de elétrons)

EI Electron Impact Ionization (Ionização por Impacto de Elétrons)

EM Espectrometria de Massas

EMBRAPA Empresa Brasileira de Pesquisa Agropecuária

ESI Electrospray Ionization (Ionização por eletrospray)

FAO Food and Agriculture Organization (Organização do Alimento e Agricultura)

GCB Graphitized Carbon Black (Carvão ativo grafitizado)

GPC Gel Permeation Chromatography (Cromatografia de permeação em gel)

IBAMA Instituto Brasileiro do Meio Ambiente e dos Recursos Naturais Renováveis

IBGE Instituto Brasileiro de Geografia e Estatística

IDA Ingestão Diária Aceitável

INMETRO Instituto Nacional de Metrologia 
IR Infrared (Infravermelho)

ISO International Organization for Standardization (Organização Internacional para Padronização)

ITEP Instituto de Tecnologia de Pernambuco

IUPAC International Union of Pure and Applied Chemistry (União Internacional de Química Pura e Aplicada)

LC-MS/MS Liquid Chromatography - Mass Spectrometry (Cromatografia Líquida acoplada a Espectrometria de Massas)

LD Limite de Detecção

LDI Laser Desorption Ionization (Ionização/dessorção com laser)

LLE Liquid-Liquid Extraction (Extração Líquido-Líquido)

LMR Limite Máximo de Resíduo

LQ Limite de Quantificação

MALDI Matrix-Assisted Laser Desorption/Ionization (Ionização/dessorção a laser de matriz assistida)

MAPA Ministério da Agricultura, Pecuária e Abastecimento

MSPD Matrix Solid Phase Dispersion (Dispersão da matriz em fase sólida)

PSA Primary Secondary Amine (Amina primária secundária) (NPropiletilenodiaminossilano)

QuEChERS Quick, Easy, Cheap, Rugged and Safe (Rápido, fácil, econômico, robusto e seguro)

RSD Relative Standard Deviation (Desvio padrão relativo)

SFE Supercritical Fluid Extraction (Extração com fluido supercrítico)

SIM Selected Ion Monitoring (Monitoramento de Íon Selecionado)

SINDAG Sindicato Nacional da Indústria de Produtos para Defesa Agrícola

SINITOX Sistema Nacional de Informações Tóxico-Farmacológicas

SPE Solid Phase Extraction (Extração em fase sólida)

SPME Solid Phase Micro-Extraction (Micro extração em fase sólida)

SRM Selected Reaction Monitoring (Monitoração de reação selecionada)

TOF Time of Flight (Detector por tempo de vôo) 
USDA United State Department of Agriculture (Departamento de Agricultura dos Estados Unidos)

UV

Ultravioleta 


\section{SUMÁRIO}

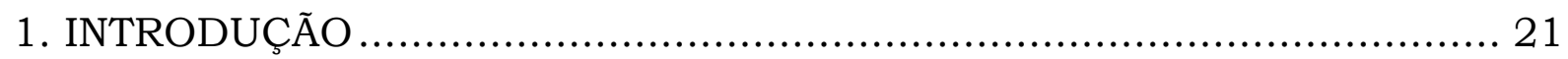

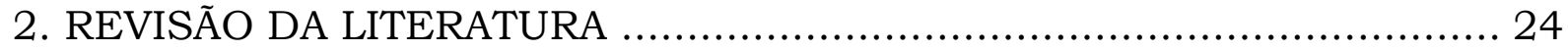

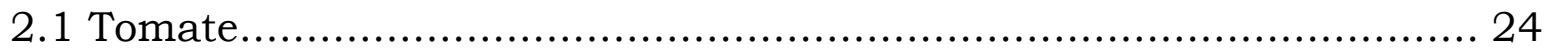

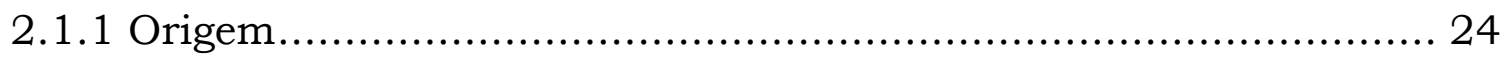

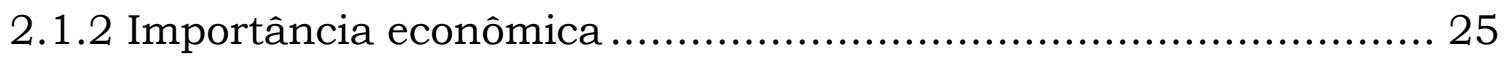

2.1.3 Importância nutricional e composição ...................................... 26

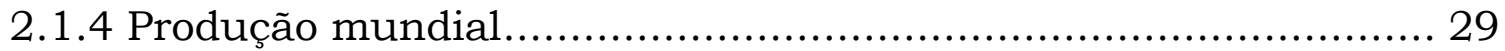

2.1.5 Produção no Brasil.............................................................. 30

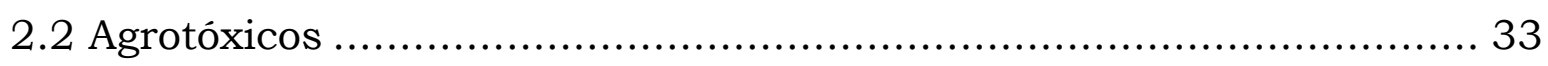

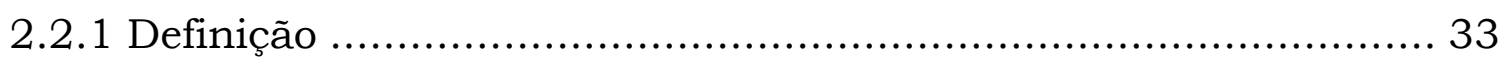

2.2.2 Histórico no mundo e no Brasil ............................................ 35

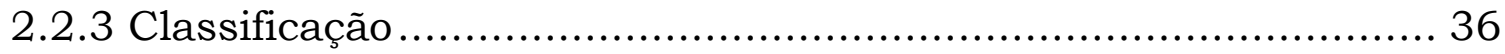

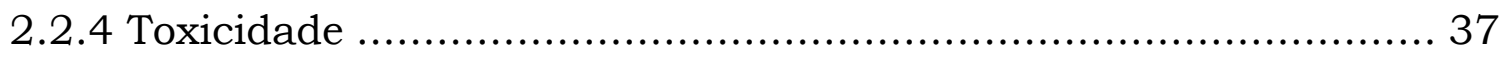

2.2.5 Limites máximos de resíduos (LMR) ...................................... 40

2.2.6 Uso de agrotóxicos no cultivo de tomate ................................. 41

2.3 Análise de agrotóxicos em alimentos ........................................ 42

2.3.1 Extração de agrotóxicos ...................................................... 45

2.3.2 Método QuEChERS - extração em fase sólida dispersiva (dSPE) . 48

2.3.3 Análise de agrotóxicos por cromatografia gasosa acoplada a espectrometria de massas ............................................... 52

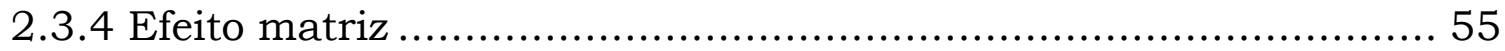

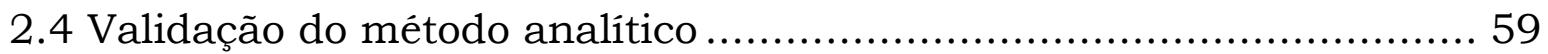

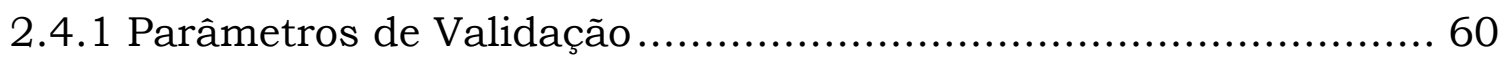

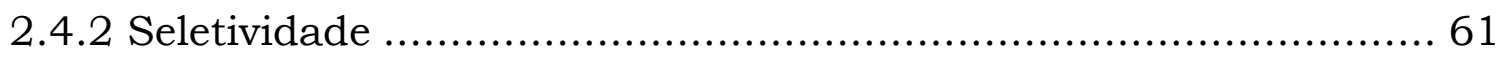

2.4.3 Linearidade e faixa linear de trabalho....................................... 62

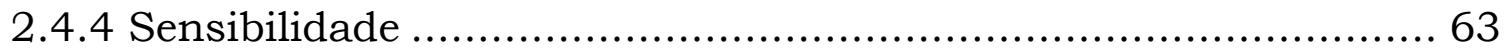

2.4.5 Limite de detecção e limite de quantificação .............................. 64

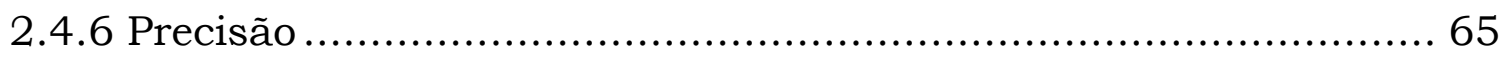

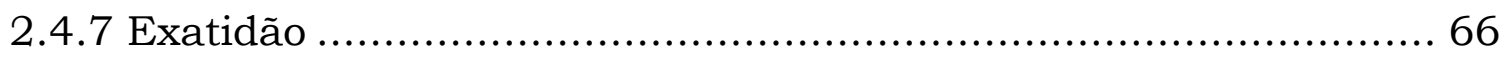

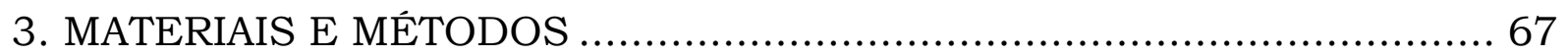




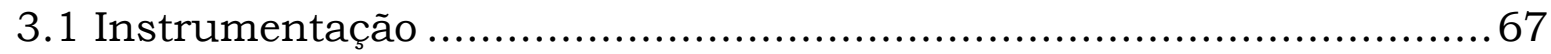

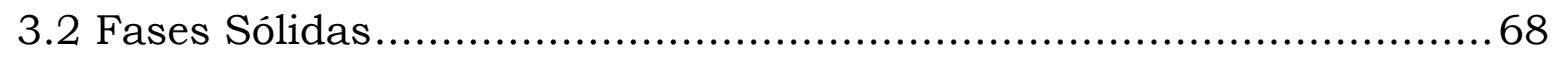

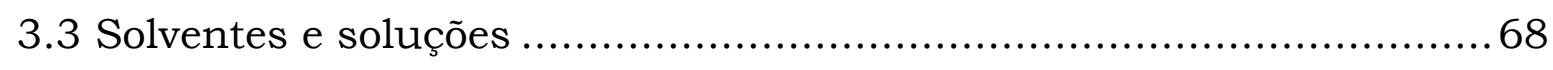

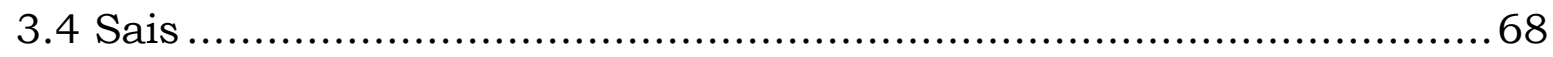

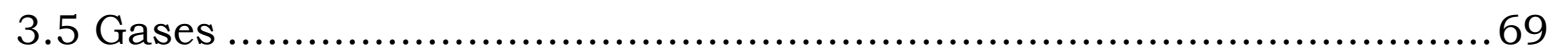

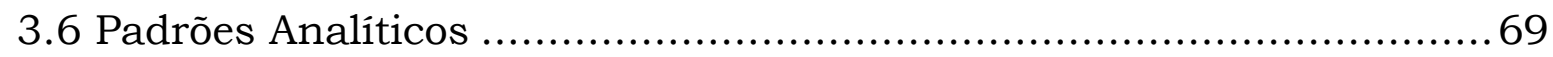

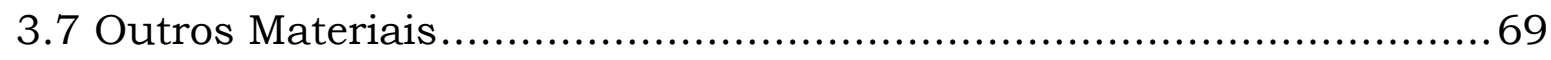

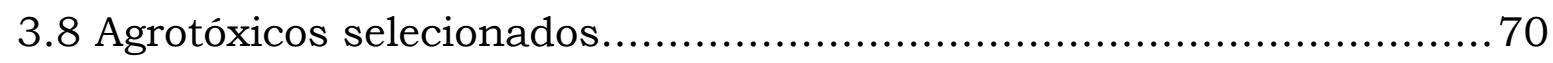

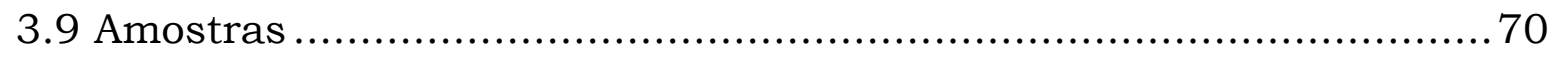

3.10 Preparo das amostras ........................................................... 71

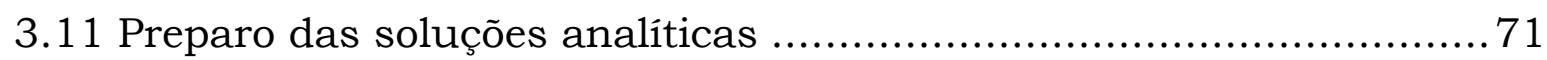

3.11.1 Soluções de padrões de agrotóxicos ........................................71

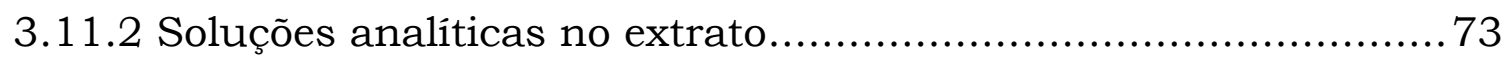

3.11.3 Soluções analíticas em solvente ............................................ 73

3.12 Fortificações de amostras de tomate ...........................................73

3.13 Análises Cromatográficas por CG-EM …................................... 74

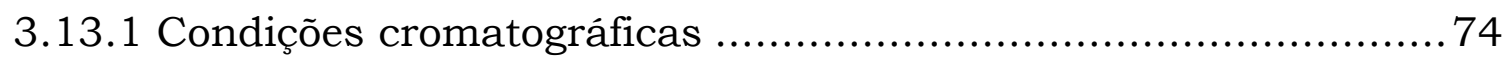

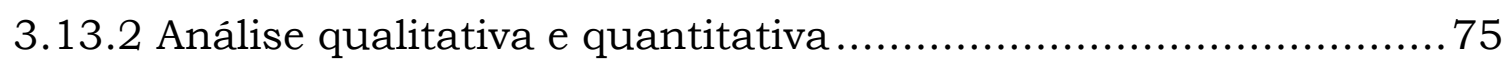

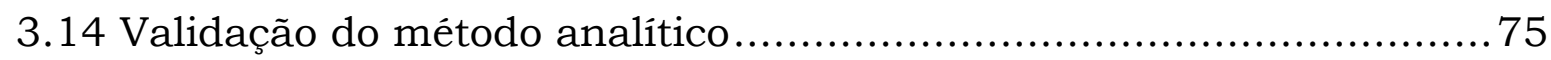

3.14.1 Determinação da linearidade das curvas analíticas .................. 75

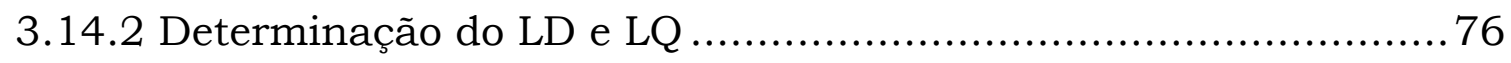

3.14.3 Ensaios de extração, fortificação e recuperação (\%) ....................76

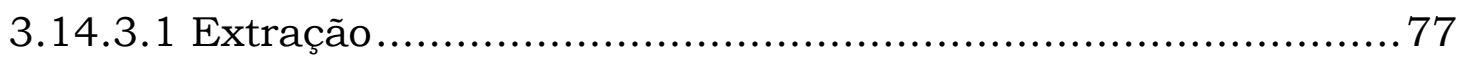

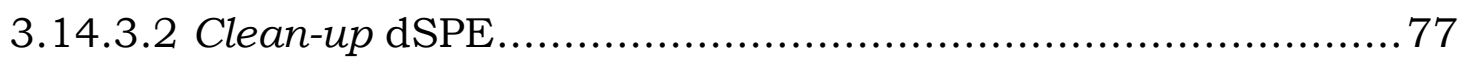

3.14.3.3 Evaporação e troca de solvente ......................................... 80

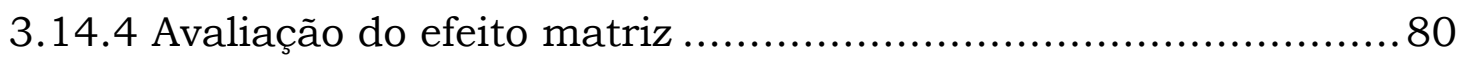

3.15 Ensaios de extração para análise das amostras............................82

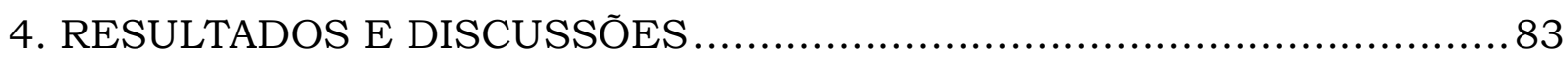

4.1 Condições de análise por CG-EM (Modo SIM) ................................ 83

4.2 Validação do método analítico................................................... 84

4.2.1 Determinação dos valores de LD e LQ ...................................... 85

4.2.2 Linearidade das curvas analiticas ...................................... 87

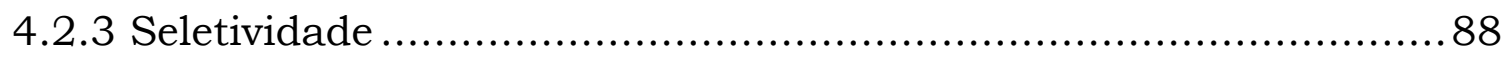




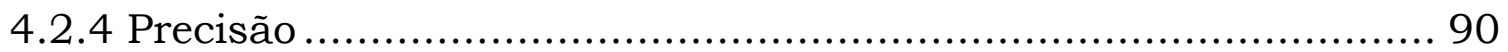

4.2.5 Ensaios de fortificação para recuperação (\%) .............................. 91

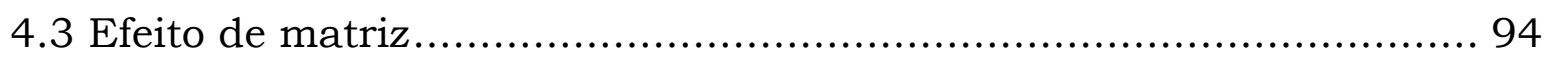

4.4 Determinação de agrotóxicos em amostras comerciais de tomate..... 97

4.5 Agrotóxicos acefato, deltametrina, difenoconazol e fenpropatrina...... 98

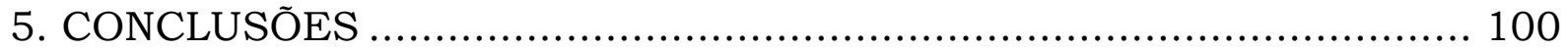

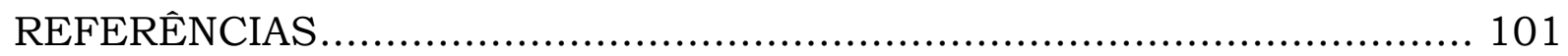

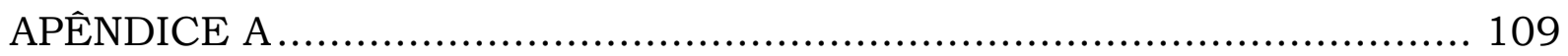




\section{INTRODUÇÃO}

O crescimento da população mundial e a consequente necessidade do aumento da produtividade no setor agrícola levaram a intensificação do uso de agrotóxicos na produção de alimentos, cujas consequências para a saúde do homem e o impacto ambiental não são totalmente conhecidos. No Brasil, a presença de resíduos de defensivos em alimentos, somada à contaminação da água, constitui um problema de saúde pública (ARAÚJO et al., 2000).

A rapidez de ação, facilidade de uso, economicidade e eficiência dos produtos químicos aparentemente constituíram-se na solução de inúmeros problemas agrícolas, fazendo com que houvesse um incremento substancial na produção e consumo de agrotóxicos nas ultimas décadas. Entretanto, essa grande utilização, muitas vezes de forma inadequada, pode eventualmente trazer problemas de saúde pública, com grande número de intoxicações (PESSINI, 2003).

A falta de orientação técnica na aplicação dos agrotóxicos na cultura de tomate revela também o fato de estes serem aplicados preventivamente. Isto é um grave problema fitossanitário, porque possibilita o aumento da resistência de pragas e requer um crescente uso de novos produtos e misturas, o que pode acarretar em perdas de produção e elevação de custos (ARAÚJO et al., 2000).

$\mathrm{Na}$ busca para eliminação deste problema, os ambientalistas assumiram a defesa de uma agricultura sem a utilização de agrotóxicos. Entretanto, sabe-se que culturas livres de agrotóxicos geram colheitas com menor rendimento, o que conduz a maiores áreas de cultivo para se obter a mesma quantidade de alimentos, colocando em risco novos ecossistemas. Por isso, os agrotóxicos sintéticos continuam sendo as alternativas mais eficazes no controle de pragas (PINHO, 2007). 
A análise de resíduos de agrotóxicos desempenha um papel indispensável na estimativa da exposição dos seres humanos e do ambiente a esses produtos e no controle do cumprimento dos agricultores às boas práticas agrícolas, visando facilitar as decisões regulamentares e comerciais e reforçar a confiança dos consumidores na segurança alimentar. Para suprir essas necessidades, fabricantes de instrumentos e analistas de resíduos ao redor do mundo estão em constante desenvolvimento e implementação de novas técnicas analíticas e abordagens com o objetivo de simplificar e acelerar os procedimentos, melhorar a qualidade da análise e reduzir o consumo de reagentes e trabalho analitico (ANASTASSIADES; SCHERBAUM, 2005).

Desde que a presença de resíduos de agrotóxicos em produtos agrícolas tornou-se evidente e, como conseqüência dos riscos potenciais que representam para a saúde humana, diversas leis de proteção da saúde pública foram aprovadas em numerosos países. Tal interesse, não apenas dos governos, mas que também refletiu na opinião pública, levou à intensificação das ações para assegurar a segurança do fornecimento de alimentos e para proteger os seres humanos dos resíduos danosos. Neste contexto, a química analítica tem uma posição fundamental, pois desempenha um papel importante em vários domínios: a definição de "níveis seguros", bem como fornecer informações adicionais para o estabelecimento dos mecanismos básicos de toxicidade; localização destes compostos na cadeia alimentar; fornecer apoio para o estabelecimento dos níveis regulamentares ou "limites máximos de resíduos" (LMR); e a determinação da presença de resíduo de agrotóxicos e/ou seus metabólitos no abastecimento alimentar (AGÜERA; KOK, 2005).

Tradicionalmente, a cromatografia gasosa (CG) tem sido a técnica analítica escolhida para análise de resíduo em alimentos, e avanços nesta área têm sido estreitamente associados à evolução da técnica. $O$ acoplamento com a espectrometria de massa (EM) tornou-se viável com a introdução da coluna capilar. A introdução de detectores ion-trap, no final de 1980, representou uma melhora importante na análise dos resíduos de 
agrotóxicos, consequência de sua excelente sensibilidade em niveis de picograma (AGÜERA; KOK, 2005).

Visto que a utilização de agrotóxicos para o controle de doenças e pragas na cultura de tomate no Brasil é expressiva, o monitoramento detalhado e eficiente dos resíduos nesta hortaliça é de fundamental importância, principalmente para assegurar a qualidade dos alimentos que chegam à mesa do consumidor. Para isso faz-se necessário um estudo no qual sejam efetuadas análises multirresiduos de agrotóxicos com metodologia analítica que possa alcançar resultados de alta qualidade simultaneamente para uma ampla variedade de agrotóxicos.

Este estudo tem como propósito a validação do método multirresíduo de extração QuEChERS para amostras de tomate e análise por cromatografia gasosa acoplada a espectrometria de massas (CG-EM) dos agrotóxicos: acefato, buprofezina, carbofurano, a-endossulfam, $\beta$-endossulfam, sulfato de endossulfam, deltametrina, difenoconazol, fenpropatrina e monocrotofós, de diferentes grupos químicos, bem como o monitoramento de agosto de 2007 a outubro de 2008 em amostras $(n=33)$ coletadas em varejões da cidade de Piracicaba-SP, visando facilitar e incentivar a investigação de multirresíduos nesta matriz. 


\section{REVISÃO DA LITERATURA}

\subsection{Tomate}

O tomate é uma planta anual, que pode atingir uma altura de mais de dois metros. A primeira colheita é realizada 45-55 dias após a florescência, ou 90-120 dias depois da sementeira. A forma dos frutos difere conforme a cultivar (variedade cultivada). O fruto não maduro é verde, o maduro varia entre amarelo, cor-de-laranja a vermelho. No geral, o fruto é redondo, com uma superficie lisa ou canelada (NAIKA et al., 2006).

A cultura do tomate, nas regiões tropicais e subtropicais, é geralmente afetada por expressivas quebras de rendimento e depreciação da qualidade de matéria-prima, em razão da ocorrência de doenças, pragas e estresses abióticos. Entre as pragas de maior preocupação na tomaticultura destacam-se a mosca-branca e a traça-do- tomateiro (MELO; VILELA, 2005).

\subsubsection{Origem}

É originário da zona andina de América do Sul, mas foi domesticado no México e introduzido na Europa em 1544. Mais tarde disseminou-se da Europa para a Ásia Meridional e Oriental, África e Oriente Médio. Mais recentemente, o tomate silvestre foi distribuido para outras partes da América do Sul e do México (NAIKA et al., 2006). 


\subsubsection{Importância econômica}

No último relatório divulgado em 2008 pelo United State Department of Agriculture - USDA o Brasil não importou tomates em 2007, mas ampliou as exportações, devido a um período prolongado de geada na Argentina, de praticamente zero para 10.000 toneladas. O maior consumo e exportação de tomate levaram a preços mais elevados em todas as áreas. O clima mais seco e quente manteve sob controle doenças e insetos, contribuindo para elevados rendimentos da cultura em 2007 no Brasil, sendo que os maiores produtores foram os estados de Goiás, Minas Gerais e São Paulo, que juntos alcançaram $57 \%$ do total da produção (USDA, 2008).

As importações de tomate fresco no Brasil, que eram principalmente provenientes de outros países sul-americanos, caíram consideravelmente nos últimos anos. O Uruguai é tradicionalmente a maior fonte de importações do Brasil de tomate fresco (USDA, 2008).

O preço médio do tomate entre abril e outubro de 2007 foi de $\mathrm{R} \$ 19,59$ (US\$ 12) por caixa de 23 quilos em Minas Gerais e R\$17 (US\$10), em São Paulo, equivalente a um aumento de $82 \%$ sobre os preços de 2006 . A alta no consumo e na exportação do tomate foi um incentivo para os produtores brasileiros aumentarem os investimentos em máquinas e tecnologia fora da estação, o que tem causado impacto sobre o rendimento (USDA, 2008).

Os tomates podem ser cultivados em várias regiões do Brasil, e o clima favorável permite produção durante todo o ano em muitas áreas, mas a principal temporada vai de junho a setembro. Os rendimentos são mais elevados em regiões com inverno suave e baixa chance de geada. A produção no verão apresenta maiores riscos para doenças e problemas, e é concentrada em altitudes mais elevadas. O custo de produção do tomate é muito elevado, uma vez que implica a utilização intensiva de mão de obra e insumos importados, tais como sementes, fertilizantes e produtos químicos (USDA, 2008). 
2.1.3 Importância nutricional e composição

O fruto caracteriza-se por ser carnoso, macio, com dois ou mais lóculos, protegido por uma cutícula quase impermeável a gases e a água, que contém internamente uma cavidade locular (Figura 1) com quantidades variáveis de ar. O tomate é sensivel ao empilhamento, a quedas e a outros impactos. Por isso deve-se atentar para os cuidados na pós-colheita. Quanto menor o manuseio, melhor será a manutenção dos atributos de qualidade da matéria-prima (ANDREUCCETTI, 2005).

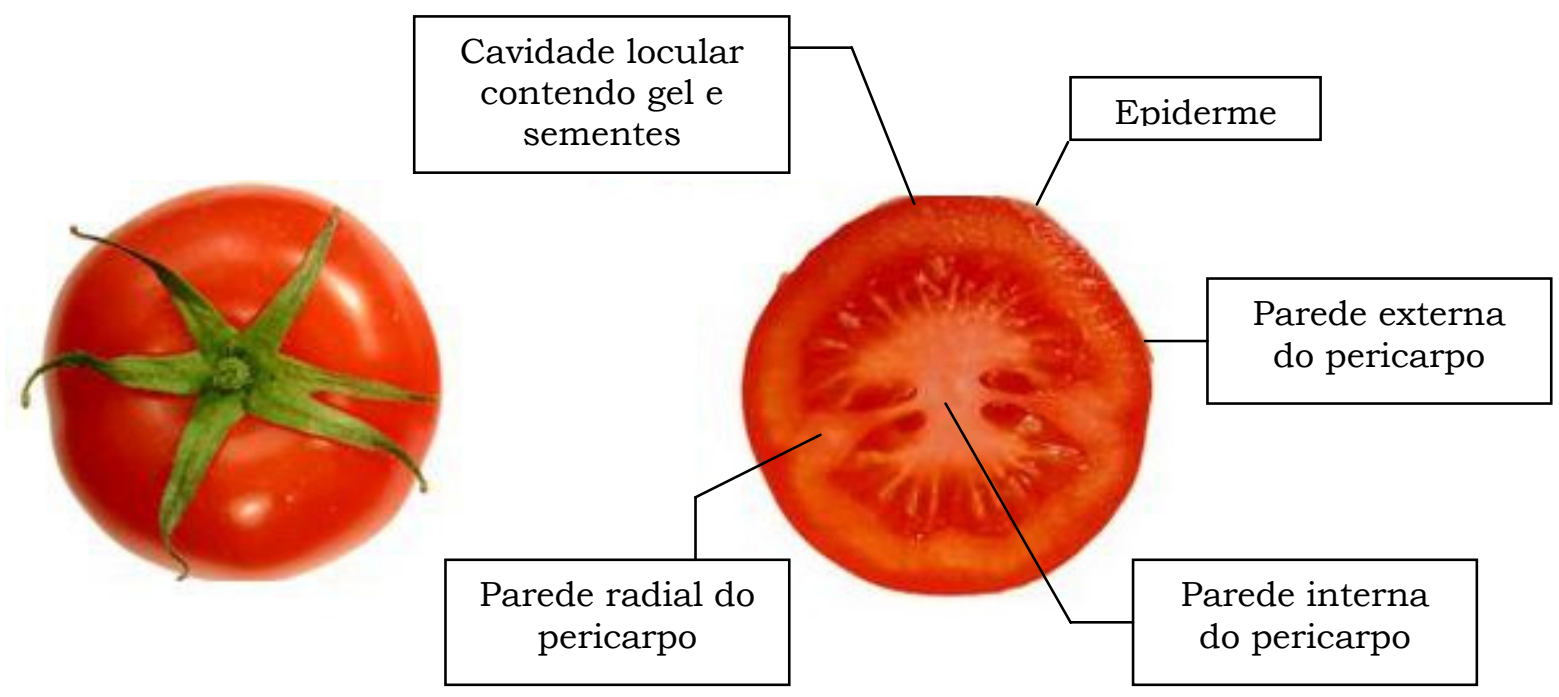

Fonte: Adaptado de ANDREUCCETTI (2005)

Figura 1 - Seção transversal do fruto do tomateiro.

O crescente consumo de tomate está relacionado, entre outros fatores, à solidificação de redes de fast food, que utilizam essa hortaliça nas formas processada e fresca. Além disso, a necessidade de maior rapidez no preparo de alimentos, elevou a demanda por alimentos industrializados ou semiprontos - no caso do tomate, principalmente na forma de molhos pré- 
preparados ou prontos para consumo, como os catchups. Mais recentemente, a demanda por tomate foi reforçada pela busca de alimentos mais saudáveis, favorecendo também o crescimento da venda do produto fresco (CARVALHO; PAGLIUCA, 2007). De acordo com o IBGE (2003), no período 2002-2003 a aquisição alimentar domiciliar per capita anual no Brasil foi de $13,413 \mathrm{Kg}$ para hortaliças frutosas, sendo que destas, a hortaliça mais consumida foi o tomate com $37,27 \%$ seguida da cebola com $25,87 \%$ do consumo.

O consumo per capita de tomate no Brasil é bastante baixo comparado a outros países, especialmente para tomates frescos. Segundo a CEAGESP no ano de 2007 o consumo per capita de tomate no Brasil foi de 6,5 quilos por ano, enquanto o consumo per capita na Noruega, Grécia, Suíça e outros países excedeu a 40 quilos por ano. O consumo do tomate fresco no Brasil deverá aumentar com o crescimento econômico, a melhoria das variedades e o controle de qualidade (USDA, 2008).

O tomate é um alimento funcional devido aos altos teores de vitaminas A e C, além de ser rico em licopeno, vitamina B, ferro, potássio e fósforo. Pesquisas apontam que o consumo de licopeno, um antioxidante que combate os radicais livres, presente tanto no fruto fresco como no processado, ajuda na prevenção de cânceres, principalmente câncer de próstata (CARVALHO; PAGLIUCA, 2007). Os efeitos anticarcinogênicos do licopeno se realizam através de vários mecanismos: como inibidor da proliferação de células cancerígenas G0-G1 do ciclo reprodutivo celular e impedindo a carcinogênese, protegendo importantes biomoléculas celulares incluindo lipoproteínas e DNA. Estudos mostram que os produtos à base de tomate podem desempenhar papel importante na prevenção do câncer de próstata. No entanto, este efeito é modesto. O licopeno apresenta um potencial interessante como agente terapêutico, no entanto até o presente momento, nenhum benefício clinicamente relevante foi encontrado em pacientes que consumiram suplementos de licopeno em estágios avançados da doença (ETMINAN; TAKKOUCHE; CAAMAÑO-ISORNA, 2004). 
A composição dos frutos, além de ser uma característica da cultivar, pode ser também influenciada pelas condições edafoclimáticas da região produtora. Durante o processo de maturação dos frutos ocorrem grandes transformações nas características dos mesmos (EMBRAPA, 2003).

$\mathrm{Na}$ Tabela 1 apresenta-se a composição centesimal do tomate (Lycopersicum esculentum Mill) cru, segundo a Tabela Brasileira de Composição de Alimentos da Faculdade de Ciências Farmacêuticas da Universidade de São Paulo (USP/FCF, 2008).

Tabela 1 - Composição centesimal do tomate (Lycopersicum esculentum Mill ) cru (em cada $100 \mathrm{~g})$

\begin{tabular}{lcc}
\hline Composição Centesimal & Unidade & $\begin{array}{c}\text { Valor por } \\
\mathbf{1 0 0}\end{array}$ \\
\hline Umidade & $\mathrm{g}$ & 94,86 \\
Energia & $\mathrm{Kcal}$ & 15 \\
Energia & $\mathrm{kJ}$ & 63 \\
Proteínas & $\mathrm{g}$ & 1,20 \\
Lipídeos Totais & $\mathrm{g}$ & 0,33 \\
Carboidratos Totais (por diferença) & $\mathrm{g}$ & 3,16 \\
Carboidratos “Disponiveis" (por diferença) & $\mathrm{g}$ & 1,81 \\
Cinzas & $\mathrm{g}$ & 0,45 \\
Fibra Alimentar Total & $\mathrm{g}$ & 1,35 \\
\hline
\end{tabular}

Fonte: Departamento de Alimentos e Nutrição Experimental (USP/FCF, 2008) 


\subsubsection{Produção mundial}

Segundo os últimos dados divulgados pela FAO, em 2007 os dez maiores produtores mundiais de tomate foram: China, Estados Unidos, Turquia, Índia, Egito, Itália, Irã, Espanha, Brasil e México (Figura 2). Estes países respondem a mais de $72,96 \%$ da produção mundial desta hortaliça (FAO, 2009c).

A produção mundial de tomate em 2007 foi de 126,246 milhões de tonelada, aproximadamente $53,70 \%$ de todo o tomate produzido no mundo é proveniente da Ásia. A China é o principal produtor mundial de tomate com 33,645 milhões de toneladas, ou seja, 26,65\% do total produzido, seguido pelos Estados Unidos com 9,11\% (FAO, 2009c).

A produção global do tomate duplicou nos últimos 20 anos. Um dos principais fatores para a expansão da cultura é o crescimento do consumo. Entre 1983 e 2003, o consumo mundial per capita aumentou de $11 \mathrm{Kg}$ por pessoa por ano para $16 \mathrm{Kg}$, um aumento de 45,5\% de acordo com dados da Organização das Nações Unidas para Agricultura e Alimentação (FAO, 2009b).

Apesar dos avanços na produtividade em muitos países, o rendimento médio mundial pouco avançou, passando de 23,84 t/ha em 1987 para apenas 27,28 t/ha em 2007 (FAO, 2009c). Parte dos maiores produtores mundiais de tomate ainda apresenta pequeno rendimento, decorrente da baixa tecnologia aplicada e do uso de variedades menos produtivas. Cerca de $80 \%$ da produção da China, maior produtor do mundo, é realizada com plantas de polinização aberta, que tem rendimento inferior ao dos híbridos. A produtividade na China é de aproximadamente 23,12 t/ha, portanto é inferior à média mundial (CARVALHO; PAGLIUCA, 2007). 


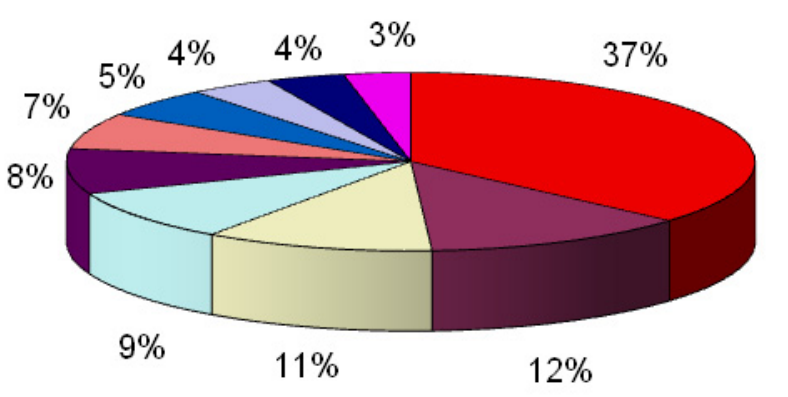

$\square$ China

口USA

口Turquia

口Índia

口 Egito

口Itália

口 Irã

口Espanha

- Brasil

口México

Figura 2 - Maiores produtores mundiais de tomate em 2007 (FAO, 2009c)

\subsubsection{Produção no Brasil}

O Brasil destaca-se como o $9^{\circ}$ maior produtor de tomate no mundo, sendo que a produção de tomate, na safra de 2007 foi de 3,364 milhões de toneladas. A produção brasileira corresponde a $2,66 \%$ da produção mundial. A produção média do país cresceu 1,324 milhões de toneladas do período 20 anos (FAO, 2009c).

De acordo com o IBGE, no ano de 2007 a área plantada no Brasil da cultura de tomate foi de 58.575 ha, sendo que 23.705 ha foram plantadas na região sudeste que se destacou como maior região produtora. A quantidade total produzida foi de $3.431 .232 \mathrm{t}$, dentre as quais $43,54 \%$ foram produzidas na região sudeste e apresentaram uma produção de 944.421 mil reais (IBGE, 2007). 
A distribuição territorial da área plantada de tomate no Brasil está apresentada na Figura 3, para a safra de 2007 (IBGE, 2007).

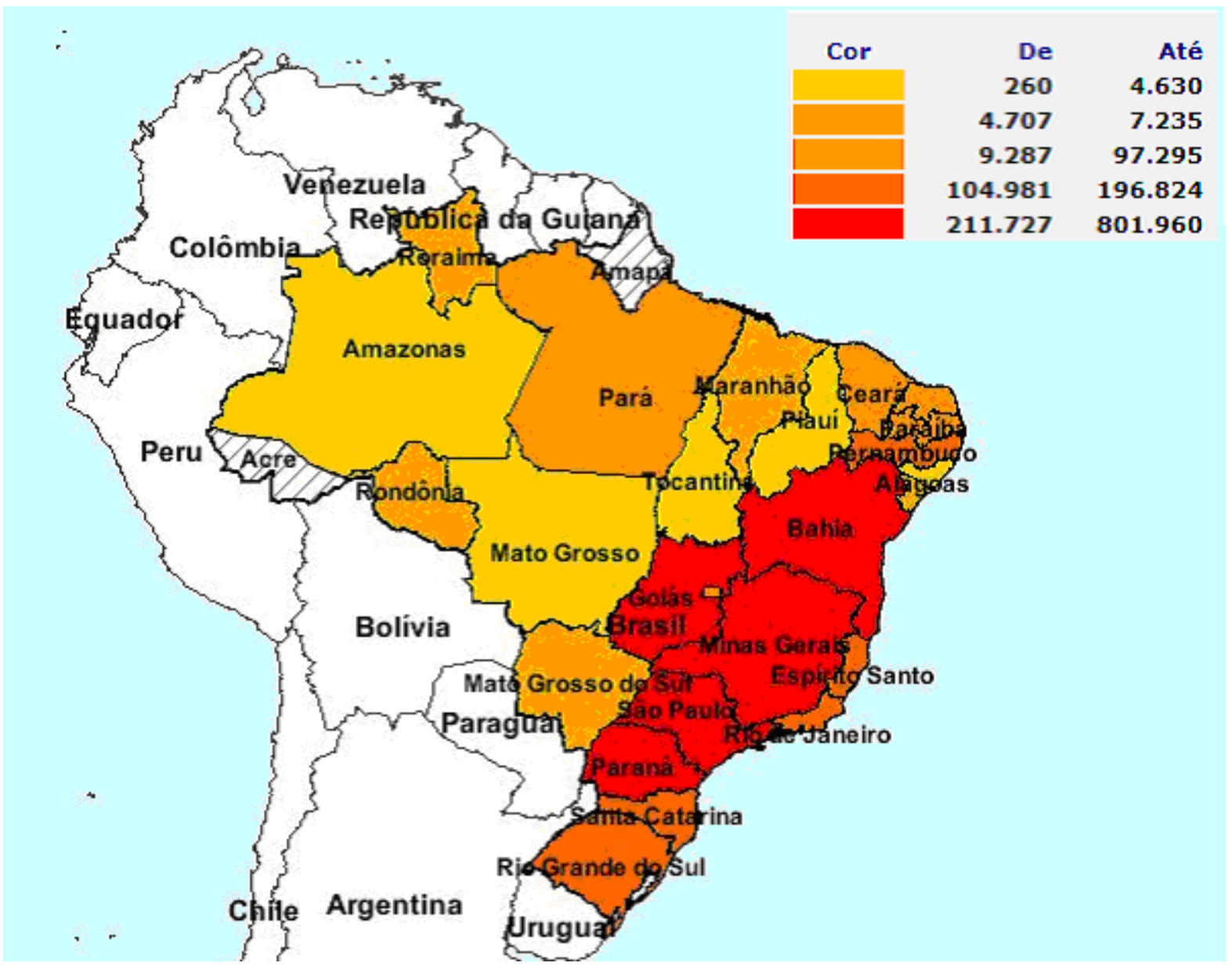

Fonte: IBGE Produção Agrícola Municipal (2007)

Figura 3 - Cartograma da produção de tomate (em toneladas) no Brasil, na safra de 2007

O maior estado produtor de tomate em 2007 foi Goiás com 801.960 t (Figura 4) seguido por São Paulo com produção de 763.227 t e Minas Gerais com 421.455 t. A área plantada nesses estados foram respectivamente 9.820, 12.466 e 6.879 hectares (IBGE, 2007). 
No Brasil, a difusão de técnicas de irrigação, o uso intensivo de insumos e a introdução de híbridos mais produtivos e com menores perdas na pós-colheita foram os principais fatores que contribuíram para o aumento da produtividade do tomate nacional. O rendimento médio do tomate no Brasil em 2007 foi de 59,36 t/ha (FAO, 2009c), contudo produtores mais tecnificados chegam a alcançar mais de $100 \mathrm{t} / \mathrm{ha}$, valores muito maiores que a média de rendimento mundial (CARVALHO; PAGLIUCA, 2007).

Segundo dados do Ministério da Agricultura, Pecuária e Abastecimento - MAPA, em 2005 o Brasil exportou 476 toneladas de tomates frescos ou refrigerados e 9.809 toneladas de tomates preparados ou conservados (BRASIL, 2006). Esses dados mostram que o Brasil ainda apresenta baixa inserção no mercado internacional, tanto no segmento de fruto destinado ao consumo in natura quanto no de pasta de tomate. As razões para essa baixa inserção são: alto custo do produto nacional, grande distância dos principais países consumidores e barreiras ao comércio externo (CARVALHO; PAGLIUCA, 2007).

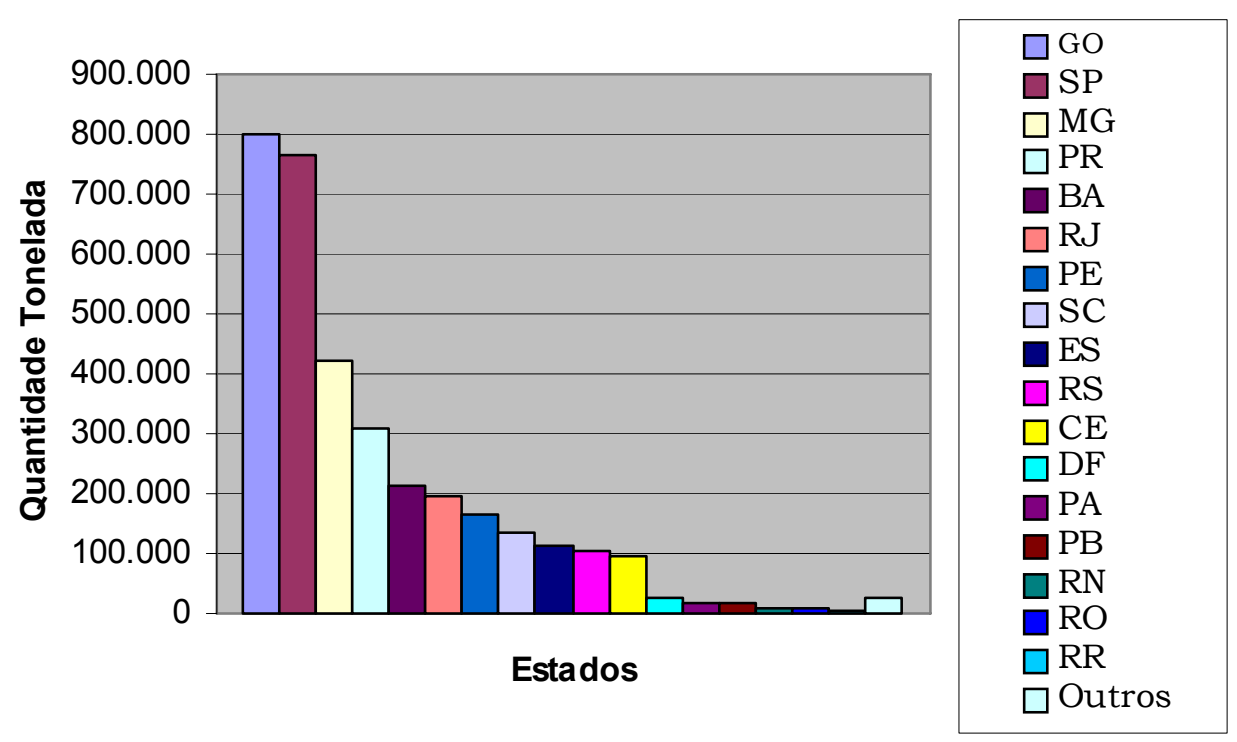

Fonte: IBGE, 2007

Figura 4 - Quantidade produzida em tonelada no ano de 2007 para a cultura de tomate nos estados brasileiros 


\subsection{Agrotóxicos}

Os agrotóxicos e o manejo químico dos problemas fitossanitários enfrentados na agricultura constituem técnicas adotadas muito difundidas nos padrões praticados nos principais centros mundiais de produção de alimentos, nos últimos 40 anos. Alguns autores sustentam que as perdas globais nos cultivos decorrentes dos ataques de pragas e doenças poderiam sofrer um aumento estimado em $42 \%$, atingindo cerca de $70 \%$ de perdas na ausência das práticas de controle químico (ALVES FILHO, 2002)

\subsubsection{Definição}

O Código Internacional de Conduta para distribuição e utilização de pesticidas (FAO, 2002) define agrotóxicos como qualquer substância ou mistura de substâncias destinadas a prevenir, destruir ou controlar qualquer praga, incluindo os vetores de enfermidades humanas ou de animais, as espécies de plantas ou animais indesejáveis que causam prejuizo ou que interfiram de qualquer outra forma na produção, elaboração, armazenamento, transporte ou comercialização de alimentos, produtos agrícolas, madeira e produtos de madeira ou alimentos para animais, ou que possam ser administrados aos animais para combater insetos, aracnídeos ou outras pragas. O termo inclui as substâncias destinadas como reguladoras de crescimento das plantas, desfolhantes, dessecantes, agentes para reduzir a densidade de frutas ou agentes para evitar a queda prematura de frutas, e as substâncias aplicadas aos cultivos antes ou depois da colheita para proteger o produto contra a deterioração durante o armazenamento e transporte. 
O resíduo de pesticida é definido pelo Código Internacional, como qualquer substância específica presente nos alimentos, produtos agrícolas ou alimentos para animais como consequência do uso de pesticida. O termo inclui qualquer derivado de pesticida, como produtos de conversão, metabólitos, produtos de reação, e impurezas consideradas de importância toxicológica. O termo "resíduo de pesticida" inclui tanto os resíduos de procedência desconhecidas ou inevitáveis (por exemplo, ambientais), como os derivados de usos conhecidos da substância química (FAO, 2002).

No Brasil, a adoção dos termos defensivos agrícolas, produtos fitossanitários, pesticidas, biocidas e agrotóxicos tem sido marcada por controvérsias há anos. A legislação brasileira adotou e definiu o termo agrotóxico segundo o decreto $\mathrm{n}^{\circ} 4.074$, de 4 de janeiro de 2002, que regulamentou a lei no 7.802/ 1989, como: "produtos e agentes de processos físicos, químicos ou biológicos, destinados ao uso nos setores de produção, no armazenamento e beneficiamento de produtos agrícolas, nas pastagens, na proteção de florestas, nativas ou plantadas, e de outros ecossistemas e de ambientes urbanos, hídricos e industriais, cuja finalidade seja alterar a composição da flora ou da fauna, a fim de preservá-las da ação danosa de seres vivos considerados nocivos, bem como as substâncias e produtos empregados como desfolhantes, dessecantes, estimuladores e inibidores de crescimento" (BRASIL, 2002).

A principal diferença observada entre as definições é que o Código Internacional também classifica como agrotóxicos as substâncias utilizadas após a colheita, para a proteção do produto contra a deterioração durante o armazenamento e transporte.

O emprego de agrotóxicos na agricultura tem seus beneficios econômicos, uma vez que asseguram o controle e combate de pragas e doenças, protegendo a qualidade da produção. Por outro lado, os consumidores destes produtos agrícolas podem estar expostos aos agrotóxicos, devido a presenças destes nos alimentos. Entre os efeitos nocivos causados ao homem, por estas substâncias, podemos citar: danos ao 
sistema nervoso central, problemas no sistema reprodutivo e locomotor, deficiência mental, entre outros (ALDER et al., 2006).

2.2.2 Histórico no mundo e no Brasil

O desenvolvimento da sintese orgânica durante a Segunda Guerra Mundial e a consolidação da agricultura chamada moderna tiveram importância fundamental no desenvolvimento da indústria mundial de agrotóxicos. Em 1939, com a descoberta das propriedades inseticidas do DDT (Dicloro Difenil Tricloroetano), um composto orgânico sintetizado por Otto Ziedler em 1874, foi dado início a um marco revolucionário nas tecnologias até então empregadas para o combate às pragas (ALVES FILHO, 2002; SPADOTTO et al., 2004).

No Brasil, os primeiros registros de compostos organoclorados foram feitos no ano de 1946. Nesse mesmo período foram introduzidos os inseticidas sistêmicos e, em 1958, os antibióticos à base de sais de estreptomicina. Durante os anos de 1954 a 1960, foi intenso o processo de novos produtos junto ao Ministério da Agricultura. Os números divulgados pelo serviço de defesa sanitária vegetal davam conta de que 2.045 produtos haviam sido registrados no período (ALVES FILHO, 2002).

Já na década de 60 começaram a surgir novos produtos classificados como de "terceira geração" (produtos biológicos, fisiológicos, ferormônios e piretróides), numa fase onde a busca por produtos menos tóxicos para o homem e o ambiente passaram a ocupar a estratégia da indústria química. Essa preocupação ocorreu devido a graves problemas identificados, tanto relacionados aos processos de intoxicações agudas e crônicas sofridas pelas populações expostas direta ou indiretamente, como pelos acidentes ambientais e problemas de eficiência agronômica dos produtos, estes últimos 
desencadeados pelos mecanismos de resistência das populações de pragas aos produtos utilizados (ALVES FILHO, 2002).

Os avanços nos estudos entomológicos permitiram a criação de produtos da "quarta geração" que possuem algumas vantagens, como alta capacidade de degradação ambiental e especificidade de ação. A utilização de substâncias químicas para o combate de pragas a partir do desenvolvimento de produtos sintéticos sempre causou conflitos sobre os reais prejuízos e beneficios advindos dos agrotóxicos (ALVES FILHO, 2002).

No Brasil, a década de 70 foi a época de grande expansão da produção e do uso dos agrotóxicos, principalmente pelos incentivos para a produção agrícola e para a política de exportação. Neste período, a elevação do custo da mão-de-obra no setor agrícola e o êxodo rural estimularam o uso de controle químico na eliminação de plantas daninhas e os herbicidas passaram a ser cada vez mais utilizados. Isto justifica o aumento no consumo de herbicidas no período de $1964-1979$ que foi de $5414 \%$, ao passo que o de inseticidas foi de 234\% (LARA; BATISTA, 1992).

Segundo dados do Sindicato Nacional da Indústria de Produtos para Defesa Agrícola houve aumento nas vendas dos seguimentos de inseticida e fungicida no ano de 2008, devido ao crescimento das culturas de soja, milho, trigo, feijão, batata e tomate. As vendas de agrotóxicos de janeiro a outubro de 2008, comparado ao mesmo período de 2007, apresentaram um crescimento acumulado de $31 \%$, totalizando um mercado de 10.246 milhões de reais indicando crescimento de aproximadamente 17\% (SINDAG, 2008).

\subsubsection{Classificação}

Os agrotóxicos podem ser classificados quanto à finalidade (aficida, ovicida, larvicida, raticida, formicida, acaricida, inseticida, entre outros), 
toxicidade, ao modo de ação (ingestão, contato, microbiano e fumegante) e a sua estrutura química, sendo classificados em clorados, fosforados, carbamatos, piretróides, tiocarbamatos, benzimidazóis, derivados de uréia, tiadiazinona, triazóis, etc. Quanto à origem, a divisão envolve os compostos inorgânicos (compostos de mercúrio, bário, enxofre e cobre), os agrotóxicos de origem vegetal, bacteriana e fúngica (piretrinos, antibióticos e fitocidas), e os agrotóxicos orgânicos (CELLA, 2002; SANCHES et al., 2003).

Quanto à persistência, os agrotóxicos são classificados segundo o tempo de meia vida, que é o tempo necessário para que a concentração dos agrotóxicos seja reduzida para a metade da quantidade aplicada, através de processos de degradação biológica ou química. As persistências são consideradas: curta (até 90 dias); média (de 91 a 180 dias); longa (maior que 180 dias). O deslocamento dos agrotóxicos no perfil do solo durante sua meia vida pode ser pequeno (até $20 \mathrm{~cm}$ ), médio (de 21 a $60 \mathrm{~cm}$ ) ou grande (maior que 60 cm) (SANCHES et al., 2003; SHEN; HU; HU, 2009).

\subsubsection{Toxicidade}

Com o objetivo de distinguir seu grau de toxicidade, os agrotóxicos são classificados em quatro classes toxicológicas. Esta classificação é baseada na identificação do componente de risco referente a uma substância química e diferencia a toxicidade dos agrotóxicos, com base no ingrediente ativo e sua formulação (SANCHES et al., 2003). A toxicidade da maioria dos agrotóxicos é expressa em valores referentes à Dose Média Letal (DL50), por via oral, representada por miligramas do ingrediente ativo do produto por quilograma de peso vivo, que são necessários para matar 50\% da população de ratos ou de outro animal teste. A $\mathrm{DL}_{50}$ é usada para estabelecer as medidas de segurança a serem seguidas para reduzir os riscos que o produto pode apresentar à saúde humana (BARRIGOSSI, 2006). 
Os agrotóxicos são agrupados em classes, de acordo com a sua toxicidade, e no Brasil as formulações são obrigadas a apresentar no rótulo a cor correspondente à classe de sua toxicidade, conforme demonstrado na Tabela 2.

A Portaria Normativa IBAMA N ${ }^{\circ} 84$, de 15 de outubro de 1996, no seu Art. $3^{\circ}$ classifica os agrotóxicos quanto ao potencial de periculosidade ambiental baseando-se nos parâmetros bioacumulação, persistência, transporte, toxicidade a diversos organismos, potencial mutagênico, teratogênico, carcinogênico, obedecendo a seguinte graduação: Classe I Produto Altamente Perigoso, Classe II - Produto Muito Perigoso, Classe III Produto Perigoso E Classe IV - Produto Pouco Perigoso (IBAMA, 1996).

Tabela 2 - Classes toxicológicas dos agrotóxicos e respectivas cores obrigatórias nos rótulos das formulações

\begin{tabular}{|c|c|c|}
\hline Classe & Classificação & $\begin{array}{c}\text { Cor da faixa no } \\
\text { rótulo da } \\
\text { embalagem }\end{array}$ \\
\hline $\bar{I}$ & $\begin{array}{l}\text { Extremamente tóxico } \\
\text { (DL50 menor que } 50 \mathrm{mg} / \mathrm{kg} \text { de peso vivo) }\end{array}$ & Vermelho vivo \\
\hline II & $\begin{array}{l}\text { Altamente tóxico } \\
\text { (DL }{ }_{50} \text { de } 50 \mathrm{mg} \text { a } 500 \mathrm{mg} / \mathrm{kg} \text { de peso vivo) }\end{array}$ & Amarelo intenso \\
\hline III & $\begin{array}{l}\text { Medianamente tóxico } \\
\text { (DL50 de } 500 \mathrm{mg} \text { a } 5.000 \mathrm{mg} / \mathrm{kg} \text { de peso vivo) }\end{array}$ & Azul intenso \\
\hline IV & $\begin{array}{l}\text { Pouco tóxico } \\
\text { (DL50 maior que } 5.000 \mathrm{mg} / \mathrm{kg} \text { de peso vivo) }\end{array}$ & Verde intenso \\
\hline
\end{tabular}

Fonte: BARRIGOSSI, 2006 
Em 1980 foi criado o Sistema Nacional de Informações TóxicoFarmacológicas (SINITOX), pelo Ministério da Saúde, a partir da constatação da necessidade de se criar um sistema abrangente de informação e documentação em toxicologia e farmacologia de alcance nacional, capaz de fornecer informações sobre medicamentos e demais agentes tóxicos existentes em nosso meio, às autoridades de saúde pública, aos profissionais de saúde e áreas afins e à população em geral (FIOCRUZ, 2006). Na Tabela 3 apresentam-se os últimos dados divulgados pelo SINITOX sobre casos registrados de intoxicação humana por agrotóxicos no Brasil referentes ao ano de 2003.

Tabela 3 - Casos de intoxicação por agrotóxicos de uso agrícola no Brasil em 2003, segundo circunstâncias e evolução

\begin{tabular}{lclc}
\hline \multicolumn{1}{c}{ Circunstâncias } & $\begin{array}{c}\mathbf{n}^{\mathbf{0}} \\
\text { Intoxicações }\end{array}$ & Evolução & $\begin{array}{c}\mathbf{n}^{\mathbf{0}} \\
\text { Intoxicações }\end{array}$ \\
\hline Acidente Individual & 1613 & Cura & 3053 \\
Acidente Coletivo & 113 & Cura não confirmada & 808 \\
Acidente Ambiental & 23 & Sequela & 17 \\
Ocupacional & 1748 & Óbito & 164 \\
Ingestão de Alimentos & 4 & Óbito outra circunstância & 7 \\
Tentativa de Suicídio & 2185 & Outra & 68 \\
Tentativa de Aborto & 9 & Ignorada & 1828 \\
Violência/Homicídio & 22 & & \\
Uso Indevido & 25 & & \\
Outra & 64 & & \\
Ignorada & 139 & & \\
Total & 5945 & Total & \\
\hline
\end{tabular}

Fonte: Fiocruz, 2006 
2.2.5 Limites máximos de resíduos (LMR)

A proteção das lavouras contra o ataque de insetos, plantas daninhas e doenças, utilizando agrotóxicos é uma prática bastante comum na agricultura. Porém, quando a utilização de agrotóxicos não é realizada de acordo com as Boas Práticas Agrícolas, resíduos destes compostos podem ser encontrados nos alimentos.

O risco potencial que os agrotóxicos oferecem aos consumidores, devido a uma exposição crônica diária, determinou que LMR's fossem estabelecidos para diferentes combinações cultura/ agrotóxico. Em função disto, vários países possuem programas de monitoramento dos níveis de resíduos de agrotóxicos, a fim de garantir a segurança alimentar (STEPAN; TICHA; HAJSLOVA, 2005).

O Limite máximo de resíduos é definido, segundo o Código Internacional de conduta para a distribuição e utilização de pesticidas (FAO, 2002) como a concentração máxima de um resíduo de pesticidas que se permite ou reconhece legalmente como aceitável em um alimento, produto agrícola ou ração para animais.

No âmbito nacional, a Agência Nacional de Vigilância Sanitária ANVISA é o órgão regulador responsável pela avaliação toxicológica dos agrotóxicos, seus componentes e afins, definindo normas relativas ao estabelecimento dos limites máximo de resíduos, entendido como a concentração máxima de resíduos de agrotóxicos que pode estar presente nos alimentos consumidos pela população sem trazer prejuízos à saúde (IMOTO, 2004).

Os LMR's estabelecidos pelo Codex Alimentarius estão baseados nas práticas agrícolas internacionais com o objetivo de proteger e preservar a saúde humana, garantindo o comércio internacional de alimentos livres de barreiras, com respeito aos resíduos. Contudo, o nivel de resíduos de 
agrotóxicos em alimentos depende também de fatores agronômicos e climáticos, e muitos países estabelecem seus próprios limites baseados nas boas práticas agrícolas que são praticadas localmente (IMOTO, 2004).

Provavelmente não há outra classe de compostos químicos tão regulamentada como a dos agrotóxicos, os LMR's estabelecidos na maioria dos países, existem para impedir impactos adversos na saúde pública e para promover boas práticas na agricultura. Devido a estas razões um grande número de laboratórios está envolvido na vigilância destes limites ou na identificação e quantificação de agrotóxicos nos mais diversos tipos de matrizes (ALDER et al., 2006).

2.2.6 Uso de agrotóxicos no cultivo de tomate

A principio, todas as culturas requerem o controle de plantas daninhas, doenças e pragas. A escolha do método de controle de pragas normalmente é feita baseando-se na informação disponível sobre a estimativa da perda, eficiência do método, custo de controle e impacto ambiental. No caso do tomate, o controle de insetos e ácaros não se restringe apenas ao controle químico ou biológico. Um manejo eficiente é obtido com a adoção das seguintes recomendações: adotar rotação de culturas, destruir os restos culturais imediatamente após a colheita, manter a lavoura livre de plantas daninhas e outras hospedeiras de insetos e ácaros e utilizar cultivares mais adaptados à região (EMBRAPA, 2003).

As plantas daninhas interferem diretamente no desenvolvimento do tomateiro, competindo por água, nutrientes, luz e liberando substâncias aleloquímicas que afetam a germinação e o crescimento. Deve-se, por isso, evitar o plantio de tomate em áreas infestadas por espécies que possuam substâncias inibitórias, como a tiririca, o capim-maçambará, a grama-seda e o feijão-de-porco. Indiretamente, as plantas daninhas interferem como 
hospedeiras de um número grande de pragas e de patógenos que atacam o tomateiro (EMBRAPA, 2003).

Muitas doenças atacam o tomateiro, causando grande redução da produtividade e da qualidade do produto. O conhecimento da etiologia, da sintomatologia e dos métodos gerais de controle permite a identificação precoce e o tratamento preventivo das doenças. Para isso, recomendam-se vistorias freqüentes na lavoura, procurando identificar as anomalias - como crescimento deficiente, murcha, manchas e mofos. Os principais causadores de doenças são: bactérias, fungos, vírus, nematóides e danos fisiológicos (EMBRAPA, 2003).

Devido ao grande número de pragas que causam danos em hortaliças, o agricultor se vê obrigado a utilizar métodos de controle preventivos, aplicando uma série de defensivos. As principais pragas que ameaçam o tomateiro são: traça-do-tomateiro, mosca branca, ácaros, larva minadora, tripes, pulgões, lagarta-rosca, broca grande, broca pequena, lagarta-militar e burrinho (EMBRAPA, 2003).

Os produtos analisados neste estudo são utilizados para o manejo de pragas e doenças com o intuito de diminuir as perdas de produção. De acordo com a ANVISA (2000), a buprofezina tem aplicação foliar na cultura do tomate e é indicada para o controle da mosca branca e o carbofurano tem aplicação no solo e é utilizado para controle de vaquinha-verde-amarela, tripés, nematóide-das galhas e pulgão verde. Os produtos endossulfam e monocrotofós tem sido utilizados indevidamente na cultura de tomate.

\subsection{Análise de agrotóxicos em alimentos}

Estatísticas indicam que a agricultura mundial, com uma eventual produção de um bilhão de toneladas, é anualmente acometida por pragas, e 
que a redução da produção devido à invasão de pragas alcança de $20-30 \%$. Os agrotóxicos tem desempenhado um papel muito importante no desenvolvimento da agricultura desde a sua descoberta e sintese, aumentaram significativamente a produção agrícola e impulsionaram a pecuária, mas os perigos ocasionados pela sua aplicação refletem na preocupação com a segurança alimentar e na saúde humana, sendo cada vez mais o foco de atenção mundial. Assim, diversos países têm estabelecido seus próprios limites de resíduos no comércio internacional e muitos métodos analiticos vem sendo desenvolvidos para serem aplicados à determinação de resíduos de agrotóxicos em diferentes tipos de alimentos (PANG et al., 2006).

As propriedades físico-químicas dos agrotóxicos podem variar consideravelmente, uma vez que, podem apresentar caráter ácido, básico e neutro. Estes compostos podem conter em sua estrutura, halogêneos, fósforo, enxofre ou nitrogênio, heteroátomos que possuem uma grande relevância no método de detecção destes compostos. Um grande número de agrotóxicos é muito volátil, outros não, e esta grande diversidade provoca sérios problemas no desenvolvimento de um método "universal" para análise de resíduos destes compostos (ALDER et al., 2006).

Existem muitos métodos para análises multirresíduos de agrotóxicos em produtos agrícolas, mas é fundamental que a técnica possa extrair dezenas ou mesmo centenas de substâncias de matrizes complexas, que grande quantidade de interferentes co-extraídos possam ser eliminados na etapa do clean-up, e que as técnicas analíticas de detecção adotadas sejam indicadas para a determinação (PANG et al., 2006).

A análise de resíduos de agrotóxicos, além de ser um instrumento de proteção a saúde humana, está também relacionada a fatores econômicos. Atualmente, estima-se que no mundo, cerca de 200.000 amostras de alimentos são analisadas anualmente para resíduos de agrotóxicos com uma variedade de propósitos (LEHOTAY, 2005). 
Nas últimas décadas, os métodos para determinação de resíduos de agrotóxicos mudaram consideravelmente. Desde 1970 as análises de resíduos de agrotóxicos de rotina eram conduzidas por cromatografia gasosa, em combinação com captura de elétrons, nitrogênio e fósforo, ou detector fotométrico de chama. Para a confirmação dos resultados era necessária a utilização da cromatografia gasosa equipada com um tipo diferente de coluna ou detector. Atualmente, utilizando cromatografia gasosa combinada com espectrometria de massa, são feitas simultaneamente a determinação e a confirmação de resíduos de agrotóxicos numa mesma corrida analitica. $\mathrm{Na}$ maioria dos casos, a sensibilidade obtida com CG-EM é semelhante a de CG com detectores clássicos. A seletividade do sistema CG-EM pode ser ajustada pela seleção adequada dos íons resultantes da fragmentação das moléculas para evitar interferências de materiais co-extraídos da amostra. Assim, a importância da CG com detector de captura de elétrons, nitrogênio e fósforo, ou detector fotométrico de chama tem diminuído em laboratórios de resíduos de agrotóxicos (ALDER et al., 2006).

No passado, métodos baseados em cromatografia líquida (CL) eram pouco aplicados para análise de resíduos porque os detectores tradicionais UV (ultravioleta), arranjo de diodo, e fluorescência são menos seletivos e sensiveis do que instrumentos CG. Mas nos últimos anos, a disponibilidade da ionização de pressão atmosférica (atmospheric pressure ionization - API) causou uma espetacular mudança, pois em combinação com o EM aumentou a sensibilidade da detecção CL em várias ordens de grandeza, comparado aos tradicionais detectores eletrospray (electrospray ionization ESI) e ionização química a pressão atmosférica (atmospheric pressure chemical ionization - APCI). Além disso, as técnicas de troca de coluna da CL e extensos processos de limpeza da amostra tornam-se desnecessárias se o acoplamento EM-EM for utilizado e operado no modo de monitoração de reação selecionada (selected reaction monitoring - SRM) (ALDER et al., 2006).

O monitoramento de agrotóxicos nos alimentos é uma ferramenta importante para a caracterização e o gerenciamento dos riscos decorrentes do uso desses produtos nas condições reais de aplicação. O monitoramento 
do uso de agrotóxicos no campo é uma prática de dificil controle, podendo ocorrer uso inadequado de ingredientes ativos nas culturas ou colheita antecipada da matéria prima antes do término do período de carência do produto aplicado (GODOY; OLIVEIRA, 2004).

Os dados obtidos em programas de monitoramento possibilitam verificar a qualidade e a segurança dos alimentos consumidos pela população com a identificação das fontes de contaminação, proporcionando uma avaliação quanto ao uso inadequado e não autorizado de agrotóxicos, para estimular a adoção de Boas Práticas Agrícolas, além de fornecer subsídios para uma possivel reavaliação dos agrotóxicos (IMOTO, 2004).

\subsubsection{Extração de agrotóxicos}

Nos últimos anos, a preocupação com a segurança alimentar provocou um rápido desenvolvimento de métodos analíticos necessários para a determinação de resíduos de agrotóxicos. A pesquisa sobre resíduos na área ambiental e na saúde pública é direcionada para a identificação e quantificação de centenas de substâncias com diferentes propriedades físicoquímicas em diferentes tipos de matrizes. Assim, uma das principais tarefas da pesquisa analítica é fornecer métodos confiáveis, de fácil aplicação e com baixo custo.

O desenvolvimento de um método para análise de resíduos de agrotóxicos em alimentos é dificultado por diversos fatores, tais como tempo, necessidade de grandes volumes de solvente orgânico, várias etapas de extração, tornando a análise extremamente laboriosa (FRENICH; BOLAÑOS; VIDAL, 2007).

Os métodos multirresíduos são comumente preferidos para determinação de resíduos de agrotóxicos porque permitem a determinação 
de vários compostos em uma única corrida. Diversas pesquisas relativas à determinação de resíduos em frutas e legumes indicam que novos métodos estão sendo desenvolvidos para a extração e quantificação de agrotóxicos. Estes métodos envolvem: homogeneização; extração; clean-up dos analitos da amostra com solventes adequados; concentração; e determinação analítica. O passo do clean-up é o mais trabalhoso e demorado e é crucial na análise de resíduos em alimentos. Se não for executado com precisão, os problemas relacionados com a presença de interferentes na matriz tornam dificil a identificação dos compostos. O clean-up deve ser realizado a fim de evitar perdas de analitos mais voláteis, mas deve ser suficientemente abrangente para eliminar compostos co-extraídos da matriz; evitar falsos positivos; e permitir a identificação, quantificação e confirmação do analito (LACORTE; FERNÁNDEZ-ALBA, 2005).

Dentre as técnicas de extração normalmente utilizadas para análises de resíduos destacam-se a extração líquido-líquido (liquid-liquid extraction LLE), a extração com fluido supercrítico (supercritical fluid extraction - SFE), a extração em fase sólida (solid phase extraction - SPE), dispersão da matriz em fase sólida (matrix solid phase dispersion - MSPD) e, mais recentemente, a micro extração em fase sólida (solid phase micro-extraction - SPME) e extração em fase sólida dispersiva (dispersive solid-phase extraction - dSPE) (BARRIONUEVO; LANÇAS, 2001; ANASTASSIADES; SCHERBAUM, 2005)

A técnica de extração mais frequentemente usada é a Extração Líquido-Líquido (LEE). Entretanto, é um método tedioso, de elevado custo, de difícil automação e que consome grandes quantidades de solventes orgânicos (LANÇAS, 2004).

A SFE se assemelha a extração de Soxhlet, mas o solvente utilizado é um fluido supercrítico, ou seja, uma substância acima da sua temperatura crítica e pressão, que proporciona uma combinação rara de propriedades. Fluidos supercríticos espalham-se através dos sólidos como gases, mas dissolvem os analitos como líquidos, de modo que a taxa de extração é melhor e ocorre menos degradação térmica. Além disso, muitos pré- 
tratamentos das amostras podem ser feito com fluidos supercríticos não tóxicos, como o dióxido de carbono, que é uma excelente alternativa aos caros e potencialmente perigosos solventes utilizados na extração Soxhlet (BULDINI; RICCI; SHARMA, 2002).

A SPE é uma das técnicas de extração mais utilizadas. Nesta técnica, os analitos contidos numa matriz aquosa são extraídos, juntamente com os compostos interferentes, após passarem por um cartucho contendo sorvente. Um solvente orgânico seletivo é geralmente utilizado para remover os interferentes e então, outro solvente é usado para lavar os analitos de interesse. Apesar da SPE apresentar vantagens com relação aos métodos mais clássicos, tais como praticidade e maior sensibilidade, esta técnica tem algumas limitações. Uma delas refere-se à etapa de dessorção do analito aprisionado no cartucho de SPE que requer geralmente, o uso de solventes tóxicos (BARRIONUEVO; LANÇAS, 2001).

A MSPD envolve a homogeneização e dispersão de uma pequena quantidade de matriz com adsorvente geralmente $\mathrm{C}_{18}$ (octadecilsilano), seguido por lavagem com uma pequena quantidade de solvente e eluição adequada para extrair uma vasta gama de compostos (DÓREA; LANÇAS, 1999).

A SPME baseia-se originalmente na adsorção dos analitos em uma fibra de sílica coberta com uma camada de sorvente. A fibra é introduzida diretamente na amostra aquosa e, por partição, concentra o analito em sua superficie (sorvente). Posteriormente, os analitos são dessorvidos termicamente em um cromatógrafo gasoso. É um método rápido, que não requer o uso de solventes (BARRIONUEVO; LANÇAS, 2001). 
2.3.2 Método QuEChERS - extração em fase sólida dispersiva (dSPE)

A utilização de uma etapa de clean-up anterior a análise cromatográfica é importante, uma vez que reduz o background e o efeitomatriz, além de diminuir as manutenções no sistema cromatográfico. Em 2003, ANASTASSIADES et al. introduziram um método para extração de resíduos de agrotóxicos denominado QuEChERS (quick, easy, cheap, effective, rugged and safe). Este método envolve uma única extração inicial de $10 \mathrm{~g}$ de amostra com $10 \mathrm{~mL}$ de acetonitrila $(\mathrm{MeCN})$, seguida pela partição líquido-líquido formada pela adição de $4 \mathrm{~g}$ de sulfato de magnésio anidro $\left(\mathrm{MgSO}_{4}\right)$ mais $1 \mathrm{~g}$ de cloreto de sódio $(\mathrm{NaCl})$. A remoção de água residual e o clean-up são realizadas simultaneamente por meio de um procedimento rápido chamado extração em fase sólida dispersiva, em que $150 \mathrm{mg}$ de $\mathrm{MgSO}_{4}$ anidro e $25 \mathrm{mg}$ de sorvente PSA (amina primária secundária) são simplesmente misturados com $1 \mathrm{ml}$ do extrato em MeCN. A extração em fase sólida dispersiva com PSA efetivamente elimina muitos componentes polares da matriz, tais como ácidos orgânicos, certos pigmentos polares e açúcares. A CG-EM é então utilizada para a confirmação e quantificação dos agrotóxicos. Recuperações entre 85 e 101\% (comumente > 95\%) e repetitividade tipicamente $<5 \%$ foram atingidos para uma vasta gama de agrotóxicos analisados, incluindo muito polares e compostos básicos, tais como metamidofós, acefato, ometoato, imazalil e tiabendazol. Usando este método, um único analista pode preparar um lote de 8 amostras anteriormente homogeneizadas em menos de $30 \mathrm{~min}$, com aproximadamente \$ 1 dólar de materiais por amostra.

Porém, a degradação de certos agrotóxicos, como por exemplo folpete, captana, diclofluanida e clorotalonil, pode ocorrer durante a etapa de extração devido ao meio básico. A fim de minimizar este problema, uma etapa de tamponamento do extrato foi adicionada o que promoveu um melhora nos resultados obtidos para aqueles agrotóxicos dificeis de serem analisados. O método QuEChERS com etapa de tamponamento envolve a 
extração com $\mathrm{MeCN}$ contendo $1 \%$ de ácido acético (v/v) e simultaneamente partição líquido-líquido promovida pela adição de acetato de sódio (NaAc) e $\mathrm{MgSO}_{4}$, o qual é conhecido como método QuEChERS modificado (LEHOTAY; MASTOVSKA; LIGHTFIELD, 2005).

Uma vantagem do emprego da $\mathrm{MeCN}$ na etapa da extração é que quando comparada com outros solventes misciveis em água, a MeCN é superior principalmente porque oferece melhor separação na presença de $\mathrm{NaCl}$ e $\mathrm{MgSO}_{4}$. A presença de água nos extratos conduz a uma maior porcentagem de componentes polares co-extraidos, tais como proteinas e carboidratos. Assim, a MeCN minimiza a extração de proteínas e carboidratos que serão eliminados na fase aquosa da extração. $\mathrm{O} \mathrm{MgSO}_{4}$ foi apontado como melhor dissecante para remoção de água em soluções com $\mathrm{MeCN}$, sua hidratação é altamente exotérmica (aproximadamente $40^{\circ} \mathrm{C}$ ), e o calor gerado durante a extração demonstra que a água reagiu com o desidratante do extrato. O aumento de temperatura durante a extração não é suficiente para volatizar ou degradar os agrotóxicos, tornando a extração mais efetiva e auxiliando na remoção de água (LEHOTAY, 2000; LEHOTAY et al., 2001)

A dSPE depende apenas do processo de extração para fornecer uma aliquota homogênea a partir de uma amostra original de qualquer tamanho, sendo que apenas uma pequena quantidade de sorvente é utilizado. Ao utilizar uma quantidade muito menor de sorvente, a dSPE economiza tempo, trabalho, dinheiro e solvente, em comparação com a tradicional abordagem SPE. Não é necessário o condicionamento de cartuchos, não exige capacidade analítica e diferentemente do formato dos cartuchos, todo o sorvente interage igualmente com a matriz em dSPE, e uma maior capacidade por miligrama de sorvente é alcançada (ANASTASSIADES et al., 2003).

Díez et al. (2006) realizaram uma comparação entre os métodos de QuEChERS empregando MeCN na extração; o método mini Luke; o método de extração com acetato de etila, que envolve um posterior clean-up por 
cromatografia de permeação em gel (gel permeation chromatography - GPC) e que é o método de extração oficial utilizado por algumas agências regulamentadoras européias; e ainda com uma simples extração em acetona para verificar as diferenças entre os métodos. Os extratos foram analisados por CG com detector de espectrometria de massas por tempo de vôo (time of fligth - TOF) e por cromatografia líquida acoplada a espectrometria de massas (liquid chromatography-tandem mass spectrometry - LC-MS/MS).

Nesta comparação, em todos os procedimentos foi encontrado efeito induzido pela matriz, incluindo ou não a etapa do clean-up, sendo necessário quantificar os agrotóxicos com solução padrão nos extratos. Os extratos obtidos pelo método QuEChERS não foram tão limpos quanto os realizados por GPC, mas não diferiram tanto, considerando que o clean-up pelo QuEChERS é muito mais fácil e menos demorado. Enfim, os resultados apresentados pelo método QuEChERS com menor tempo de extração e pequeno volume de solvente orgânico utilizado, mostraram-se muito promissores em comparação a extrações por procedimentos mais complicados (DÍEZ et al., 2006).

O método mini-Luke mostrou-se mais eficiente para a extração de compostos mais apolares e medianamente polares, enquanto as melhores recuperações para compostos polares foram obtidas pelo método QuEChERS e pelo método com acetato de etila na extração. QuEChERS foi o único método que apresentou recuperações entre 60 e $70 \%$ para todos os compostos, com algumas exceções devido à interferentes na matriz. O cleanup por extração em fase sólida dispersiva foi eficiente e não diferiu muito dos extratos obtidos pelo método de extração com acetato de etila (DÍEZ et al., 2006).

Modificações do método original QuEChERS já foram recentemente realizadas com o principal objetivo de analisar matrizes com alto teor de gordura utilizando na etapa do clean-up $\mathrm{C}_{18}$ e carvão ativo grafitizado (graphitized carbon Black - GCB) (LEHOTAY; MASTOVSKA; YUN, 2005). 
$\mathrm{Na}$ Tabela 4 estão descritos alguns estudos recentes utilizando o método QuEChERS para análise de resíduos de agrotóxicos em diferentes matrizes.

Tabela 4 - Recentes publicações de análises multirresíduos utilizando o método QuEChERS em diferentes matrizes

\begin{tabular}{|c|c|c|c|}
\hline Artigo & Autores & Matriz & $\begin{array}{l}\text { Agrotóxicos } \\
\text { selecionados }\end{array}$ \\
\hline $\begin{array}{l}\text { Analysis of pesticide residues in bananas } \\
\text { harvested in the Canary Islands (Spain) }\end{array}$ & $\begin{array}{l}\text { HERNÁNDEZ- } \\
\text { BORGES et al., } \\
2009\end{array}$ & Banana & 11 \\
\hline $\begin{array}{l}\text { Development of a matrix solid-phase } \\
\text { dispersion method for the simultaneous } \\
\text { determination of pyrethroid and } \\
\text { organochlorinated pesticides in cattle feed }\end{array}$ & $\begin{array}{l}\text { FERNANDEZ- } \\
\text { ALVAREZ et al., } \\
2009\end{array}$ & Ração bovina & 36 \\
\hline $\begin{array}{l}\text { Fast low-pressure gas chromatography- } \\
\text { mass spectrometry method for the } \\
\text { determination of multiple pesticides in } \\
\text { grapes, musts and wines }\end{array}$ & $\begin{array}{l}\text { CUNHA et al., } \\
2009\end{array}$ & $\begin{array}{l}\text { Uva, mosto e } \\
\text { vinho }\end{array}$ & 27 \\
\hline $\begin{array}{l}\text { Fast GC-MS Pesticide Multiresidue } \\
\text { Analysis of Apples }\end{array}$ & $\begin{array}{c}\text { HÚŠKOVÁ; } \\
\text { MATISOVÁ; } \\
\text { KIRCHNER, } 2008\end{array}$ & Maça & 61 \\
\hline $\begin{array}{l}\text { Determination of pesticides in cereals using } \\
\text { the QuEChERS method and GC-ITD }\end{array}$ & $\begin{array}{c}\text { HERRMANN; } \\
\text { POULSEN, } 2007\end{array}$ & $\begin{array}{l}\text { Aveia, arroz, } \\
\text { centeio e } \\
\text { trigo }\end{array}$ & 83 \\
\hline $\begin{array}{l}\text { Evaluation of Two Fast and Easy Methods } \\
\text { for Pesticide Residue Analysis in Fatty Food } \\
\text { Matrixes }\end{array}$ & $\begin{array}{l}\text { LEHOTAY; } \\
\text { MASTOVSKA; } \\
\text { YUN, } 2005\end{array}$ & $\begin{array}{l}\text { Ovos, leite e } \\
\text { abacate }\end{array}$ & 32 \\
\hline
\end{tabular}


2.3.3 Análise de agrotóxicos por cromatografia gasosa acoplada a espectrometria de massas

Atualmente, a espectrometria de massa é uma das técnicas mais freqüentemente empregadas na execução de análises quantitativas. A sua especificidade, seletividade e limite de detecção característicos são mais que suficientes para enfrentar a maioria dos problemas analíticos. O desenvolvimento da EM nos últimos 30 anos tem levado esta técnica a ser aplicada em praticamente todos os campos analíticos. A espectrometria de massas é baseada na produção de íons do analito, na análise com relação à razão massa/carga $(\mathrm{m} / \mathrm{z})$ e nos valores de detecção. Consequentemente, a nível instrumental três componentes são essenciais: fonte de íons, analisador de massa e detector, e a performance destes três componentes reflete sobre a qualidade dos dados quantitativos e qualitativos (LAVAGNINI et al., 2006).

A produção de íons é um fenômeno que afeta fortemente a qualidade dos dados obtidos. A escolha do método de ionização a ser empregado é dependente das propriedades físico-químicas dos analitos de interesse (volatilidade, peso molecular, termolabilidade, e a complexidade da matriz) (LAVAGNINI et al., 2006).

As fontes de íons normalmente utilizadas podem ser subdivididas em duas classes principais: as que exigem amostra na fase gasosa antes de ionização; e aquelas capazes de gerir amostras de baixa volatilidade e alto peso molecular. A primeira categoria inclui ionização por impacto de elétrons (electron impact ionization - EI) e ionização química (chemical ionization - CI) que representam as fontes mais difundidas no mundo inteiro, devido à sua ampla utilização em sistemas CG-EM. A segunda categoria pode ser dividida em as que operam com soluções de amostra [ionização electrospray (electrospray ionization - ESI), ionização química a pressão atmosférica, fotoionização à pressão atmosférica (atmospheric pressure photoionization - 
APPI)] e aquelas baseadas em amostras dessorvidas e ionizadas de um substrato sólido [ionização/dessorção a laser de matriz assistida (matrixassisted laser desorption/ionization - MALDI) e ionização/dessorção com laser (laser desorption ionization - LDI)] (LAVAGNINI et al., 2006).

A EI é baseada na interação de um feixe de elétrons energético (70 eV) com a amostra vaporizada (a uma pressão na faixa de $10^{-7}-10^{-5}$ Torr). Esta interação leva à produção de uma série de íons relacionados com as propriedades químicas do composto em estudo. Conduz a formação de um íon molecular, originado pela perda de um elétron a partir da molécula neutra $\left(\mathrm{M}+\mathrm{e}^{-} \rightarrow \mathrm{M}^{{ }^{\bullet}}+2 \mathrm{e}^{-}\right)$, e a uma série de fragmentos (LAVAGNINI et al., 2006).

Atualmente, pode-se argumentar que a quantificação do analito não tem sentido sem a confirmação de sua identidade. Tradicionalmente, para a confirmação dos resultados positivos para os resíduos de agrotóxicos nos alimentos ou em qualquer compartimento ambiental, diferentes abordagens eram adotadas, como CG com dois diferentes detectores ou duas colunas de diferentes polaridades, combinação de duas técnicas cromatográficas ou de reação química seguida pela análise de derivatização. No entanto, estas técnicas clássicas de confirmação não fornecem a informação estrutural suficiente sobre o analito. De acordo com as recentes normas divulgadas na Comunidade Européia e Estados Unidos, a informação estrutural necessária para a confirmação do analito somente é alcançada aplicando-se técnicas espectrométricas (EM, IR- infrared). A combinação de CG com EM, tornou-se a ferramenta principal de confirmação para análise de resíduos de contaminantes (SOBOLEVA; KARAM; AMBRUS, 2004).

$\mathrm{Na}$ técnica de EM, o modo de monitoramento do íon selecionado (selected íon monitoring - SIM) tem sido o modo mais utilizado na análise de resíduos de agrotóxicos, fornecendo a seletividade e sensibilidade requeridas. Atualmente instrumentos por tempo de vôo fornecem possibilidades adicionais (SOBOLEVA; KARAM; AMBRUS, 2004). 
Nos detectores ion-trap modo SIM, somente os íons de razão $\mathrm{m} / z$ de interesse são selecionados e confinados, reduzindo drasticamente o background, ou seja, componentes interferentes com tempo de retenção similares não são detectados (LAVAGNINI et al., 2006).

Há determinados pontos que são comuns nos documentos oficiais que tratam dos critérios de confirmação, como por exemplo: a determinação do tempo de retenção relativo e seleção dos íons para cada analito. As diretrizes para monitoramento de agrotóxicos na União Européia estabelecem uma exigência mínima de três íons de razão $\mathrm{m} / z>100$ ou dois íons de razão $\mathrm{m} / z$ $>200$. Outras exigências na seleção do ion no modo SIM incluem preferencialmente o ion molecular, ou ions com intensidades maiores que 30\% (SOBOLEVA; KARAM; AMBRUS, 2004).

Nas análises multirresíduos, onde a identificação de mais de 250 compostos com diferentes propriedades é comum, alguns critérios são dificeis ou impossiveis de se aplicar, devido a diversas razões práticas. Um dos problemas é a falta de um número suficiente de íons com a abundância exigida nos espectros de massa de alguns agrotóxicos (SOBOLEVA; KARAM; AMBRUS, 2004).

A cromatografia gasosa é muito utilizada devido a sua potencialidade de determinar diversos agrotóxicos em uma única análise. As vantagens de sua combinação com a espectrometria de massas são a quantificação e a confirmação de baixas concentrações de agrotóxicos em extratos complexos, podendo ser realizadas em uma única etapa com elevado nível de confiança. Por esta razão, diversos métodos empregando CG-EM tem sido propostos para analisar resíduos de agrotóxicos em vegetais e frutas. Alguns autores recomendam o uso do modo full scan, mas este modo de aquisição possui determinadas limitações com relação à sensibilidade quando baixas concentrações do analito devem ser determinadas na presença de altas concentrações de interferentes da matriz. O aumento da seletividade e conseqüentemente um aumento na sensibilidade são realizados utilizando modo SIM. Este modo de discriminação entre o analito e os sinais 
interferentes, reduz os limites de detecção e de quantificação do método (ARREBOLA et al., 2003).

\subsubsection{Efeito matriz}

Nos métodos empregados para análises multirresíduos de agrotóxicos em alimentos, as diferentes propriedades físico-químicas dos analitos de interesse tornam bastante difícil a remoção eficiente dos componentes endógenos da matriz, fazendo com que estes estejam presentes no extrato final da amostra juntamente com os analitos alvo, mesmo após extensivo clean-up, pois estes interferentes são normalmente solúveis nos solventes utilizados nas etapas de extração e clean-up (SCHENCK; LEHOTAY; VEGA, 2002).

Extensivos clean-up dos extratos podem resultar em perda parcial de alguns compostos, bem como um aumento no custo e trabalho, mas um clean-up inadequado pode levar a efeitos adversos relacionados com a qualidade dos dados gerados, tais como: mascaramento de picos de resíduos por componentes da matriz coeluídos, ocorrência de falsos positivos e quantificação inexata. Os problemas devido à presença de impurezas na amostra analisada podem ser encontrados no detector e no injetor. Neste último caso, com o aumento da transferência de componentes co-extraídos da matriz para a coluna cromatográfica pode ocorrer, devido ao bloqueio dos sítios ativos dentro do injetor por esses compostos, o impedimento da degradação/adsorção térmica dos analitos de interesse no injetor, aumentando assim a resposta cromatográfica. Esse fenômeno conhecido como "efeito de matriz" permite explicação para as recuperações superiores a 100\%, que são relatadas para alguns agrotóxicos estudados utilizando padrões de calibração dissolvidos em solvente puro. A extensão deste efeito de matriz está relacionada à estrutura química e ao tipo de matriz (HAJSLOVA et al., 1998). 
Este fenômeno resultante do efeito causado pela presença da matriz no aumento da resposta cromatográfica é conhecido como "resposta cromatográfica aumentada, induzida pela matriz", o qual foi discutido pela primeira vez por Erney et al. (1993) durante a análise de resíduos de agrotóxicos organofosforados em amostras de leite e manteiga.

A presença de vários sítios ativos no sistema cromatográfico, principalmente no liner (grupos silanóis livres e metais potencialmente presentes na superficie, mesmo quando produzido com vidro de alta qualidade, classificado como "desativado"), pode ser responsável pela adsorção e/ou decomposição (catalítica/térmica) de analitos susceptíveis, diminuindo a quantidade de moléculas do respectivo analito, que são introduzidas na coluna. Quando os analitos são injetados na presença da matriz, os componentes endógenos desta competem com os analitos pelos sítios ativos do liner, fazendo com que as interações do analito no injetor sejam diminuídas e permitindo que uma quantidade maior de moléculas do analito seja introduzida na coluna, melhorando a eficiência da injeção para o analito alvo (HAJSLOVA; ZROSTLÝKOVA, 2003). Uma ilustração simplificada deste processo é representada na Figura 5.

Os efeitos de matriz são muito variáveis em ocorrência e intensidade e são resultantes de vários processos químicos e físicos relacionados à estrutura química dos compostos envolvidos e à natureza da matriz, entre outros, sendo difícil eliminá-los (HAJSLOVA; ZROSTLÝKOVA, 2003). Até o estado em que se encontra o sistema CG pode influenciar neste efeito.

Os agrotóxicos termolábeis e /ou mediamente polares e aqueles capazes de realizarem interações tipo ponte de hidrogênio são os mais propícios a apresentarem resposta cromatográfica aumentada, provocada pelo efeito de matriz. Os compostos contendo as seguintes estruturas/grupos funcionais característicos em sua molécula são tipicamente problemáticos neste contexto: organofosforados $(-\mathrm{P}=\mathrm{O})$; carbamatos (-O-CO-NH-); compostos hidroxilicos (-OH); compostos aminos 
(R-NH-); imidazóis, benzimidazóis $(-\mathrm{N}=)$ e derivados da uréia (-NH-CO-NH-) (HAJSLOVA; ZROSTLÝKOVA, 2003).

No entanto, substâncias hidrofóbicas e apolares, como os persistentes contaminantes organoclorados (com algumas exceções, como o DDT, que pode ser degradado termicamente em um injetor sujo) não são sujeitos aos problemas descritos (HAJSLOVA; ZROSTLÝKOVA, 2003).

Além da estrutura química do analito, a concentração do analito também desempenha uma importante função, pois com a diminuição da concentração do analito a super estimação do resultado torna-se mais pronunciada. A razão para este efeito é bem representada na Figura 5. A razão $(\mathrm{C}-\mathrm{X}) /(\mathrm{C}-\mathrm{Y})$ pode ser aumentada significativamente quando a concentração do analito aproxima-se do nivel de traço. Outro fator importante é a composição da matriz em estudo, ou seja, a característica e a quantidade de co-extrativos deixados na amostra submetida à análise cromatográfica (HAJSLOVA; ZROSTLÝKOVA, 2003).

Existem algumas alternativas teóricas para evitar a super estimação dos resultados devido ao tipo de efeito de matriz descrito; dentre elas estão a eliminação das causas primárias e/ou sua efetiva compensação, mas na prática são soluções pouco viáveis podendo aumentar o trabalho e o custo das análises (HAJSLOVA; ZROSTLÝKOVA, 2003). 


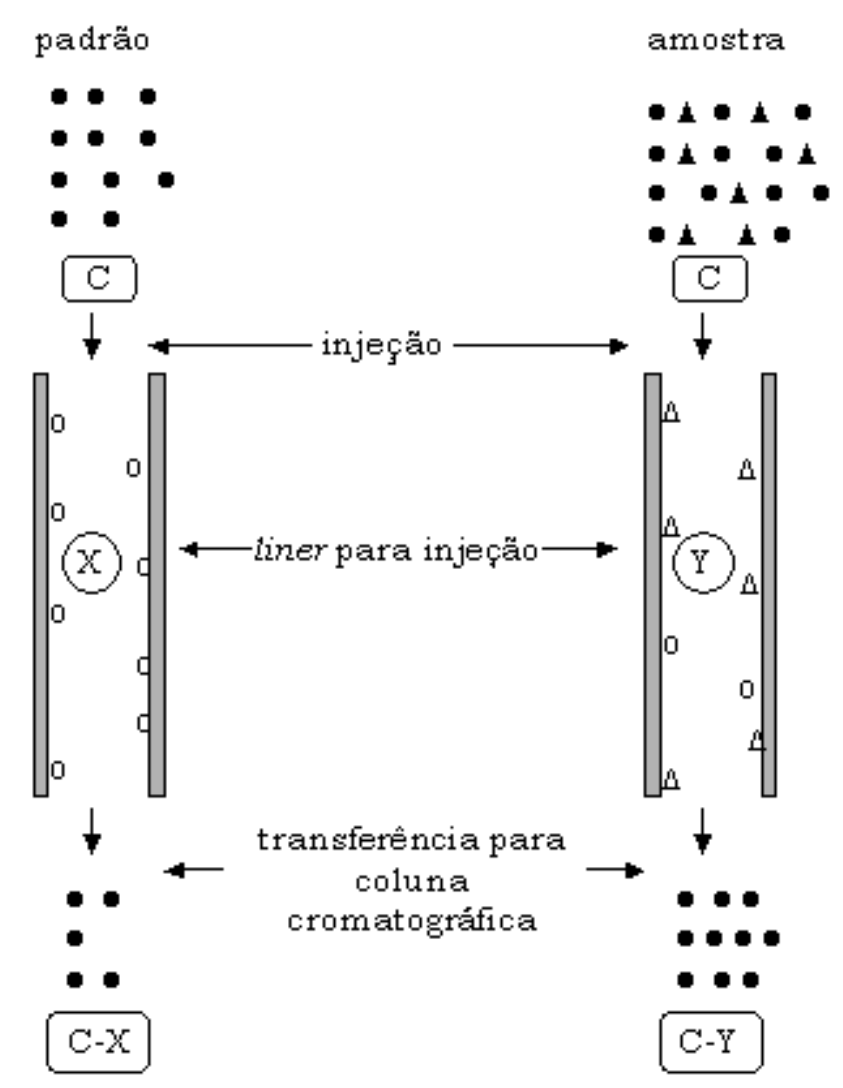

Fonte: HAJSLOVA; ZROSTLÝKOVA, 2003

Figura 5 - Ilustração simplificada da causa do efeito de matriz no aumento de resposta cromatográfica; C - número de moléculas do analito injetadas; $\mathrm{X}$ e Y - números de sítios ativos livres para adsorção de moléculas no injetor; • moléculas do analito na amostra injetada; - porção das moléculas do analito adsorvidas no liner, moléculas de componentes da matriz na amostra injetada; $\Delta$ porção dos componentes da matriz adsorvidos no liner, $(\mathrm{C}-\mathrm{X})<$ $(\mathrm{C}-\mathrm{Y})$

Para minimizar as causas primárias do efeito de matriz seria necessário eliminar os sítios ativos do sistema cromatográfico e os componentes da matriz na amostra. Um sistema de CG livre de sítios ativos 
é a princípio uma solução inviável, não apenas pela indisponibilidade de materiais comerciais verdadeiramente inertes que sejam estáveis sob exposição prolongada a altas temperaturas (maiores que $200^{\circ} \mathrm{C}$ ), mas também devido à incontrolável formação de novos sítios ativos a partir do material não volátil da matriz depositado no sistema. Uma estratégia mais concebivel seria evitar que os componentes da amostra fossem injetados no sistema CG. Infelizmente, a presença de componentes residuais da amostra não pode ser evitada, mesmo após o clean-up, porque uma quantidade mínima de compostos endógenos da matriz, os quais possuam propriedades similares aos analitos, será co-eluida na mesma fração do extrato. De qualquer modo, é importante considerar um clean-up eficiente para auxiliar na performance total do sistema CG (HAJSLOVA; ZROSTLÝKOVA, 2003).

Uma alternativa aparentemente simples para solucionar o problema criado pelos sítios ativos no injetor seria mascará-los intencionalmente, durante a injeção do padrão de calibração (HAJSLOVA; ZROSTLÝKOVA, 2003). Para isso, uma das abordagens mais confiáveis é o uso de matrizes fortificadas ou combinadas, ou seja, padrões preparados na mesma composição da matriz da amostra analisada (branco) (ZROSTLÝKOVA et al., 2001). Esta estratégia é recomendada por alguns guias para análise de resíduos, no entanto, para propósitos de validação, a presença ou ausência dos efeitos de matriz deve ser demonstrada sobre a faixa de concentração de interesse (INMETRO, 2007; EUROPEAN COMMISSION, 2007).

\subsection{Validação do método analítico}

A necessidade de mostrar a qualidade de medições químicas através de sua comparabilidade, rastreabilidade e confiabilidade, está sendo cada vez mais reconhecida e exigida. Para garantir que um novo método analítico gere informações confiáveis e interpretáveis sobre a amostra, ele deve sofrer uma avaliação denominada validação (RIBANI et al., 2004). "A validação deve 
garantir, através de estudos experimentais, que o método atenda às exigências das aplicações analíticas, assegurando a confiabilidade dos resultados" (BRASIL, 2003a).

Dentro do contexto geral de validação de métodos é possivel distinguir dois tipos, sendo o primeiro chamado de validação no laboratório ("in house validation") que consiste nas etapas de validação dentro de um único laboratório, seja para validar um método novo que tenha sido desenvolvido localmente ou para verificar se um método adotado de outras fontes está sendo bem aplicado. A validação no laboratório é utilizada nas etapas preliminares do desenvolvimento de uma metodologia e na publicação de artigos para revistas científicas, em que são avaliadas todas as características de desempenho da validação da metodologia, porém sem verificar a reprodutibilidade. Pode-se considerar esta etapa como sendo preliminar à validação completa ("full validation"). O segundo tipo, a validação completa, envolve todas as características de desempenho de um estudo interlaboratorial utilizado para verificar como a metodologia se comporta com uma determinada matriz em vários laboratórios, estabelecendo a reprodutibilidade da metodologia e a incerteza expandida associada à metodologia como um todo. Só assim a metodologia pode ser aceita como uma metodologia oficial para uma determinada aplicação (RIBANI et al., 2004).

\subsubsection{Parâmetros de Validação}

É necessário que os estudos de validação sejam representativos e conduzidos de modo que a variação da faixa de concentração e os tipos de amostras sejam adequados. Um método para um composto majoritário requer um critério de aceitação e uma abordagem diferente de um método desenvolvido para análise de resíduos. Os parâmetros analíticos devem ser baseados na intenção do uso do método. Por exemplo, se um método será 
usado para análise qualitativa em nível de resíduos, não há necessidade de testar e validar a linearidade do método sobre toda a faixa linear dinâmica do equipamento. Desta forma, os experimentos podem ser limitados para o que realmente é necessário (RIBANI et al., 2004).

Os parâmetros analíticos normalmente considerados para validação de métodos de separação são: seletividade; linearidade e faixa de aplicação; precisão; exatidão; limite de detecção; limite de quantificação e robustez (RIBANI et al., 2004).

\subsubsection{Seletividade}

A seletividade de um método instrumental de separação é a capacidade de avaliar inequivocamente as substâncias em exame (analitos) na presença de componentes que podem interferir na sua determinação em uma amostra complexa. A seletividade avalia o grau de interferência de espécies como outro ingrediente ativo, impurezas e produtos de degradação, bem como outros compostos de propriedades similares que possam estar, por acaso, presentes. A seletividade garante que o pico de resposta seja exclusivamente do composto de interesse. A seletividade precisa estar assegurada para que a linearidade, a exatidão e a precisão não sejam comprometidas. O mesmo significado tem sido freqüentemente utilizado para o termo especificidade gerando confusão desnecessária. Isto pode ser evitado utilizando somente o termo seletividade, como sugerido pela IUPAC. Um método instrumental de separação que produz resposta para uma única substância de interesse pode ser chamado de específico e um método que produz resposta para vários compostos químicos, com uma característica em comum, pode ser chamado de seletivo. Desde que existem poucos métodos cromatográficos que respondem a apenas uma substância, o termo seletividade é mais apropriado (RIBANI et al., 2004). 
A seletividade pode ser obtida de várias maneiras. A primeira forma de se avaliar a seletividade é comparando a matriz isenta da substância de interesse e a matriz adicionada com esta substância (padrão), sendo que nesse caso, nenhum interferente deve eluir no tempo de retenção da substância de interesse, que deve estar bem separada dos demais compostos presentes na amostra. Uma segunda maneira é através da avaliação com detectores (arranjo de diodos, espectrômetro de massas), que comparam o espectro do pico obtido na separação com o de um padrão e utiliza-se isto como um indicativo da presença do composto puro (RIBANI et al., 2004).

2.4.3 Linearidade e faixa linear de trabalho

Linearidade é a habilidade de um método analítico em produzir resultados que sejam diretamente proporcionais à concentração do analito em amostras, em uma dada faixa de concentração. A quantificação requer que se conheça a dependência entre a resposta medida e a concentração do analito. A linearidade é obtida por padronização interna ou externa e formulada como expressão matemática usada para o cálculo da concentração do analito a ser determinado na amostra real (INMETRO, 2007). A equação da reta que relaciona as duas variáveis é:

$$
y=a x+b
$$

Onde:

$\mathrm{y}=$ resposta medida (área do pico);

$\mathrm{x}=$ concentração;

$\mathrm{a}$ = inclinação da curva de calibração = sensibilidade;

$\mathrm{b}=$ interseção com o eixo $\mathrm{y}$, quando $\mathrm{x}=0$. 
A linearidade de um método pode ser observada pelo gráfico dos resultados dos ensaios em função da concentração do analito ou então calculada a partir da equação da regressão linear, determinada pelo método dos mínimos quadrados.

O coeficiente de determinação $\left(\mathrm{r}^{2}\right)$ é freqüentemente usado para indicar o quanto pode ser considerada adequada a reta como modelo matemático (INMETRO, 2007).

A faixa linear de trabalho de um método de ensaio é o intervalo entre os niveis inferior e superior de concentração do analito no qual foi demonstrado ser possivel a determinação com a precisão, exatidão e linearidade exigidas, sob as condições especificadas para o ensaio. A faixa linear é definida como a faixa de concentrações na qual a sensibilidade pode ser considerada constante e é normalmente expressa nas mesmas unidades do resultado obtido pelo método analítico (INMETRO, 2007).

\subsubsection{Sensibilidade}

A sensibilidade é um parâmetro que demonstra a variação da resposta em função da concentração do analito. Pode ser expressa pela inclinação da reta de regressão de calibração, e é determinada simultaneamente aos testes de linearidade. A sensibilidade depende da natureza do analito e da técnica de detecção utilizada (INMETRO, 2007). 
2.4.5 Limite de detecção e limite de quantificação

O limite de detecção (LD) representa a menor concentração da substância em exame que pode ser detectada, mas não necessariamente quantificada, utilizando um determinado procedimento experimental. O LD pode ser calculado de três maneiras diferentes: método visual, método relação sinal-ruído e método baseado em parâmetros da curva analítica (RIBANI et al., 2004).

Pelo método baseado em parâmetros da curva analítica o limite de detecção pode ser expresso como:

$$
L D=3,3 \frac{s}{S}
$$

onde:

$\mathrm{s}=$ estimativa do desvio padrão da resposta, ou o coeficiente linear da equação;

$\mathrm{S}=$ inclinação ("slope") ou coeficiente angular da curva analítica (RIBANI et al., 2004).

O limite de quantificação (LQ) representa a menor concentração da substância em exame que pode ser medida, utilizando um determinado procedimento experimental. Assim, como o LD, pode ser calculado de três maneiras diferentes: método visual, método relação sinal-ruído e método baseado em parâmetros da curva analítica (RIBANI et al., 2004).

Pelo método baseado em parâmetros da curva analítica o limite de quantificação pode ser expresso como: 


$$
L Q=10 \frac{S}{S}
$$

onde:

$\mathbf{s}=$ estimativa do desvio padrão da resposta, ou o coeficiente linear da equação;

$\mathrm{S}=$ inclinação ("slope") ou coeficiente angular da curva analítica (RIBANI et al., 2004).

\subsubsection{Precisão}

Precisão é um termo geral para avaliar a dispersão de resultados entre ensaios independentes, repetidos de uma mesma amostra, amostras semelhantes ou padrões, em condições definidas. É normalmente determinada para circunstâncias específicas de medição e as duas formas mais comuns de expressá-la são por meio da repetitividade e a reprodutibilidade, sendo usualmente expressas pelo desvio-padrão (INMETRO, 2007).

A precisão pode ser medida através da estimativa do desvio padrão relativo (RSD), também conhecido como coeficiente de variação $(\mathrm{CV})$.

$$
C V(\%)=\frac{S}{\bar{x}} 100
$$

onde:

$\mathrm{S}=$ estimativa do desvio padrão absoluto;

$\bar{x}=$ média aritmética de um pequeno número de medições (média das determinações) (RIBANI et al., 2004). 


\subsubsection{Exatidão}

É definida como sendo a concordância entre o resultado de um ensaio e o valor de referência aceito como convencionalmente verdadeiro. Os processos normalmente utilizados para avaliar a exatidão de um método são, entre outros: uso de materiais de referência, participação em comparações interlaboratoriais e realização de ensaios de recuperação (INMETRO, 2007).

A exatidão do método deve ser verificada a partir de, no mínimo, 9 (nove) determinações contemplando o intervalo linear do procedimento, ou seja, 3 (três) concentrações, baixa, média e alta, com 3 (três) réplicas cada. A exatidão é expressa pela relação entre a concentração média determinada experimentalmente e a concentração teórica correspondente (BRASIL, 2003a):

Exatidão $=\underline{\text { concentração média experimental } \_} \times 100$

concentração teórica

A limitação do procedimento de recuperação é a de que a substância adicionada não está, necessariamente, na mesma forma que a presente na amostra. Isso pode implicar, por exemplo, na presença de substâncias adicionadas em uma forma que proporcione melhor detecção, ocasionando avaliações excessivamente otimistas da recuperação. Pelo fato de outros componentes da matriz poderem interferir na separação, detecção ou na quantificação da substância, efeitos dos componentes da matriz devem ser investigados. É importante considerar como a eficiência do método varia em função da concentração da substância. Na maioria dos casos, a dispersão dos resultados aumenta com a diminuição da concentração e a recuperação pode diferir substancialmente a altas e baixas concentrações. Por esse motivo, a recuperação deve ser avaliada na faixa de concentração esperada para o composto de interesse (RIBANI et al., 2004). 


\section{MATERIAIS E MÉTODOS}

O desenvolvimento experimental consistiu na avaliação do Método QuEChERS (ANASTASSIADES et al., 2003) para a extração de agrotóxicos em tomate, sendo submetidos ao procedimento de purificação por extração em fase sólida dispersiva e análise por CG-EM modo SIM.

Este estudo foi desenvolvido no laboratório de Ecotoxicologia do Centro de Energia Nuclear na Agricultura CENA/USP, Piracicaba, São Paulo.

\subsection{Instrumentação}

Sistema CG-EM: Cromatógrafo Gasoso Finnigan Mat GCQ equipado com:

- coluna capilar de sílica fundida 5-EM Quadrex, com fase estacionária 5\% fenil, 95\% metil-polisiloxano, $30 \mathrm{~m}$ de comprimento, diâmetro interno de 0,25 mm e espessura do filme de 0,25 $\mu \mathrm{m}$;

- detector de espectrometria de massas Ion Trap, atuando no modo SIM (Finnigan Mat GCQ);

- Sistema de aquisição de dados utilizando software X-Calibur versão 1.2

Processador doméstico Walita Mega Master 500W;

Homogeneizador Ultra-Turrax Marconi modelo MA102 (12.000 rpm);

Centrifuga Beckman J2-HS;

Balança analítica de precisão com 4 casas decimais Shimadzu AX200; 
Balança analítica com 2 casas decimais Gehaka BG4400;

Banho de ultrassom Bandelin Sonorex RK510S.

\subsection{Fases Sólidas}

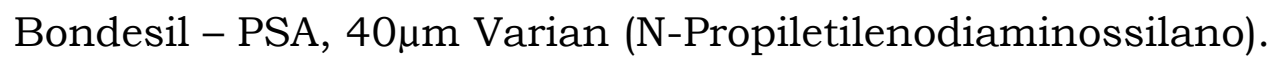

\subsection{Solventes e soluções}

Tolueno HPLC/Spectro 99,8\% Tedia Company, INC;

Acetonitrila (MeCN) HPLC/Spectro 99,9\% Tedia Company, INC;

Ácido fórmico 88\% (90,1\%) J. T. Baker;

Ácido fórmico 5\% em MeCN.

3.4 Sais

Sulfato de magnésio anidro $\left(\mathrm{MgSO}_{4}\right)$, grau reagente $\geq 97 \%$ Sigma-Aldrich;

Cloreto de sódio 99,5\% ( $\mathrm{NaCl})$ Mallinckrodt. 


\subsection{Gases}

Hélio $\left(\mathrm{H}_{2}\right)$ ultra puro, White Martins (gás de arraste do cromatógrafo gasoso);

Nitrogênio $\left(\mathrm{N}_{2}\right)$ comercial, White Martins (para concentração das amostras).

3.6 Padrões Analíticos

Padrões sólidos dos agrotóxicos, fornecedores conforme Tabela 5.

\subsection{Outros Materiais}

Seringa de polipropileno descartável;

Filtro de seringa Teflon PTFE Sartorius 0,45 $\mu \mathrm{m}$ 25mm;

Tubo de centrífuga de Teflon de 50 mL e 25 mL Nalgene®;

Balões volumétricos de 10,0 e 25,0 mL;

Frascos de vidro âmbar de diferentes volumes;

Frasco âmbar com tampa de teflon de $2 \mathrm{~mL}$;

Micropipeta de 200, 1000 e $10000 \mu \mathrm{L}$;

Outros materiais usuais em laboratório (béquer, proveta, pipeta volumétrica, balão volumétrico, tubo de ensaio). 
A vidraria utilizada foi preparada por imersão em sabão alcalino Derquim LM01- Derquim ${ }^{\circledR}$ (diluição 1:1000) durante 02 horas, lavada em água corrente até completa remoção do sabão, e posteriormente com água destilada e para finalização lavada com acetona. A secagem da vidraria foi feita em estufa a $30^{\circ} \mathrm{C}$ seguida de identificação e vedação com papel alumínio. O resíduo gerado na preparação foi armazenado em frasco para posterior entrega ao setor de gerenciamento de resíduos do CENA-USP.

\subsection{Agrotóxicos selecionados}

Os agrotóxicos selecionados para este estudo estão listados na Tabela 5, com sua pureza, fornecedor, classe, grupo químico e fórmula molecular, as estruturas químicas destes compostos e informações adicionais estão localizadas no Apêndice A.

\subsection{Amostras}

Foi coletado mensalmente 1 (um) $\mathrm{kg}$ de tomate (Lycopersicon esculentum Mill) selecionados aleatoriamente, de procedência nacional, comercializados no varejão Vale Verde e varejão Benjamim na cidade de Piracicaba-SP. As amostras foram processadas, identificadas e armazenadas em freezer para posterior análise.

As amostras de tomate foram coletadas no período de agosto de 2007 a outubro de 2008 totalizando 33 amostras. 
As amostras "branco" da matriz (livre de agrotóxico) foram adquiridas em supermercado, sob selo de certificação da Associação de Agricultura Orgânica certificada pela Ecocert Brasil.

\subsection{Preparo das amostras}

As amostras de tomate foram coletadas mensalmente em dois varejões localizados na cidade de Piracicaba, sendo as amostras de diferentes unidades produtoras. As amostras foram primeiramente lavadas em água corrente e aproximadamente 1 (um) kg de amostra foi cortada e triturada com processador doméstico até alcançar textura consistente. Em seguida, transferiu-se aproximadamente $200 \mathrm{~g}$ para um recipiente de vidro com vedação para armazenamento em freezer à temperatura de $-20^{\circ} \mathrm{C}$. Uma segunda sub-amostra foi imediatamente extraída, o recipiente lacrado e armazenado em freezer à temperatura de $-20^{\circ} \mathrm{C}$ para eventual necessidade de re-análises.

\subsection{Preparo das soluções analíticas}

\subsubsection{Soluções de padrões de agrotóxicos}

O preparo de soluções foi realizado de acordo com Lehotay (2005). Soluções individuais dos padrões de agrotóxicos foram preparadas pesando $10,0 \mathrm{mg}$ do padrão em frasco de vidro âmbar, e em seguida 1,0 mL de tolueno foi adicionado com pipeta volumétrica. A concentração da solução preparada foi corrigida pela pureza de cada padrão (Tabela 5). Estas soluções "estoque" apresentam estabilidade desde que armazenadas em freezer, a $-20^{\circ} \mathrm{C}$, e sejam corretamente manipuladas. 
A partir destas soluções foram preparadas soluções padrão de trabalho de agrotóxicos $\left(50 \mathrm{ng} \cdot \mathrm{\mu L}^{-1}\right)$ adicionando tolueno até a concentração desejada.

Após a preparação da solução de trabalho de cada agrotóxico foi feita uma solução mix na concentração $10 \mathrm{ng} \cdot \mu \mathrm{L}^{-1}$ contendo uma mistura dos agrotóxicos em estudo.

Todas as soluções de padrões de agrotóxicos foram estocadas em frascos de vidro âmbar, com tampa de teflon, e armazenadas em freezer $\left(-20^{\circ} \mathrm{C}\right)$ até o momento do uso.

Para verificar o tempo de retenção de cada composto e o perfil de resposta do detector, bem como o ín alvo e os qualificadores, foram injetadas individualmente soluções padrão na concentração de 10 ng. $\mu \mathrm{L}-1$ de cada agrotóxico no CG-EM (modo full scan).

Tabela 5 - Agrotóxicos analisados por CG-EM modo SIM, com informações de pureza, classe, fornecedor, grupo químico e fórmula molecular

\begin{tabular}{|c|c|c|c|c|c|}
\hline Agrotóxico & Pureza & Classe & Fornecedor & $\begin{array}{c}\text { Grupo } \\
\text { Químico }\end{array}$ & $\begin{array}{c}\text { Fórmula } \\
\text { Molecular }\end{array}$ \\
\hline Acefato & $99 \%$ & A-I & $\begin{array}{l}\text { AccuStandard, } \\
\text { New Haven, USA }\end{array}$ & Organofosforado & $\mathrm{C}_{4} \mathrm{H}_{10} \mathrm{NO}_{3} \mathrm{PS}$ \\
\hline Buprofezina & $99 \%$ & A-I & $\begin{array}{l}\text { AccuStandard, } \\
\text { New Haven, USA }\end{array}$ & Tiadiazinona & $\mathrm{C}_{16} \mathrm{H}_{23} \mathrm{~N}_{3} \mathrm{OS}$ \\
\hline Carbofurano & $99 \%$ & A-C-I-N & $\begin{array}{l}\text { AccuStandard, } \\
\text { New Haven, USA }\end{array}$ & $\begin{array}{l}\text { Metilcarbamato } \\
\text { de benzofuranila }\end{array}$ & $\mathrm{C}_{12} \mathrm{H}_{15} \mathrm{NO}_{3}$ \\
\hline Deltametrina & $99 \%$ & F-I & $\begin{array}{l}\text { AccuStandard, } \\
\text { New Haven, USA }\end{array}$ & Piretróide & $\mathrm{C}_{22} \mathrm{H}_{19} \mathrm{Br}_{2} \mathrm{NO}_{3}$ \\
\hline Difenoconazol & $99 \%$ & $\mathrm{Fu}$ & $\begin{array}{l}\text { AccuStandard, } \\
\text { New Haven, USA }\end{array}$ & Triazol & $\mathrm{C}_{19} \mathrm{H}_{17} \mathrm{Cl}_{2} \mathrm{~N}_{3} \mathrm{O}_{3}$ \\
\hline $\begin{array}{l}\text { Endossulfam- } \\
\text { alfa }\end{array}$ & $99 \%$ & A-F-I & $\begin{array}{l}\text { Riedel-de-Haën, } \\
\text { Seelze }\end{array}$ & Ciclodienoclorado & $\mathrm{C}_{9} \mathrm{H}_{6} \mathrm{Cl}_{6} \mathrm{O}_{3} \mathrm{~S}$ \\
\hline $\begin{array}{l}\text { Endossulfam- } \\
\text { beta }\end{array}$ & $99 \%$ & A-F-I & $\begin{array}{l}\text { Riedel-de-Haën, } \\
\text { Seelze }\end{array}$ & Ciclodienoclorado & $\mathrm{C}_{9} \mathrm{H}_{6} \mathrm{Cl}_{6} \mathrm{O}_{3} \mathrm{~S}$ \\
\hline $\begin{array}{l}\text { Endossulfam- } \\
\text { sulfato }\end{array}$ & $99 \%$ & A-F-I & $\begin{array}{l}\text { Riedel-de-Haën, } \\
\text { Seelze }\end{array}$ & Ciclodienoclorado & $\mathrm{C}_{9} \mathrm{H}_{6} \mathrm{Cl}_{6} \mathrm{O}_{4} \mathrm{~S}$ \\
\hline Fenpropatrina & $99 \%$ & A-I & $\begin{array}{l}\text { AccuStandard, } \\
\text { New Haven, USA }\end{array}$ & Piretróide & $\mathrm{C}_{22} \mathrm{H}_{23} \mathrm{NO}_{3}$ \\
\hline Monocrotofós & $99 \%$ & A-I & $\begin{array}{l}\text { AccuStandard, } \\
\text { New Haven, USA }\end{array}$ & Organofosforado & $\mathrm{C}_{7} \mathrm{H}_{14} \mathrm{NO}_{5} \mathrm{P}$ \\
\hline
\end{tabular}

A: Acaricida I: Inseticida N: Nematicida C: Cupinicida F: Formicida Fu: Fungicida 
3.11.2 Soluções analíticas no extrato

Para a avaliação do efeito de matriz foram preparadas soluções analiticas no extrato. Para o preparo das matrizes foram utilizados tomates cultivados no sistema orgânico (livre de agrotóxicos). Foi realizada a extração conforme item 3.17.3, o extrato foi evaporado em fluxo de Nitrogênio e ressuspendido em $500 \mu \mathrm{L}$ da solução padrão mix em tolueno na concentração correspondente ao ponto da curva analítica.

\subsubsection{Soluções analíticas em solvente}

A curva de calibração foi preparada a partir de diluições das soluções mix 10 ng. $\mu \mathrm{L}^{-1}$ em tolueno. As concentrações dos padrões para a elaboração da curva analítica foram de: 0,$25 ; 0,50 ; 1,00 ; 2,00 ; 3,00$ e 4,00 ng. $\mu \mathrm{L}^{-1}$ para os agrotóxicos buprofezina, carbofurano, a-endossulfam, $\beta$-endossulfam, sulfato de endossulfam e monocrotofós.

3.12 Fortificações de amostras de tomate

Para avaliar o parâmetro exatidão, foram realizadas fortificações em $10 \mathrm{~g}$ de tomate orgânico, a partir das soluções mix de trabalho, para obtenção de 3 pontos de concentrações diferentes $(0,25 ; 1,00$ e 4,00 ng. $\left.\mu \mathrm{L}^{-1}\right)$ em 3 réplicas injetadas em triplicatas.

Após a fortificação, as amostras de tomate foram submetidas ao processo de extração conforme item 3.17.3. 
A recuperação percentual em cada ponto de fortificação foi avaliada através da razão entre a concentração obtida, calculada por padronização externa a partir da curva de calibração nos extratos da matriz, e a concentração real adicionada à matriz (tomate), multiplicado por 100, conforme Equação 5.

\subsection{Análises Cromatográficas por CG-EM}

\subsubsection{Condições cromatográficas}

A temperatura inicial da coluna foi de $100^{\circ} \mathrm{C}$ mantida por 3 minutos com taxa de aquecimento de $25^{\circ} \mathrm{C} \cdot \mathrm{min}^{-1}$ até $175^{\circ} \mathrm{C}$, após foi aquecido até $290^{\circ} \mathrm{C}$ com taxa de aquecimento de $8^{\circ} \mathrm{C}$ e mantida por 5 minutos. O tempo da corrida foi de 25,38 minutos. A rampa de temperatura foi ajustada durante a otimização do método, de modo a permitir um melhor desempenho da técnica cromatográfica para os analitos em estudo.

As injeções foram realizadas com injetor manual no modo splitless. A temperatura do injetor foi de $250^{\circ} \mathrm{C}$, foi utilizado liner de quartzo com lã de vidro. O gás de arraste utilizado foi Hélio (ultra puro) a uma vazão de 1,00 $\mathrm{mL}$. $\mathrm{min}^{-1}$. O volume injetado foi de $2 \mu \mathrm{L}$.

A temperatura da linha de transferência foi de $275^{\circ} \mathrm{C}$ e do Ion Source de $175^{\circ} \mathrm{C}$. O espectrômetro de massas foi operado no modo SIM (Selected Ion Monitoring), com fonte de íons de impacto de elétrons (EI) a $70 \mathrm{eV}$. O start time do detector foi a 5 minutos.

Os íons de cada agrotóxico, selecionados para a análise por CG-EM no modo EI de ionização e modo SIM de aquisição, estão listados na Tabela 6, com seus tempos de retenção e massa molar. 
3.13.2 Análise qualitativa e quantitativa

As análises qualitativa e quantitativa dos agrotóxicos foram realizadas utilizando-se o modo SIM.

Foram definidos três íons de cada composto: íon alvo e dois íons qualificadores $(\mathrm{Q} 1, \mathrm{Q} 2)$. Para identificação dos íons de cada agrotóxico, cada padrão foi injetado primeiramente sozinho e monitorado no modo full scan (varredura), para ser identificado o tempo de retenção e o perfil de fragmentação dos íons de cada composto, e desta maneira escolher o íon alvo e os íons qualificadores. Os agrotóxicos estudados e íons monitorados $(\mathrm{m} / \mathrm{z})$ estão listados na Tabela 6.

\subsection{Validação do método analítico}

3.14.1 Determinação da linearidade das curvas analíticas

Foi avaliada a linearidade das curvas analíticas a partir das soluções analiticas preparadas no item 3.13 em solvente e nos extratos da matriz tomate (item 3.12), nas concentrações de 0,$25 ; 0,50 ; 1,00 ; 2,00 ; 3,00$ e 4,00 ng. $\mu L^{-1}$ dos produtos buprofezina, carbofurano, a-endossulfam, $\beta$ endossulfam, sulfato de endossulfam e monocrotofós. A sequência analítica foi injetada 3 vezes.

Posteriormente, realizaram-se os cálculos da média das áreas, do CV (\%), da equação da regressão linear da curva analítica bem como do coeficiente de determinação para cada composto analisado por CG-EM. 
3.14.2 Determinação do LD e LQ

Os limites de detecção (LD) e quantificação (LQ) para cada um dos agrotóxicos foram determinados usando os parâmetros da curva analítica. Para este cálculo construiu-se uma curva analítica utilizando soluções padrão contendo buprofezina, carbofurano, a-endossulfam, $\beta$-endossulfam, sulfato de endossulfam e monocrotofós nas concentrações 0,$05 ; 0,10 ; 0,15$; 0,$25 ; 0,30$ e $0,50 \mathrm{ng} \cdot \mu \mathrm{L}^{-1}$. O LD e o LQ foram considerados 3,3 e 10 vezes, respectivamente, a razão entre os coeficientes linear e angular da curva analítica (RIBANI et al., 2004).

3.14.3 Ensaios de extração, fortificação e recuperação (\%)

Os ensaios de fortificação e recuperação tem por objetivo avaliar a exatidão do método como um todo, uma vez que se calcula a concentração real medida no final de todo o procedimento, em comparação com a concentração conhecida adicionada inicialmente na matriz. Assim, através das recuperações obtidas dos agrotóxicos analisados pode-se avaliar a exatidão do método, e através dos coeficientes de variação calculados, obtem-se informações sobre a repetitividade (precisão) dos dados obtidos.

Este procedimento de fortificação foi realizado 3 vezes $(n=3)$ para cada nível de fortificação (3 níveis), e também para o tomate "branco", que é aquele sem a adição dos agrotóxicos (orgânico) para a verificação da real ausência desses compostos na matriz. Este extrato da matriz é chamado de "branco" da matriz e também foi utilizado para o preparo das soluções analíticas, quando em extrato da matriz. 


\subsubsection{Extração}

O método de extração empregado foi o descrito por Anastassiades et al. (2003).

O tomate orgânico foi previamente homogeneizado e em seguida foram transferidos 10,0 \pm 0,1 g para frasco de $50 \mathrm{~mL}$ de Teflon. Logo após, efetuouse a fortificação com solução padrão mix de agrotóxicos utilizando microseringa, nos níveis 0,$25 ; 1,00$ e 4,00 ng. $\mu L^{-1}$ com soluções diluídas em MeCN. As amostras fortificadas foram deixadas em recipiente aberto à temperatura ambiente por aproximadamente 30 minutos, para evaporação do solvente e incorporação ao extrato. A Figura 6 ilustra os passos analíticos para a realização do método.

A seguir, foi adicionado $10 \mathrm{~mL}$ de $\mathrm{MeCN}$ e agitado em homogeneizador por 2 minutos a $12.000 \mathrm{rpm}$. Acrescentou-se 4,0 g de $\mathrm{MgSO}_{4}$ anidro e 1,0 g de $\mathrm{NaCl}$ observando se estes sólidos não permaneceram nas bordas do tubo prejudicando o contato com o líquido. Após, o extrato foi agitado vigorosamente por 1 minuto manualmente assegurando a completa interação entre o extrato líquido e os reagentes sólidos. Depois o extrato foi centrifugado a $5000 \mathrm{rpm}$ por 5 minutos.

\subsubsection{Clean-up dSPE}

Foi transferida uma aliquota de $6 \mathrm{~mL}$ do sobrenadante para frasco de $15 \mathrm{~mL}$ de Teflon contendo $900 \mathrm{mg}$ de $\mathrm{MgSO}_{4}$ anidro e $150 \mathrm{mg}$ de sorvente PSA e agitado vigorosamente por 1 minuto manualmente. A seguir o extrato foi centrifugado a $5000 \mathrm{rpm}$ por 5 minutos. O Fluxograma da Figura 7 mostra as etapas efetuadas durante o procedimento de extração e clean-up. 

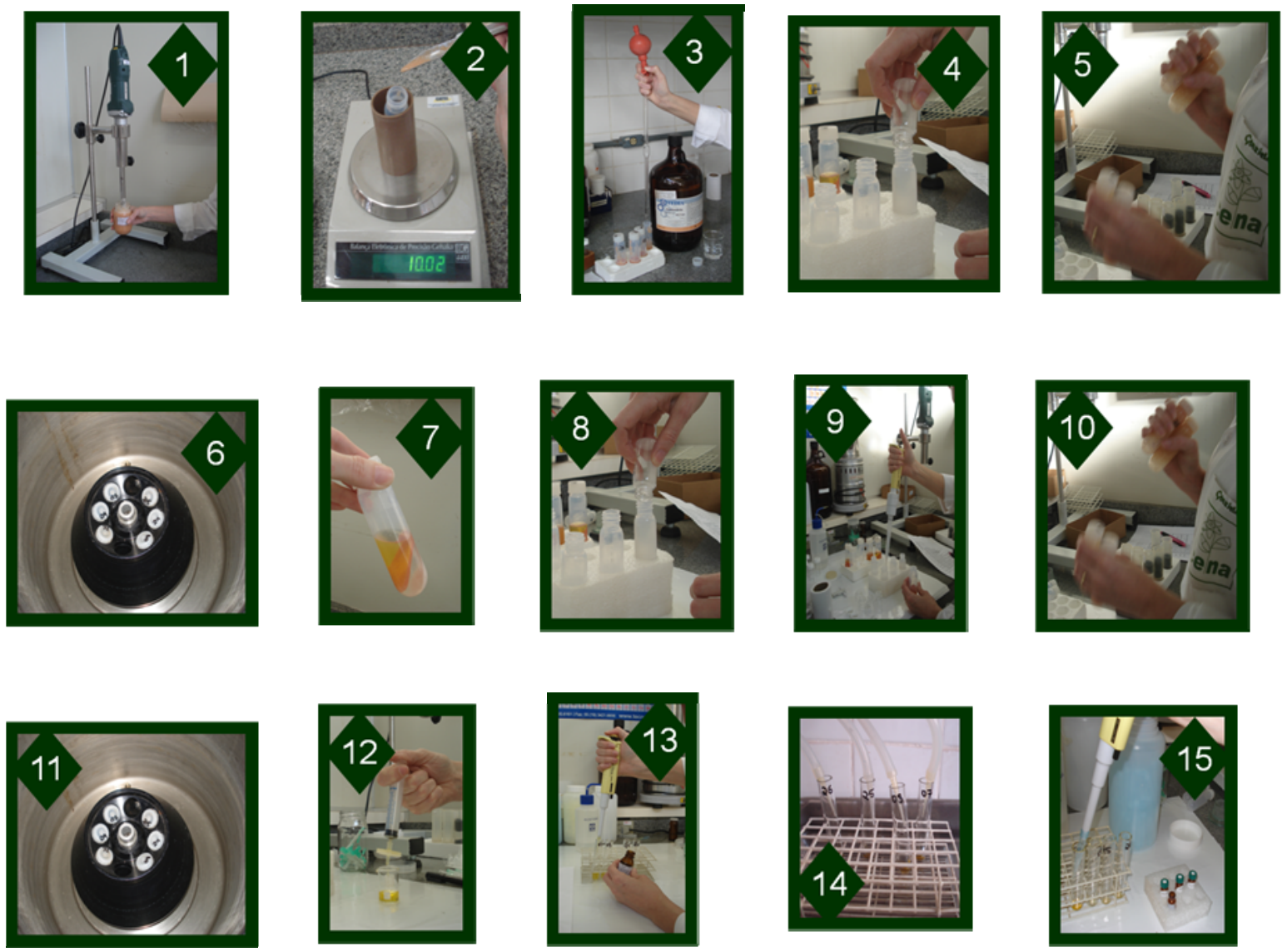

1) Homogeneização da amostra de tomate, 2) Pesagem de 10,0g, 3) Adição de $10 \mathrm{~mL}$ de $\mathrm{MeCN}$, 4) Adição de 4,0g de $\mathrm{MgSO}_{4}$ anidro e 1,0g de $\mathrm{NaCl}$, 5) Agitação manual por 1 minuto, 6) Centrifugação a $5000 \mathrm{rpm}$ por 5 minutos, 7) Separação do extrato líquido e sólidos, 8) Adição de 900mg de $\mathrm{MgSO}_{4}$ anidro e 150mg de PSA em tubo de teflon, 9) Adição de $6 \mathrm{~mL}$ do extrato sobrenadante, 10) Agitação manual por 1 minuto, 11) Centrifugação a $5000 \mathrm{rpm}$ por 5 minutos, 12) Filtragem com filtro de teflon de $0,45 \mu \mathrm{m}$, 13) Adição de $20 \mu \mathrm{L}$ de $5 \%$ ácido fórmico em $\mathrm{MeCN}$ a $2 \mathrm{~mL}$ de extrato filtrado, 14) Evaporação com fluxo de $\mathrm{N}_{2}, 15$ ) Transferência para frasco para análise em CG-EM.

Figura 6 - Ilustração dos passos analíticos para realização do método QuEChERS nas análises da matriz tomate 


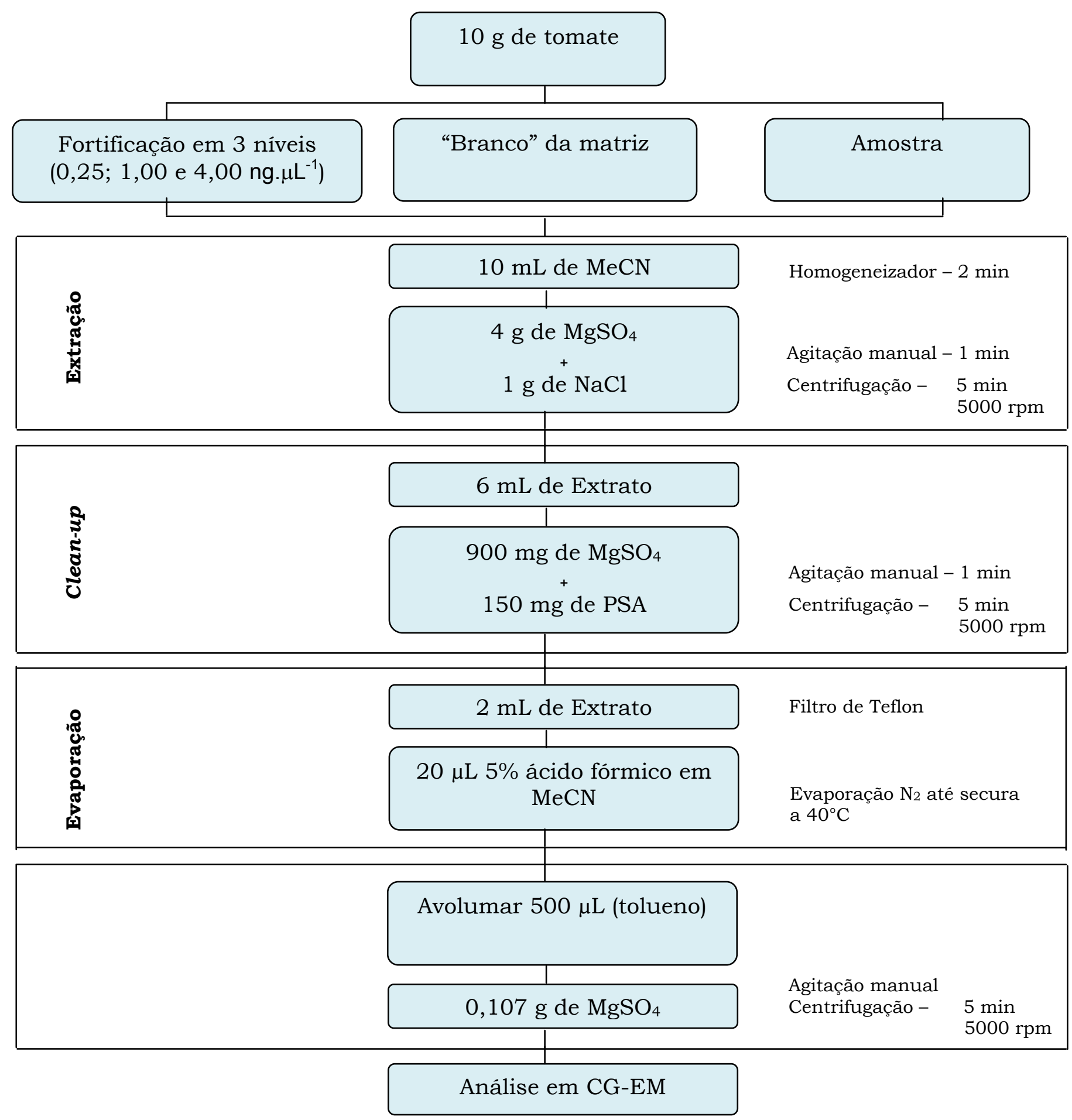

Figura 7 - Representação esquemática do método de análise de resíduos de agrotóxicos em tomate, utilizando método QuEChERS 
3.14.3.3 Evaporação e troca de solvente

O sobrenadante do extrato foi filtrado em filtro de teflon e transferido 2 $\mathrm{mL}$ para tubo de vidro de $10 \mathrm{~mL}$. Adicionou-se $20 \mu \mathrm{L}$ de solução de $5 \%$ ácido fórmico em MeCN e submeteu-se a evaporação por fluxo de $\mathrm{N}_{2}$ a $40^{\circ} \mathrm{C}$ até secura. O extrato foi ressuspendido em $500 \mu \mathrm{L}$ de tolueno e centrifugado com 0,107g $\mathrm{MgSO}_{4}$ anidro por 5 minutos a $5000 \mathrm{rpm}$. Foi transferido aproximadamente $400 \mu \mathrm{L}$ para frasco e analisados por CG-EM.

3.14.4 Avaliação do efeito matriz

Para a avaliação da existência do efeito matriz nas análises por CG-EM realizou-se a comparação entre as áreas obtidas nas soluções analíticas em tolueno e as áreas das soluções analiticas preparadas em extrato "branco" da matriz. Para isso, foram preparadas soluções analíticas em extrato da matriz e em tolueno conforme item 3.12 e 3.13 respectivamente, e injetadas nas condições do método. O cálculo foi efetuado através da Equação:

$$
\text { Efeito de Matriz (\%) }=\frac{\text { slope }(X 1)-\text { slope }(X 2)}{\text { slope }(X 2)} \times 100
$$

onde:

$X 1=$ inclinação da curva obtida pela injeção das soluções analíticas de cada agrotóxico, preparadas em extrato "branco" da matriz (tomate);

$X 2=$ inclinação da curva obtida pela injeção das soluções analíticas de cada agrotóxico, preparadas em tolueno (solvente). 
Assim, é verificado se a matriz exerce efeito positivo (aumento de sinal) ou negativo (decréscimo de sinal) sobre o resultado da análise. Quando o resultado for acima de 10\% considera-se que o efeito matriz começa a exercer influência nas análises (ZROSTLÝKOVA et al., 2001).

Outra forma para avaliação do efeito da matriz (INMETRO, 2007) consiste em aplicar os testes F (Snedecor) de homogeneidade de variâncias e o teste $\mathrm{t}$ (Student) de comparação de médias. Normalmente, parte-se da hipótese em que a matriz não afeta o sinal do analito. Primeiramente, faz-se o teste $\mathrm{F}$ para verificar se as variâncias das amostras podem ser consideradas iguais. Tem-se dois casos:

(I) se F calculado for menor que o $\mathrm{F}$ tabelado, as variâncias podem ser consideradas iguais, isto é, a matriz não tem um efeito importante sobre a precisão do método na faixa de concentração em estudo. Neste caso, os desvios padrão dos grupos de testes podem ser agrupados e a igualdade das médias dos dois conjuntos de amostras pode ser testada com a distribuição t de Student.

(II) se F calculado for maior que o $\mathrm{F}$ tabelado, as variâncias não podem ser consideradas iguais, ou seja, a matriz tem um efeito importante sobre a precisão do método na faixa de concentração em estudo, o teste $\mathrm{t}$ denominado "com dados pareados" pode ser utilizado para verificar os efeitos de matriz. Se o valor de $\mathrm{t}$ calculado for menor que o $\mathrm{t}$ tabelado, pode-se concluir que a matriz não afeta o ensaio. Se o valor de $\mathrm{t}$ for maior que o $\mathrm{t}$ tabelado, pode-se concluir que a matriz tem um efeito estatisticamente significante sobre o resultado do ensaio. 
3.15 Ensaios de extração para análise das amostras

Para a análise das amostras de tomate foi utilizado o procedimento descrito no item 3.17.3 com exceção da fortificação inicial com solução padrão mix de agrotóxicos em $\mathrm{MeCN}$. 


\section{RESULTADOS E DISCUSSÕES}

4.1 Condições de análise por CG-EM (Modo SIM)

As condições cromatográficas utilizadas nesse estudo foram estabelecidas de acordo com os estudos desenvolvidos por Anastassiades et al. (2003) e otimizadas.

Após as amostras serem submetidas à extração de matriz por fase sólida dispersiva, conforme descrito no item 3.17.3, foram analisadas cromatograficamente por CG-EM (modo de aquisição SIM e de ionização por impacto de elétrons).

Os íons de cada agrotóxico, selecionados para a análise por CG-EM no modo EI de ionização e modo SIM de aquisição, estão listados na Tabela 6, com seus tempos de retenção e massa molar. 
Tabela 6 - Agrotóxicos analisados por CG-EM, modo de aquisição SIM, valores de $t_{R}$, massa molar e íons monitorados

\begin{tabular}{lccc}
\hline \multicolumn{1}{c}{ Agrotóxicos } & $\mathbf{M}\left(\mathbf{g ~ m o l}^{-\mathbf{1}}\right)$ & $\mathbf{t}_{\mathbf{R}}(\mathbf{m i n})$ & Íons monitorados \\
\hline Acefato & 183 & 8,36 & $136^{*}+94+95$ \\
Monocrotofós & 223 & 10,93 & $127^{*}+67+97$ \\
Carbofurano & 221 & 11,62 & $164^{*}+149+122$ \\
Endossulfam-alfa & 407 & 16,29 & $195^{*}+241+277$ \\
Buprofezina & 305 & 16,78 & $175^{*}+172+105$ \\
Endossulfam-beta & 407 & 17,95 & $195^{*}+241+339$ \\
Endossulfam-sulfato & 423 & 18,85 & $272^{*}+229+387$ \\
Fenpropatrina & 349 & 20,05 & $97^{*}+181+55$ \\
Difenoconazol & 406 & 24,19 & $265^{*}+323+267$ \\
Deltametrina & 505 & 24,68 & $181^{*}+253+77$ \\
\hline
\end{tabular}

*Íon principal

Fonte: NIST, 2005

4.2 Validação do método analítico

Todas as soluções analíticas empregadas neste estudo foram preparadas em solvente (tolueno grau HPLC) e no extrato "branco" da matriz, assim foi possivel avaliar o efeito da presença do extrato da matriz que pode influenciar os resultados, dependendo dos compostos e da técnica cromatográfica empregada. 
4.2.1 Determinação dos valores de LD e LQ

A partir das soluções analiticas nas concentrações de 0,05;0,10;0,15; 0,25; 0,30 e 0,50 ng. $\mu \mathrm{L}^{-1}$, dos agrotóxicos buprofezina, carbofurano, aendossulfam, $\beta$-endossulfam, sulfato de endossulfam e monocrotofós, preparadas em matriz efetuou-se o estudo da linearidade (item 3.17.1), obtendo-se a média das áreas $(\mathrm{n}=3)$ e $\mathrm{CV}$, os resultados estão apresentados na Tabela 7.

Foram calculados o LD e o LQ para os agrotóxicos estudados considerando como 3,3 e 10 vezes respectivamente a razão entre os coeficientes linear e angular (RIBANI et al., 2004) da curva analítica nas concentrações acima mencionadas. Os coeficientes linear e angular das curvas analiticas, bem como os valores de LD e LQ obtidos, estão apresentados na Tabela 8. Para efeito de comparação foram também incluídos os limites máximos de resíduos dos agrotóxicos autorizados para aplicação na cultura de tomate. Os produtos endossulfam e monocrotofós não são permitidos pela Legislação Brasileira e pelo Codex para aplicação na cultura de tomate, portanto seus valores não estão apresentados na Tabela 8. O LMR para o Carbofurano foi estabelecido somente pela Legislação Brasileira. 


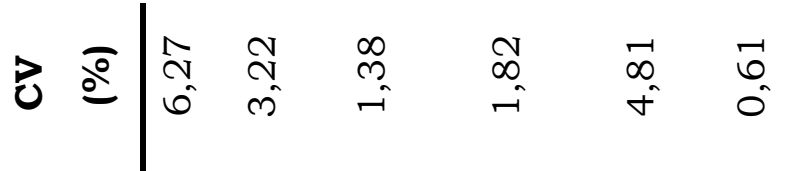

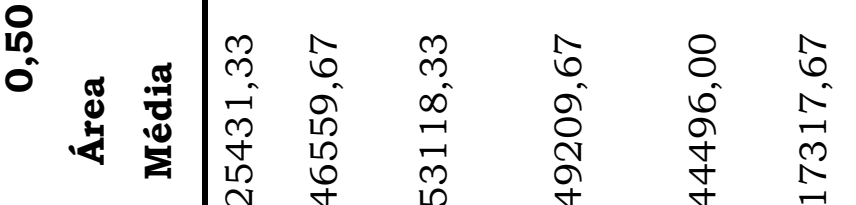

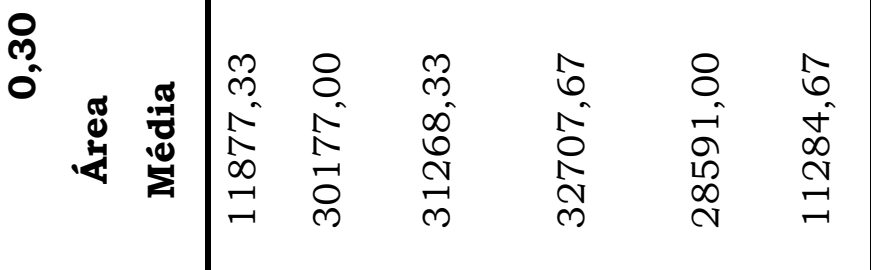

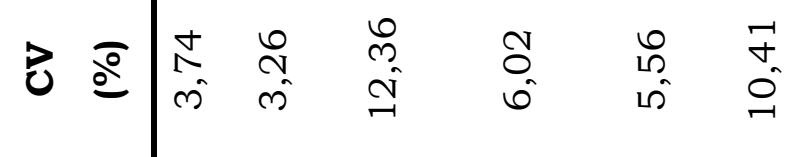

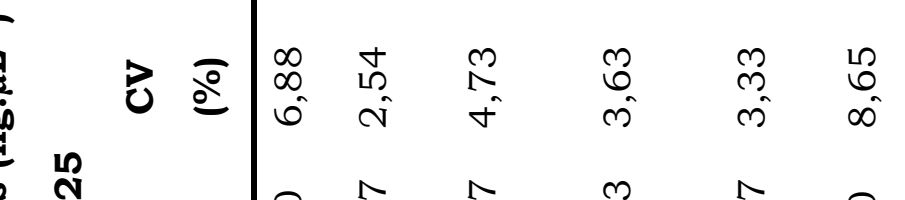

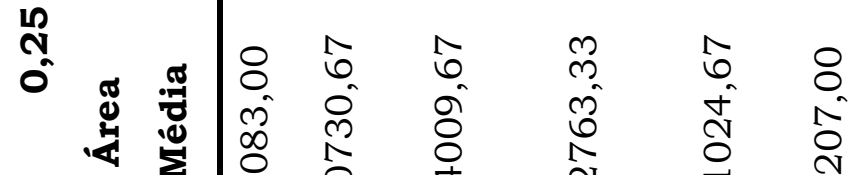

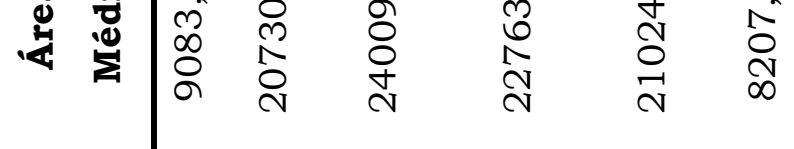

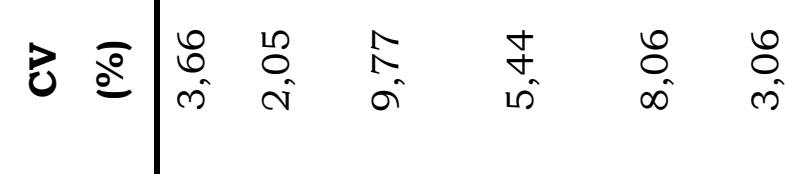

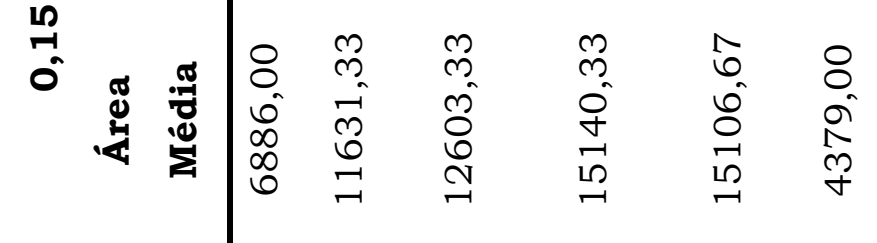

웅

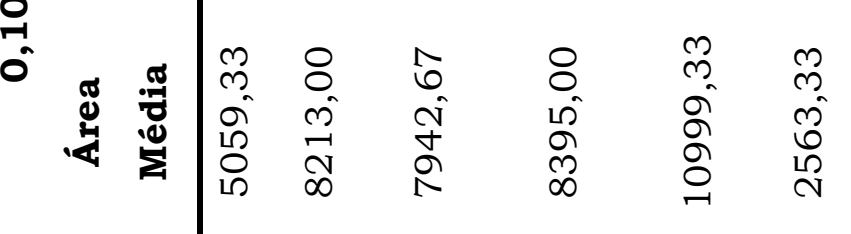


Tabela 8 - Estimativa dos coeficientes linear (s) e angular (S) das curvas analíticas, limites de detecção (LD) e quantificação (LQ) e LMR

\begin{tabular}{lccccccc}
\hline \multicolumn{1}{c}{ Agrotóxicos } & $\mathbf{s}$ & $\mathbf{s}$ & $\mathbf{2}$ & $\mathbf{L D}$ & \multicolumn{2}{c}{$\mathbf{L Q}$} & \multicolumn{2}{c}{ LMR (mg/Kg) } \\
& & & & (mg/Kg) & (mg/Kg) & Nacional & Codex \\
\hline Buprofezina & 649,2 & 24479 & 0,993 & 0,0219 & 0,0663 & 0,5 & 1,0 \\
Carbofurano & 2404 & 98390 & 0,994 & 0,0202 & 0,0611 & 0,1 & $* * *$ \\
Endossulfam-alfa & 4518,7 & 114887 & 0,999 & 0,0324 & 0,0983 & & \\
Endossulfam-beta & 146,2 & 98165 & 0,988 & 0,0012 & 0,0037 & $*$ & $* * *$ \\
Endossulfam-sulfato & 2328 & 82968 & 0,994 & 0,0231 & 0,0701 & & $*$ \\
Monocrotofós & 982,1 & 37096 & 0,995 & 0,0218 & 0,0662 & $* *$ & $* * *$ \\
\hline
\end{tabular}

*Permitido somente para aplicação foliar nas culturas de algodão, cacau, café, cana-deaçúcar e soja.

**Oficio $\mathrm{n}^{\circ}$ 008/06/GENAV de 06 de fevereiro de 2006, ficou estabelecido a data de 15 de março de 2006, como limite para comercialização de agrotóxicos a base de Monocrotofós, sendo proibido a partir desta data (BRASIL, 2003b).

***Limites máximo de resíduo não estabelecidos ou revogados (FAO, 2009a).

Avaliando os valores encontrados de LD e LQ (Tabela 8), podemos observar que estes se encontram menores que o LMR permitido para todos os agrotóxicos em estudo. Esse resultado evidencia a aplicabilidade do método utilizado para o monitoramento destes agrotóxicos na cultura de tomate.

\subsubsection{Linearidade das curvas analiticas}

Analisando os resultados apresentados na Tabela 9 pode-se observar que todos os compostos apresentaram coeficiente de determinação maior que 0,99 quando os padrões foram preparados na matriz, tendo os agrotóxicos monocrotofós, carbofurano e buprofezina apresentado coeficientes de determinação menores que 0,99 quando analisados em 
tolueno. Isso evidencia a influência positiva do efeito matriz sobre os parâmetros de intervalo linear e $\mathrm{r}^{2}$ tornando as respostas do sistema cromatográfico mais estáveis e as análises mais sensíveis, fornecendo respostas mais precisas.

Tabela 9 - Parâmetros das curvas analiticas, obtidos para os agrotóxicos analisados por CG-EM modo SIM, a partir das soluções 0,25; 0,$50 ; 1,00 ; 2,00 ; 3,00$ e 4,00 ng. $\mu \mathrm{L}^{-1}$ em tolueno e na matriz

\begin{tabular}{lcccc}
\hline Agrotóxicoss & \multicolumn{1}{c}{ Solvente } & & \multicolumn{1}{c}{ Matriz } & \\
& Equação da Curva & $\mathbf{r}^{2}$ & Equação da Curva & $\mathbf{r}^{2}$ \\
\hline $\begin{array}{l}\text { Buprofezina } \\
\text { Carbofurano }\end{array}$ & $\mathrm{y}=89757,07 \mathrm{x}-32177,33$ & 0,9862 & $\mathrm{y}=153442,61 \mathrm{x}-33397,34$ & 0,9986 \\
$\begin{array}{l}\text { Endossulfam- } \\
\text { alfa }\end{array}$ & $\mathrm{y}=157222,36 \mathrm{x}-27530,78$ & 0,9962 & $\mathrm{y}=202704,55 \mathrm{x}-426,17$ & 0,9978 \\
$\begin{array}{l}\text { Endossulfam- } \\
\text { beta }\end{array}$ & $\mathrm{y}=181893,89 \mathrm{x}-45788,52$ & 0,9953 & $\mathrm{y}=211003,89 \mathrm{x}-6258,66$ & 0,9989 \\
$\begin{array}{l}\text { Endossulfam- } \\
\text { sulfato }\end{array}$ & $\mathrm{y}=174586,30 \mathrm{x}-46726,98$ & 0,9939 & $\mathrm{y}=247295,19 \mathrm{x}-234,38$ & 0,9987 \\
Monocrotofós & $\mathrm{y}=150467,27 \mathrm{x}-67169,44$ & 0,9812 & $\mathrm{y}=142193,96 \mathrm{x}-29623,42$ & 0,9980 \\
\hline
\end{tabular}

\subsubsection{Seletividade}

Para avaliar a seletividade do método, foram analisados extratos "branco" da matriz (sem adição de agrotóxicos) e extratos fortificados com os agrotóxicos buprofezina, carbofurano, a-endossulfam, $\beta$-endossulfam, sulfato de endossulfam e monocrotofós. A amostra de tomate, apesar de possuir uma composição complexa, não apresentou interferentes nos mesmos tempos de retenção dos compostos analisados o que torna a 
metodologia seletiva. A Figura 8 apresenta o cromatograma obtido por CGEM modo SIM do extrato da matriz "branco" e a Figura 9 apresenta cromatogramas de soluções analíticas preparadas em solvente orgânico (9a) e no extrato "branco" fortificado da matriz (9b) na concentração de 1,00 ng. $\mu \mathrm{L}^{-1}$.

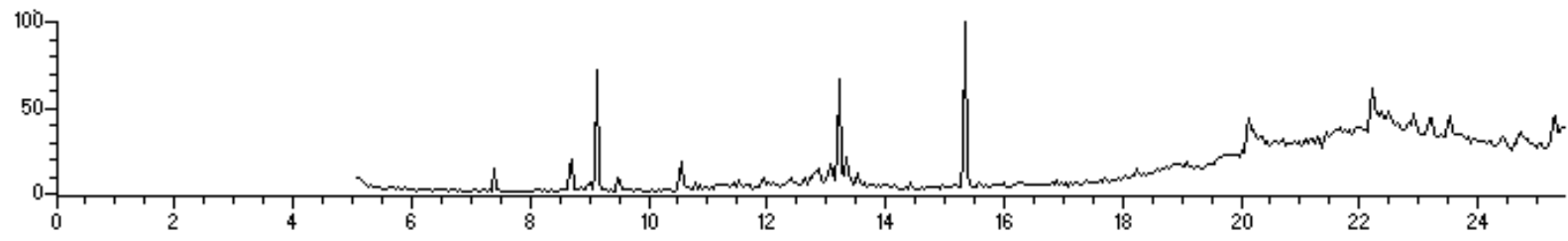

Figura 8 - Cromatograma total obtido por CG-EM modo SIM, para extrato "branco" de tomate
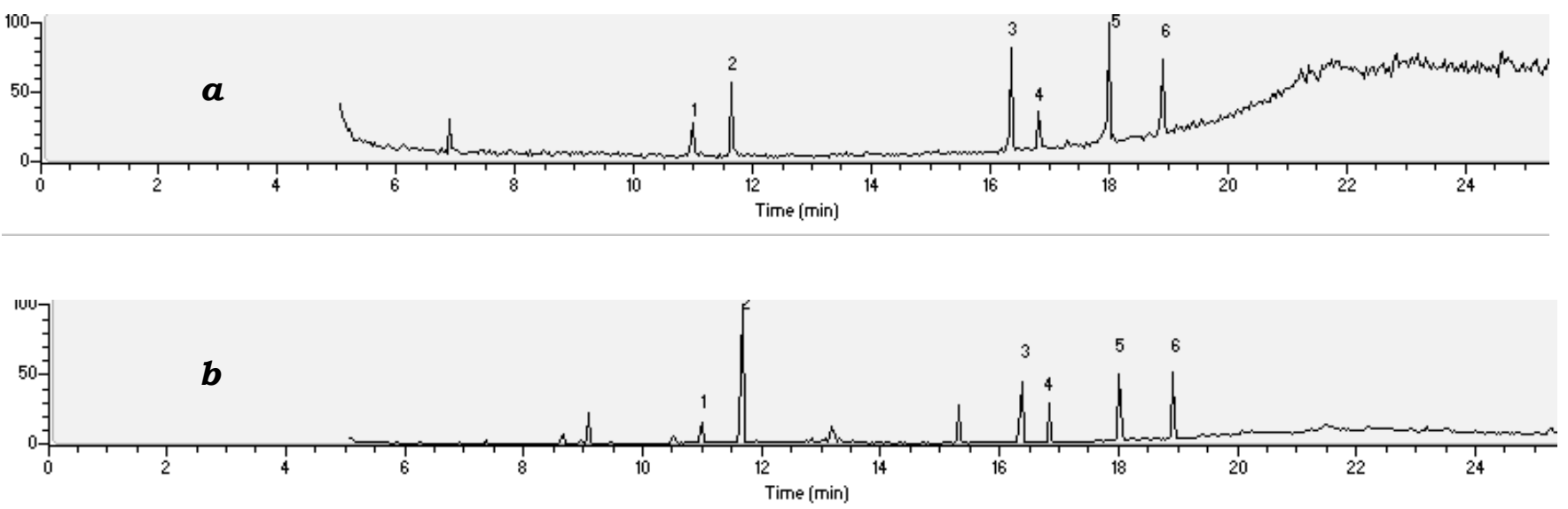

1. monocrotofós

4. buprofezina
2. carbofurano

5. $\beta$-endossulfam
3. a-endossulfam

6. sulfato de endossulfam

Figura 9 - Cromatograma dos agrotóxicos analisados por CG-EM modo SIM, quando em soluções analíticas $1,0 \mathrm{ng} \cdot \mathrm{LL}^{-1}$ preparadas em a) solvente orgânico (tolueno); b) extrato "branco" fortificado da matriz (tomate) 


\subsubsection{Precisão}

A precisão foi avaliada em termos de repetitividade dos resultados e precisão intermediária.

A repetitividade foi estudada pelo cálculo da estimativa do coeficiente de variação de três repetições do procedimento otimizado da extração em fase sólida dispersiva.

Os resultados de coeficiente de variação obtidos variaram de 3,74\% e 14,46\% (Tabela 10), tendo o organofosforado monocrotofós apresentado maior dispersão dos resultados. Entretanto esses resultados demonstram bons resultados, uma vez que os coeficientes de variação se encontram abaixo do recomendado para análise de resíduos de agrotóxicos.

A precisão intermediária foi avaliada a partir de testes de recuperação de 3 réplicas injetadas em triplicata, com amostras fortificadas em 3 niveis de concentração $(0,0625 ; 0,25$ e 1,00 mg/Kg) através de seus coeficientes de variação $\left(\mathrm{CV}_{\mathrm{M}}\right)$. Os resultados obtidos estão dispostos na Tabela 11 . 
Tabela 10 - Porcentagem de recuperação (Rec\%), desvio padrão e coeficiente de variação (CV\%) obtido após três extrações dos agrotóxicos em tomate

\begin{tabular}{lccc}
\hline \multicolumn{1}{c}{ Agrotóxicos } & Rec (\%) & $\begin{array}{c}\text { Desvio } \\
\text { Padrão }\end{array}$ & CV(\%) \\
\hline Buprofezina & 73,00 & 3,7931915 & 5,20 \\
Carbofurano & 99,82 & 5,7566556 & 5,77 \\
Endossulfam-alfa & 88,95 & 4,6586296 & 5,24 \\
$\begin{array}{l}\text { Endossulfam-beta } \\
\text { Endossulfam- }\end{array}$ & 77,12 & 8,90987 & 11,55 \\
$\begin{array}{l}\text { sulfato } \\
\text { Monocrotofós }\end{array}$ & 71,27 & 2,6646055 & 3,74 \\
\end{tabular}

4.2.5 Ensaios de fortificação para recuperação (\%)

Dentre os critérios estabelecidos pela União Européia para validação de métodos analíticos empregados para análise de resíduos de agrotóxicos em alimentos, a porcentagem de recuperação aceita para métodos multirresíduos deve ser de 70 a $120 \%$ e o valor do CV não deve exceder $20 \%$ (EUROPEAN COMMISSION, 2007).

Os valores de recuperação foram calculados utilizando-se as curvas analíticas preparadas nos extratos da matriz, de acordo com o método de extração utilizado.

A Tabela 11 apresenta os resultados das recuperações médias $(n=3)$ percentuais e o $\mathrm{CV}$, para os agrotóxicos fortificados no tomate, aos níveis de 0,0625; 0,25 e 1,00 mg/Kg, extraídos pelo método QuEChERS e analisados por CG-EM modo SIM. A Figura 10 mostra uma visualização do comportamento das recuperações apresentado pelos agrotóxicos. 
A Figura 11 apresenta os cromatogramas referentes à fortificação dos agrotóxicos nos níveis de 0,06, 0,25 e 1,00 mg/ $\mathrm{kg}$.

Tabela 11 - Média dos percentuais de recuperação $\left(\mathrm{R}_{\mathrm{M}}\right)$ e coeficiente de variação $\left(\mathrm{CV}_{\mathrm{M}}\right)$, obtidos a partir da extração com acetonitrila do tomate fortificado, aos niveis de 0,0625;0,25 e 1,00 mg/Kg dos agrotóxicos analisados por CG-EM modo SIM

\begin{tabular}{|c|c|c|c|c|c|c|c|c|}
\hline \multirow[b]{3}{*}{ Agrotóxicos } & \multicolumn{6}{|c|}{ Niveis de Fortificação } & \multirow{3}{*}{$\begin{array}{c}\text { Exatidão } \\
\mathbf{R}_{\mathbf{M}}\end{array}$} & \multirow{3}{*}{$\begin{array}{c}\text { Precisão } \\
\mathrm{CV}_{\mathbf{M}}\end{array}$} \\
\hline & \multicolumn{2}{|c|}{$0,06 \mathrm{mg} / \mathrm{Kg}$} & \multicolumn{2}{|c|}{$0,25 \mathrm{mg} / \mathrm{Kg}$} & \multicolumn{2}{|c|}{$1,00 \mathrm{mg} / \mathrm{Kg}$} & & \\
\hline & $\begin{array}{c}\text { Rec } \\
\text { Média } \\
\text { (\%) }\end{array}$ & $\begin{array}{l}\text { CV } \\
(\%)\end{array}$ & $\begin{array}{c}\text { Rec } \\
\text { Média } \\
(\%)\end{array}$ & $\begin{array}{l}\text { CV } \\
(\%)\end{array}$ & $\begin{array}{c}\text { Rec } \\
\text { Média } \\
\text { (\%) }\end{array}$ & $\begin{array}{l}\text { CV } \\
(\%)\end{array}$ & & \\
\hline Buprofezina & 77,16 & 7,51 & 72,13 & 8,04 & 63,18 & 11,85 & 70,82 & 9,13 \\
\hline Carbofurano & 106,81 & 11,38 & 101,32 & 5,71 & 125,37 & 8,40 & 111,17 & 8,50 \\
\hline Endossulfam-alfa & 93,71 & 5,88 & 80,41 & 7,92 & 74,60 & 13,33 & 82,91 & 9,04 \\
\hline Endossulfam-beta & 82,70 & 8,88 & 69,56 & 14,80 & 71,72 & 9,25 & 74,66 & 10,98 \\
\hline Endossulfam-sulfato & 99,13 & 7,40 & 71,69 & 14,02 & 66,16 & 12,29 & 78,99 & 11,24 \\
\hline Monocrotofós & 103,41 & 16,59 & 75,21 & 12,66 & 62,55 & 14,30 & 80,39 & 14,51 \\
\hline
\end{tabular}

$\mathrm{R}_{\mathrm{M}}$ é a média entre os valores de Recuperação dos três níveis de fortificação;

$\mathrm{CV}_{\mathrm{M}}$ é a média entre os valores de $\mathrm{CV}$ dos três níveis de fortificação 


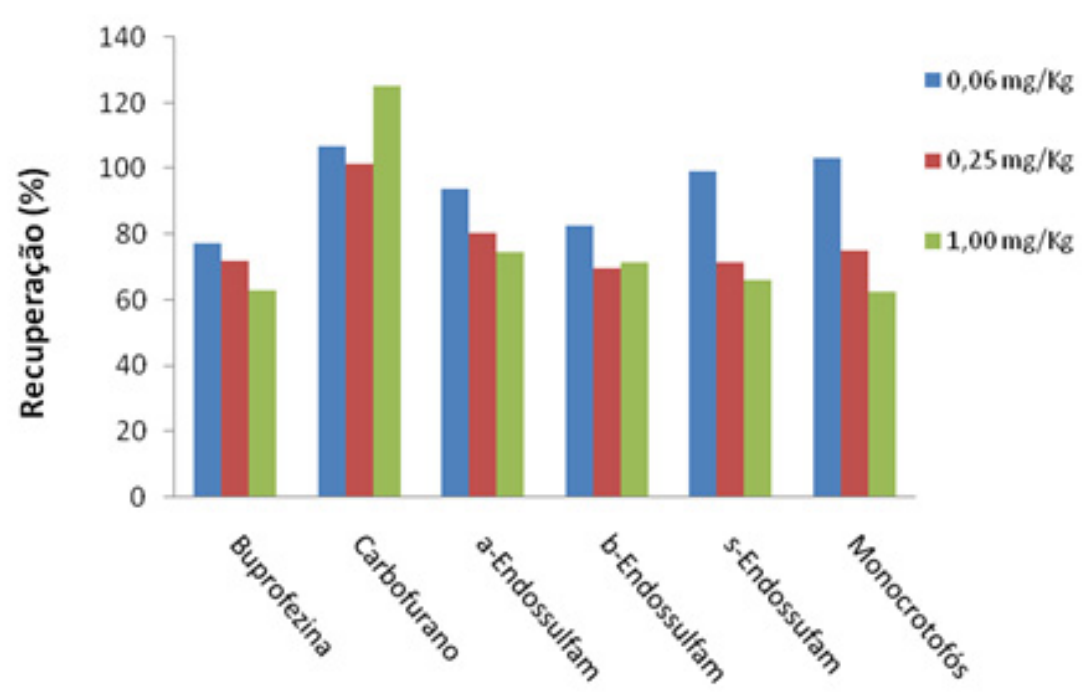

Figura 10 - Recuperações obtidas para os agrotóxicos nos três diferentes níveis de fortificação $(0,06 ; 0,25$ e $1,00 \mathrm{mg} / \mathrm{kg})$
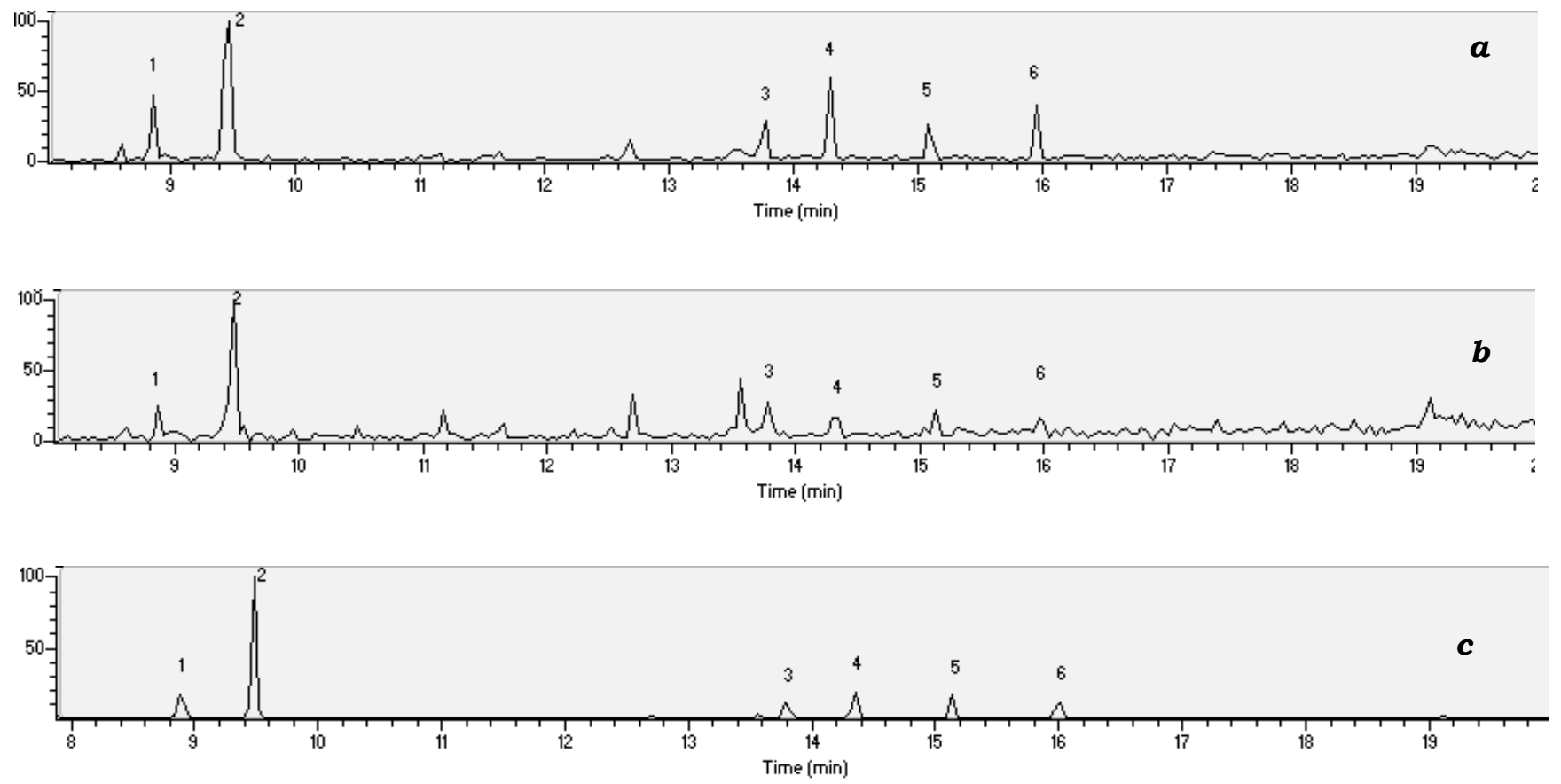

1. monocrotofós

4. buprofezina
2. carbofurano

5. $\beta$-endossulfam
3. a-endossulfam

6. sulfato de endossulfam

Figura 11 - Cromatograma obtido por CG-EM modo SIM para tomate fortificado ao nível de (a) 0,06 (b) 0,25 e (c) $1,00 \mathrm{mg} / \mathrm{kg}$ 


\subsection{Efeito de matriz}

A taxa de recuperação de agrotóxicos em alimentos nem sempre é satisfatória devido aos efeitos de matriz na análise cromatográfica. A quantificação dos compostos pode ser afetada pela presença de compostos co-extraídos da matriz. A presença dessas impurezas nas amostras analisadas pode causar problemas no detector e mais ainda em sítios do injetor (MENKISSOGLU-SPIROUDI; FOTOPOULOU, 2004).

Os sítios ativos do liner (tubo de vidro) do injetor são a principal fonte do efeito de matriz, pois adsorve e ou, induz a degradação térmica de alguns analitos, principalmente os que possuem ligação $\mathrm{P}=\mathrm{O}$ como os organofosforados (ERNEY et al., 1993). Quando as soluções padrão são preparadas no solvente puro e analisadas por cromatografia gasosa, mais sítios ativos do liner estão disponiveis para retenção dos analitos. Enquanto que ao injetar padrões no extrato da matriz, ocorre uma competição por esses sítios ativos entre os componentes da matriz e os analitos, possibilitando que uma maior quantidade do agrotóxico esteja disponível para introduzir-se na coluna cromatográfica (SCHENCK; LEHOTAY, 2000). Entretanto, quando se prepara os padrões em extratos brancos, além de aumentar o custo e o tempo da análise, a concentração dos próprios interferentes da matriz pode diferir de uma amostra para outra (RIBANI et al., 2004).

Os possiveis efeitos de matriz nas análises cromatográficas devem ser levados em consideração mesmo para comprovar a ausência ou presença do fenômeno sobre uma faixa de concentração do analito na matriz. Para isso, duas séries de soluções padrão foram preparadas, sendo uma em extratos de amostra de tomate (item 3.12) e a outra em solvente (item 3.13). As curvas analiticas preparadas em tolueno e em extrato da matriz foram comparadas e plotadas na Figura 12 . 
Os resultados dos cálculos do efeito matriz (Equação 6) para as análises realizadas por CG-EM modo SIM se encontram na Tabela 12. Para a avaliação estatística do efeito de matriz foi utilizado o programa SISVAR para o cálculo de $\mathrm{F}$ e teste $\mathrm{t}$ de Student, os resultados estão apresentados na Tabela 12 .
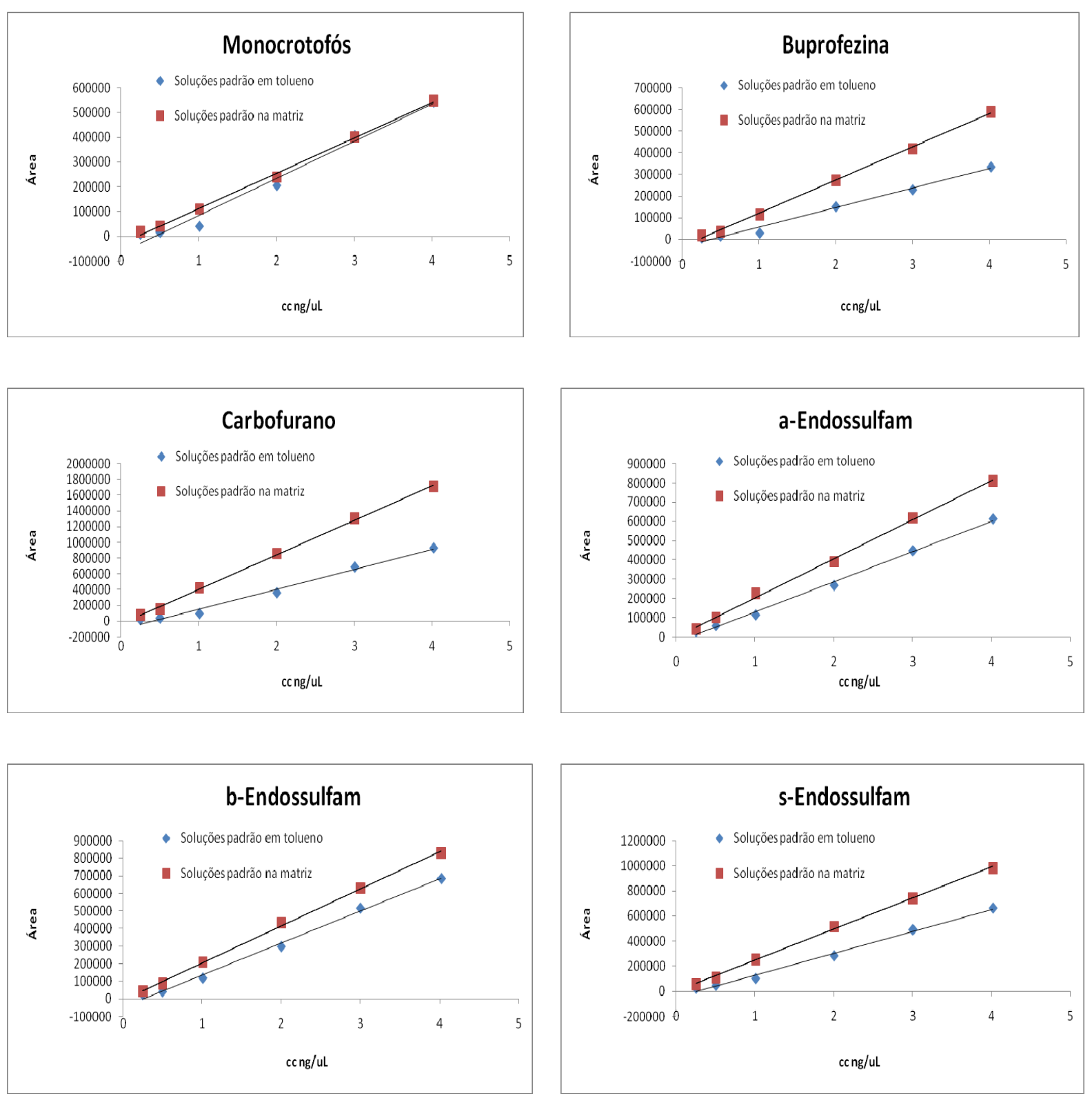

Figura 12 - Comparação visual entre as inclinações das curvas analíticas preparadas em tolueno e em matriz de tomate 
Os agrotóxicos buprofezina, carbofurano, a-endossulfam, $\beta$ endossulfam e sulfato de endossulfam, cujos padrões foram preparados em tolueno, apresentaram uma resposta menor quando comparada a dos padrões preparados em extrato de matriz, o que pode ser observado pela diferença expressiva entre os coeficientes angulares. Na análise estatística, esses produtos apresentaram diferença significativa ao nível de confiança de $95 \%$, quando avaliado o efeito de matriz.

A inclinação das curvas analíticas para o agrotóxico monocrotofós (Figura 12) quando preparado em tolueno e no extrato de matriz são muito próximas, sugerindo que este não apresenta efeito de matriz, ou seja, que a presença dos componentes da matriz não interfere significativamente em sua análise cromatográfica. Pela comparação entre os coeficientes angulares e pela análise estatística comprovou-se que este não sofreu interferência de matriz (Tabela 12).

Freitas (2005) analisou organofosforados em diferentes matrizes de frutas e observou que alguns apresentaram efeito de matriz significativo enquanto outros não, não sendo possivel estabelecer um padrão de comportamento para o efeito de cada agrotóxico em cada matriz.

O efeito de matriz pode não ser causado apenas pelo diferente grau de adsorção do analito no sistema de injeção, mas causado também pela ocorrência do processo variável de degradação, o que pode acontecer tanto quando o agrotóxico está em extrato da matriz como em solvente orgânico. Esse fato torna a interpretação do efeito matriz em CG ainda mais difícil. De maneira geral, pode-se dizer que, soluções analíticas preparadas em extratos da matriz devem ser utilizadas para a quantificação dos resíduos de agrotóxicos em tomate, analisados por CG-EM modo SIM. 
Tabela 12 - Resultado dos efeitos de matriz pela variação dos coeficientes angulares das curvas em solvente e matriz, e dos testes de F e t ao nivel de 95\% de confiança

\begin{tabular}{|c|c|c|c|}
\hline Agrotóxicos & $\begin{array}{c}\text { Variação entre coef. } \\
\text { angulares (\%) } \\
\end{array}$ & Estatistica & $\begin{array}{c}\text { Conclusão obtida pelas duas } \\
\text { avaliações }\end{array}$ \\
\hline Buprofezina & 70,95 & Teste $\mathrm{F}: \mathrm{F}_{\mathrm{cal}}>\mathrm{F}_{\mathrm{tab}}$ & Efeito de matriz significativo \\
\hline Carbofurano & 73,99 & $\begin{array}{l}\text { Teste } t: t_{c a l}>t_{t a b} \\
\text { Teste } F: F_{c a l}>F_{t a b}\end{array}$ & Efeito de matriz significativo \\
\hline Endossulfam-alfa & 28,93 & $\begin{array}{l}\text { Teste } t: t_{c a l}>t_{t a b} \\
\text { Teste } F: F_{c a l}>F_{t a b}\end{array}$ & Efeito de matriz significativo \\
\hline Fndecaulfam heta & $16 \Omega 0$ & $\begin{array}{l}\text { Teste } t: t_{c a l}>t_{t a b} \\
\text { Teste } F: F_{c a l}>F_{t a b}\end{array}$ & Ffeito de matriz sionificativo \\
\hline 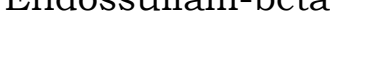 & 10,00 & Teste $\mathrm{t}: \mathrm{t}_{\mathrm{cal}}>\mathrm{t}_{\mathrm{tab}}$ & 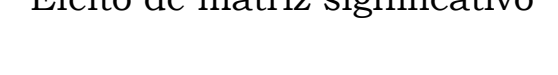 \\
\hline Endossulfam-sulfato & 41,64 & Teste $\mathrm{F}: \mathrm{F}_{\mathrm{cal}}>\mathrm{F}_{\mathrm{tab}}$ & Efeito de matriz significativo \\
\hline Monocrotofós & -5.49 & $\begin{array}{l}\text { Teste } \mathrm{t}: \mathrm{t}_{\mathrm{cal}}>\mathrm{t}_{\mathrm{tab}} \\
\text { Teste } \mathrm{F}: \mathrm{F}_{\mathrm{cal}}<\mathrm{F}_{\mathrm{tab}}\end{array}$ & Efeito de matriz não é \\
\hline & & Teste $\mathrm{t}: \mathrm{t}_{\mathrm{cal}}<\mathrm{t}_{\mathrm{tab}}$ & significativo \\
\hline
\end{tabular}

O efeito matriz pode sofrer variações ao longo do tempo e também varia dependendo da condição do instrumento utilizado, devendo, por isso, ser constantemente avaliado, tanto na etapa de desenvolvimento do método quanto na aplicação do método nas análises de rotina.

4.4 Determinação de agrotóxicos em amostras comerciais de tomate

Foram analisadas 33 amostras de tomate coletadas em 2 varejões na cidade de Piracicaba, SP no período de agosto de 2007 a outubro de 2008 pelo método de extração QuEChERS.

Em todas as amostras analisadas $(n=33)$, os niveis residuais de agrotóxicos apresentaram-se abaixo dos limites de detecção para os 
produtos: buprofezina, carbofurano, a-endossulfam, $\beta$-endossulfam, sulfato de endossulfam e monocrotofós.

Oviedo, Toledo e Vicente (2002) apresentaram resultados semelhantes aos deste estudo, analisaram resíduos de clorotalonil, aldrin, dieldrin, heptacloro, heptacloro epóxido, a-endossulfam, $\beta$-endossulfam e sulfato de endossulfam nas hortaliças: alface, acelga, chicória, repolho, tomate, chuchu, batata, cenoura, mandioca e mandioquinha. As amostras foram coletadas no restaurante da Universidade Estadual de Campinas e em todas as amostras de hortaliças analisadas $(n=151)$, os niveis residuais de agrotóxicos apresentaram-se abaixo dos limites de detecção.

No estudo realizado por Maciel (2005) em amostras comerciais de manga $(n=15)$ não foram encontrados resíduos de 32 agrotóxicos (organofosforados, organoclorados e triazois) acima do limite autorizado pela legislação.

Os resultados, obtidos neste monitoramento pontual realizado na região de Piracicaba, indicam que a legislação vigente está sendo cumprida e que as boas práticas agrícolas continuam sendo adotadas na cultura de tomate.

4.5 Agrotóxicos acefato, deltametrina, difenoconazol e fenpropatrina

Os agrotóxicos acefato, deltametrina, difenoconazol e fenpropatrina foram incluídos na etapa inicial deste estudo, mas apresentaram pouca resolução nas condições cromatográficas do método de análise empregado.

O acefato, quando injetado na concentração de $40 \mathrm{ng} \cdot \mu \mathrm{L}^{-1}(10 \mathrm{mg} / \mathrm{Kg})$, não apresentou sensibilidade analítica. 
Os produtos deltametrina, difenoconazol e fenpropatrina somente apresentaram resposta em concentrações muito altas. $\mathrm{Na}$ concentração de 10 ng. $\mu \mathrm{L}^{-1}$ não apresentaram sinal analítico, foram então testados na concentração de $40 \mathrm{ng} \cdot \mu \mathrm{L}^{-1}(10 \mathrm{mg} / \mathrm{Kg})$ muito acima de seu LMR de 0,03, 0,1 e $0,2 \mathrm{mg} / \mathrm{Kg}$ respectivamente, mas a avaliação não seria relevante em concentrações tão altas.

Diferentes técnicas cromatográficas têm sido utilizadas para a determinação e quantificação de resíduos de piretróides como a deltametrina e fenpropatrina em várias matrizes, sendo que a cromatografia em fase gasosa ainda é a técnica mais utilizada. Embora não existam sistemas específicos de detecção para piretróides, as moléculas halogenadas são bastante sensiveis ao detector por captura de elétrons (electron capture detector - ECD) (SANTOS; AREAS; REYES, 2007).

De acordo com o protocolo QuEChERS (LEHOTAY, 2005) os produtos acefato e difenoconazol podem ser analisados por CG ou CL, mas são preferivelmente analisados por CL. O acefato pode ter adsorvido ou degradado no sistema de injeção, em razão do estresse térmico sofrido durante a análise por cromatografia gasosa (PINHO et al., 2009). O difenoconazol por conter halogênios em sua estrutura, pode apresentar maior sensibilidade no sistema CG- ECD.

O sistema CG-EM não apresentou sensibilidade e seletividade requeridas para a avaliação dos compostos acefato, deltametrina, difenoconazol e fenpropatrina, tampouco as condições de temperatura empregadas no método foram adequadas para a detecção destes produtos. 


\section{CONCLUSÕES}

As análises revelaram vantagens como rapidez, simplicidade, confiabilidade, robustez, baixo custo, baixo consumo de solventes, necessidade de pouca vidraria e bons resultados para os agrotóxicos extraídos.

O método foi eficiente para análise dos agrotóxicos: buprofezina, carbofurano, a-endossulfam, $\beta$-endossulfam, sulfato de endossulfam e monocrotofós na matriz tomate.

Nas condições experimentais do estudo os produtos: acefato, deltametrina, difenoconazol e fenpropatrina não apresentaram resposta analítica no sistema CG-EM, portanto não foram avaliados.

Através das análises do efeito matriz percentual e análise estatística concluiu-se que os agrotóxicos: buprofezina, carbofurano, a-endossulfam, $\beta$ endossulfam e sulfato de endossulfam apresentaram efeito de matriz. Por isso, é recomendada a quantificação baseada no uso de padrões analíticos preparados em extrato branco da matriz para compensar os efeitos de matriz e obter resultados mais exatos.

Este estudo demonstrou que o método QuEChERS com extração em fase sólida dispersiva tem potencial para aplicação nas análises de rotina de multirresíduos em tomate, uma vez que os parâmetros de validação mostraram-se adequados para os produtos buprofezina, carbofurano, aendossulfam, $\beta$-endossulfam, sulfato de endossulfam e monocrotofós. 


\section{REFERÊNCIAS}

AGÊNCIA NACIONAL DE VIGILÂNCIA SANITÁRIA - ANVISA. Monografias: buprofezina, carbofurano, endossulfam . Disponivel em: $<$ http:// www.anvisa.gov.br/toxicologia/monografias/index.htm>. Acesso em: 04 fev. 2009.

AGÊNCIA NACIONAL DE VIGILÂNCIA SANITÁRIA - ANVISA. SAI - Sistema de Informações sobre Agrotóxicos. Brasília, 2000. Disponível em: <http://www4.anvisa.gov.br/AGROSIA/asp/frm_dados_agrotoxico.asp >. Acesso em: 24 mar. 2009.

AGÜERA, A.; KOK, A. GC-MS. II: Applications for pesticide analysis in food. In: FERNANDEZ-ALBA, A.R. (Ed.). Chromatographic-mass spectrometric food analysis for trace determination of pesticide residues. Amsterdam: Elsevier, 2005. cap.7, p.339-368. (Comprehensive analytical Chemistry, 43).

ALDER, L.; GREULICH, K.; KEMPE, G.; VIETH, B. Residue analysis of 500 high priority pesticides: Better by GC-MS or LC-MS/MS? Mass Spectrometry Reviews, Malden, v.25, p.838-865, 2006.

ALVES FILHO, J.P. Uso de agrotóxicos no Brasil: controle social e interesses corporativos. São Paulo: Annablume, 2002. 188p.

ANASTASSIADES, M.; LEHOTAY, S.J.; ŠTAJNBAHER, D.; SCHENCK, F.J. Fast and easy multiresidue method employing acetonitrile extraction/partitioning and "dispersive solid-phase extraction" for the determination of pesticide residues in produce. Journal of AOAC International, Arlington, v.86, n.2, p.412-431, 2003.

ANASTASSIADES, M.; SCHERBAUM, E. Sample handling and clean-up procedures. II New developments. In: FERNANDEZ-ALBA, A.R. (Ed.). Chromatographic-mass spectrometric food analysis for trace determination of pesticide residues. Amsterdam: Elsevier, 2005. cap.4, p.113-233. (Comprehensive analytical Chemistry, 43).

ANDREUCCETTI, C. Avaliação da qualidade do tomate de mesa tratado com gás etileno. 2005. 154f. Dissertação (Mestrado em Engenharia Agrícola) - Faculdade de Engenharia Agrícola, Universidade Estadual de Campinas, Campinas, 2005.

ARAÚJO, A.C.P.; NOGUEIRA D.P.; AUGUSTO L.G.S. 2000. Impacto dos praguicidas na saúde: estudo da cultura do tomate. Revista de Saúde Pública, São Paulo, v. 34, n.3, p.309-313, 2000.

ARREBOLA, F.J.; MARTÍNEZ VIDAL, J.L.; MATEU-SÁNCHEZ, M.; ÁLVAREZCASTELLÓN, F.J. Determination of 81 multiclass pesticides in fresh 
foodstuffs by a single injection analysis using gas chromatography-chemical ionization and electron ionization tandem mass spectrometry. Analytica Chimica Acta, Amsterdam, v.484, p.167-180, 2003.

BARRIGOSSI, J.A.F. Cultivo do arroz de terras altas no estado de Mato Grosso. Normas Gerais sobre o Uso de Agrotóxicos. Santo Antonio de Goiás: Embrapa Arroz e Feijão, 2006. (Sistemas de Produção, 7). Disponível em: <http: / / sistemasdeproducao.cnptia.embrapa.br/FontesHTML/Arroz/ArrozT errasAltasMatoGrosso/normas_gerais_uso_agrotoxicos.htm>. Acesso em: 23 mar. 2009.

BARRIONUEVO, W.R.; LANÇAS, F.M. Extração em fase sólida (SPE) e micro extração em fase sólida (SPME) de piretróides em água. Quimica Nova, São Paulo, v.24, n.2, p.172-175, 2001.

BRASIL. Agência Nacional de Vigilância Sanitária. Resolução RE nº 899, 29 de maio de 2003a: Determina a publicação do "Guia para validação de métodos analíticos e bioanalíticos"; fica revogada a Resolução RE $n^{\circ} 475$, de 19 de março de 2002. Diário Oficial da União; Poder Executivo, Brasília, de 02 de junho de 2003. Disponivel em: <http://e-legis.anvisa.gov.br /leisref/public/showAct.php?id=15132\&word>. Acesso em: 18 mar. 2009.

BRASIL. Ministério da Agricultura, Pecuária e Abastecimento. AGROFIT: Sistema de Agrotóxicos Fitossanitários. Brasília, 2003b. Disponível em: <http://agrofit.agricultura.gov.br/agrofit_cons/principal_agrofit_cons>. Acesso em: 12 jan. 2009.

BRASIL. Ministério da Agricultura, Pecuária e Abastecimento. Brasil: Tomate - exportações, importações e principais países, produtos selecionados - 1996 a 2005. Brasilia, 2006. Disponível em: <http://www.agricultura.gov.br /pls/portal/docs/PAGE/MAPA/ESTATISTICAS/AGRICULTURA_EM_NUMER OS_2005/03.04.39.XLS>. Acesso em: 16 mar. 2009.

BRASIL. Ministério da Agricultura, Pecuária e Abastecimento. Decreto $\mathbf{n}^{\circ}$ 4074, de 04 de janeiro de 2002. Dispõe sobre a pesquisa, a experimentação, a produção, a embalagem e rotulagem, o transporte, o armazenamento, a comercialização, a propaganda comercial, a utilização, a importação, a exportação, o destino final dos residuos e embalagens, o registro, a classificação, o controle, a inspeção e a fiscalização de agrotóxicos, seus componentes e afins, e dá outras providências. Disponível em: <http://extranet.agricultura.gov.br/sislegis-consulta/ consultarLegislacao. do?operacao=visualizar\&id=16764>. Acesso em: 16 mar. 2009.

BULDINI, P.L.; RICCI, L.; SHARMA, J.L. Recent applications of sample preparation techniques in food analysis. Journal of Chromatography $\mathbf{A}$, Amsterdam, v.975, n.1, p.47-70, 2002.

CARVALHO, J.L.; PAGLIUCA, L.G. Tomate: Um mercado que não pára de crescer globalmente. Hortifruti Brasil, Piracicaba, v.6, n.58, p.6-14, 2007. 
Disponivel em: <http://www.cepea.esalq.usp.br/hfbrasil/edicoes/58/full. pdf>. Acesso em: 17 mar. 2009.

CELLA, A. L. Ocorrência de agrotóxicos organofosforados e do organoclorado dicofol em maças (Malus domestica). 2002. 80f. Dissertação (Mestrado em Ciências) - Centro de Energia Nuclear na Agricultura, Universidade de São Paulo, Piracicaba, 2002.

CUNHA, S.C.; FERNANDES, J.O.; ALVES, A.; OLIVEIRA, M.B.P.P. Fast lowpressure gas chromatography-mass spectrometry method for the determination of multiple pesticides in grapes, musts and wines. Journal of Chromatography A, Amsterdam, v.1216, n.1, p.119-126, 2009.

DÍEZ, C.; TRAAG, W.A.; ZOMMER, P.; MARINERO, P.; ATIENZA, J. Comparison of an acetonitrile extraction/partitioning and "dispersive solidphase extraction" method with classical multi-residue methods for the extraction of herbicide residues in barley samples. Journal of Chromatography A, Amsterdam, v.1131, p.11-23, 2006.

DÓREA, H.S.; LANÇAS, F.M. Matrix solid-phase dispersion extraction of organophosphorus and synthetic pyrethroid pesticides in cashew nut and passion fruit. Journal of Microcolumn Separations, Provo, v.11, n.5, p.367-375, 1999.

EMBRAPA. Cultivo do tomate para industrialização. Gama: Embrapa Hortaliças, 2003. (Sistemas de Produção, 1). Disponivel em: <http://sistemasdeproducao.cnptia.embrapa.br/FontesHTML/Tomate/Tom ateIndustrial/index.htm>. Acesso em: 17 mar. 2009.

ERNEY, D.R.; GILLESPIE, A.M.; GILVYDIS, D.M.; POOLE, C.F. Explanation of the matrix-induced chromatographic response enhancement of organophosphorus pesticides during open tubular column gas chromatography with splitless or hot on-column injection and flame photometric detection. Journal of Chromatography, Amsterdam, v.638, p.57-63, 1993.

ETMINAN, M.; TAKKOUCHE, B.; CAAMAÑO-ISORNA, F. The role of tomato products and lycopene in the prevention of prostate cancer: a meta-analysis of observational studies. Cancer Epidemiology, Biomarkers \& Prevention, Denville, v.13, n.3, p.340-345, 2004.

EUROPEAN COMMISSION. Directorate General Health and Consumer Protection. SANCO/2007/3131: Method Validation and Quality Control Procedures for Pesticide Residues Analysis in Food and Feed. Brussels, 2007. 35p.

FAO. Codex Alimentarius: Pesticide Residues in Food. 2009a. Disponivel em: <http://www.codexalimentarius.net/mrls/pestdes/jsp/pest_q-e.jsp>. Acesso em: 12 jan. 2009. 
FAO. Consumption. Crops primary equivalent. Rome, 2009b. Disponivel em: <http: / / faostat.fao.org/site/609/DesktopDefault.aspx?PageID=609\#ancor\% 20per\%20capita>. Acesso em: 12 mar. 2009.

FAO. International code of conduct on the distribution and use of pesticides. Rome, 2002. Disponivel em: <http://www.fao.org/WAICENT /FAOINFO/AGRICULT/AGP/AGPP/Pesticid/Code/Download/Code.pdf>. Acesso em: 17 mar. 2009.

FAO. Production. ProdSTAT. Rome, 2009c. Disponivel em: <http: / faostat.fao.org/site/567 / DesktopDefault.aspx?PageID=567\#ancor $>$. Acesso em: 12 mar. 2009.

FERNANDEZ-ALVAREZ, M.; LLOMPART, M.; LAMAS, J.P.; LORES, M.; GARCIA-JARES, C.; CELA, R.; DAGNAC, T. Development of a matrix solidphase dispersion method for the simultaneous determination of pyrethroid and organochlorinated pesticides in cattle feed. Journal of Chromatography A, Amsterdam, v.1216, n.14, p.2832-2842, 2009.

FREITAS, S.S. Desenvolvimento de metodologia analitica para a determinação multiresiduo de pesticidas em frutas brasileiras. 2005. 181f. Tese (Doutorado em Ciências) - Instituto de Química de São Carlos, Universidade de São Paulo, São Carlos, 2005.

FRENICH, A.G.; BOLAÑOS, P.P.; VIDAL, J.L.M. Multiresidue analysis of pesticides in animal liver by gas chromatography using triple quadrupole tandem mass spectrometry. Journal of Chromatography A, Amsterdam, v.1153, n.1-2, p.194-202, 2007.

FUNDAÇÃO OSWALDO CRUZ. SINITOX - Sistema Nacional de Informações Tóxico-Farmacológicas. Rio de Janeiro, 2006. Disponível em: <http://www.fiocruz.br/sinitox/agrotoxicos/tabelas_casos/distribuicao.htm>. Acesso em: 23 mar. 2009.

GODOY, R.C.B.; OlIVEIRA, M.I. Agrotóxicos no Brasil: Processo de registro, riscos à saúde e programas de monitoramento. Cruz das Almas: Embrapa Mandioca e Fruticultura Tropical, 2004. (Documentos, 134). Disponivel em: <http://www.cnpmf.embrapa.br/publicacoes/documentos /documento_134.pdf>. Acesso em: 17 mar. 2009.

HAJSLOVA, J.; HOLADOVA, K.; KOCOUREK, V.; POUSTKA, J.; GODULA, M.; CUHRA, P.; KEMPNY, M. Matrix-induced effects: a critical point in the gas chromatographic analysis of pesticide residues. Journal of Chromatography A, Amsterdam, v.800, p.283-295, 1998.

HAJSLOVA, J.; ZROSTLÝKOVA, J. Matrix effects in (ultra)trace analysis of pesticide residues in food and biotic matrices. Journal of Chromatography A, Amsterdam, v.1000, p.181-197, 2003. 
HERNÁNDEZ-BORGES, J.; CABRERA, J.C.; RODRÍGUEZ-DELGADO, M.A.; HERNÁNDEZ-SUÁREZ, E.M.; SAÚCO, V.G. Analysis of pesticide residues in bananas harvested in the Canary Islands (Spain). Food Chemistry, Barking, v.113, n.1, p.313-319, 2009.

HERRMANN, S.S.; POULSEN, M.E. Method validation report. Determination of pesticides in cereals using the QuEChERS method and GCITD. Lyngby: National Food Institute, The Danish Technical University, 2007. 17p.

HÚŠKOVÁ, R.; MATISOVÁ, E.; KIRCHNER, M. Fast GC-MS pesticide multiresidue analysis of apples. Chromatografia, Heidelberg, v.68, p.49-55, 2008. Supplement 1.

IBGE. Pesquisa de orçamentos familiares 2002-2003. Rio de Janeiro, 2003. Disponivel em: <http://www.ibge.gov.br/home/estatistica /populacao/condicaodevida/pof/2002aquisicao/tab11.pdf>. Acesso em: 20 mar. 2009.

IBGE. Produção agricola municipal. Informações sobre culturas temporárias: quantidade e valor da produção, área plantada e colhida. Rio de Janeiro, 2007. Disponivel em: <http://www.sidra.ibge.gov.br/bda / tabela/listabl.asp?c=1612\&z=p\&o=22>. Acesso em: 11 mar. 2009.

IMOTO, M.N. Validação de método multiresiduo para pesticidas organohalogenados em maçã por cromatografia gasosa com captura de eletrons (CG/ECD) e cromatografia gasosa com espectrometria de massa (CG/MS). 2004. Dissertação (Mestrado em Tecnologia de Alimentos) Departamento de Engenharia Química, Universidade Federal do Paraná, Curitiba, 2004.

INSTITUTO BRASILEIRO DO MEIO AMBIENTE E DOS RECURSOS NATURAIS RENOVÁVEIS - IBAMA. Portaria Normativa $\mathbf{n}^{\circ} \mathbf{8 4}$, de 15 de outubro de 1996. Disponivel em: < http://servicos.ibama.gov.br/ ctf/ manual/html/Portaria_84.pdf>. Acesso em: 23 mar. 2009.

INSTITUTO NACIONAL DE METROLOGIA, NORMALIZAÇÃO E QUALIDADE INDUSTRIAL - INMETRO. Orientação sobre validação de métodos de ensaios químicos: DOQ-CGCRE-008. Rev. 02. Rio de Janeiro: INMETRO, 2007. 24p.

LACORTE, S.; FERNÁNDEZ-ALBA, A.R. Sample introduction techniques. In: FERNANDEZ-ALBA, A.R. (Ed.). Chromatographic-mass spectrometric food analysis for trace determination of pesticide residues. Amsterdam: Elsevier, 2005. cap.5, p.235-267. (Comprehensive Analytical Chemistry, 43).

LANÇAS, F.M. Extração em fase sólida (SPE). São Carlos: Rima, 2004. 96p.

LARA, W.H.; BATISTA, G.C. Pesticidas. Química Nova, São Paulo, v.15, n.2, p. 161,1992 . 
LAVAGNINI, I.; MAGNO, F.; SERAGLIA, R.; TRALDI, P. Quantitative applications of mass spectrometry. Chichester: John Wiley \& Sons, 2006. $138 \mathrm{p}$.

LEHOTAY, S.J. Analysis of pesticide residues in mixed fruit and vegetable extracts by direct sample introduction/gas chromatography/tandem mass spectrometry. Journal of AOAC International, Arlington, v.83, n.3, p.680697, 2000.

LEHOTAY, S.J.; LIGHTFIELD, A.R.; HARMAN-FETCHO, J.A.; DONOGHUE, D.J. Analysis of pesticide residues in eggs by direct sample introduction/gas chromatography/tandem mass spectrometry. Journal of Agricultural and Food Chemistry, Easton, v.49, p.4589-4596, 2001.

LEHOTAY, S.J.; MASTOVSKA, K.; LIGHTFIELD, A.R. Use of buffering and other means to improve results of problematic pesticides in a fast and easy method for residue analysis of fruits and vegetables. Journal of AOAC International, Arlington, v.88, n.2, p.615-629, 2005.

LEHOTAY, S.J.; MASTOVSKA, K.; YUN, S.J. Evaluation of two fast and easy methods for pesticide residue analysis in fatty food matrixes. Journal of AOAC International, Arlington, v.88, n.2, p.630-638, 2005.

LEHOTAY, S.J.; Quick, easy, cheap, effective, rugged, and safe approach for determining pesticide residues. In: MARTÍNEZ VIDAL, J.L.; FRENICH, A.G. (Ed.). Pesticide protocols. Totowa: Humana Press, 2005. p.239-261. (Methods in Biotechnology, 19).

MACIEL, E. Desenvolvimento e validação de metodologia analítica de multiresiduos para quantificação de residuos de pesticidas em mangas (Mangifera indica). 2005. 70f. Dissertação (Mestrado em Ecologia de Agroecossistema) - Escola Superior de Agricultura Luiz de Queiroz, Universidade de São Paulo, Piracicaba, 2005.

MELO, P.C.T.; VILELA, N.J. Desafios e perspectivas para a cadeia brasileira do tomate para processamento industrial. Horticultura Brasileira, Brasília, v.23, n.1, p.154-157, 2005.

MENKISSOGLU-SPIROUDI, U.; FOTOPOULOU, A. Matrix effect in gas chromatographic determination of insecticides and fungicides in vegetables. International Journal of Environmental Analytical Chemistry, London, v.84, n.1-3, p.15-27, 2004.

NAIKA, S.; JEUDE, J. van L.; GOFFAU, M.; HILMI, M.; DAM, B. Van. A cultura do tomate: produção, processamento e comercialização. Wageningen: Fundação Agromisa e CTA, 2006.

NATIONAL INSTITUTE OF STANDRDS AND TECHNOLOGY - NIST. Livro de quimica na Web. Tradução Rui Pinto, Isabel Correia. Gaithersburg, 2005. 
(Base de dados de Referência padrão do NIST 69). Disponível em: <http://webbook.nist.gov/chemistry>. Acesso em: 13 mar. 2009.

OVIEDO, M.T.P.; TOLEDO, M.C. de; VICENTE, E. Determinação de resíduos de agrotóxicos organoclorados em hortaliças. Pesticidas: Revista de Ecotoxicologia e Meio Ambiente, Curitiba, v.12, p.111-130, 2002.

PANG, G.F.; CAO, Y.Z.; ZHANG J.J., FAN C.L.; LIU, Y.M.; LI, X.M.; JIA, G.Q.; LI, Z.Y.; SHI, Y.Q.; WU, Y.P.; GUO, T.T. Validation study on 660 pesticide residues in animal tissues by gel permeation chromatography cleanup/gas chromatography-mass spectrometry and liquid chromatography-tandem mass spectrometry. Journal of Chromatography A, Amsterdam, v.1125, p.1-30, 2006.

PESSINI, M.M.O. Residuos de Acetamiprid e Thiamethoxam em tomate estaqueado (Lycopersicon esculentum Mill.), em diferentes modalidades de aplicação. 2003. 71 f. Dissertação (Mestrado em Entomologia) - Escola Superior de Agricultura "Luiz de Queiroz", Universidade de São Paulo, Piracicaba, 2003.

PINHO, G.P. de. Extração de pesticidas em amostras de tomate pelas técnicas: extração sólido-liquido e purificação em baixa temperatura (ESL-PBT) e dispersão da matriz em fase sólida (DMFS) para análise por cromatografia gasosa. 2007. 98f. Dissertação (Mestrado) - Universidade Federal de Viçosa.

PINHO, G.P.; NEVES, A.A.; QUEIROZ, M.E.L.R.; SILVÉRIO, F.O. Efeito de matriz na quantificação de agrotóxicos por cromatografia gasosa. Química Nova, São Paulo, v.32, n.4, p.987-995, 2009.

RIBANI, M.; BOTTOLI, C.B.G.; COLLINS, C.H.; JARDIM, I.C.S.F.; MELO, L.F.C. Validação em métodos cromatográficos e eletroforéticos. Química Nova, São Paulo, v.27, n.5, p.771-780, 2004.

SANCHES, S.M.; SILVA, C.H.T.P.; CAMPOS, S.X.; VIEIRA, E. M. Pesticidas e seus respectivos riscos associados à contaminação da água. Pesticidas: Revista de Ecotoxicologia e Meio Ambiente, Curitiba, v.13, p.53-58, 2003.

SANTOS, M.A.T.; AREAS, M.A.; REYES, F.G.R. Piretróides - Uma visão geral. Alimentos e Nutrição, Araraquara, v.18, n.3, p.339-349, 2007.

SCHENCK, F.J.; LEHOTAY, S.J. Does further clean-up reduce the matrix enhancement effect in gas chromatographic analysis of pesticide residues in food? Journal of Chromatography A, Amsterdam, v.868, p.51-61, 2000.

SCHENCK, F.J.; LEHOTAY, S.J.; VEGA, V. Comparison of solid-phase extraction sorbents for cleanup in pesticide residue analysis of fresh fruits and vegetables. Journal of Separation Science, New York, v.25, p.883-890, 2002. 
SHEN, G.; HU, X.; HU, Y. Kinetic study of the degradation of the insecticide pymetrozine in a vegetable-field ecosystem. Journal of Hazardous Materials, Amsterdam, v.164, p.497-501, 2009.

SINDICATO NACIONAL DA INDÚSTRIA DE PRODUTOS PARA DEFESA AGRÍCOLA - SINDAG. Mercado de defensivos. Câmara temática de insumos agropecuários. Porto Alegre, 2008. Disponivel em: <http://www.sindag.com.br/upload/Vendasjaneirooutubro.ppt>. Acesso em: 20 mar. 2009.

SOBOLEVA, E.; KARAM, A.; AMBRUS, A. Applicability of some mass spectrometric criteria for the confirmation of pesticide residues. The Analyst, London, v.129, p.1123-1129, 2004.

SPADOTTO, C. A.; GOMES, M. A. F.; LUCHINI, L. C.; ANDRÉA, M. M. Monitoramento do risco ambiental de agrotóxicos: princípios e recomendações. Jaguariúna: Embrapa Meio Ambiente, 2004. (Documentos, 42). Disponivel em: <http://www.cnpma.embrapa.br/download /documentos_42.pdf>. Acesso em: 23 mar. 2009.

STEPAN, R.; TICHA, J.; HAJSLOVA, J. Baby food production chain: Pesticide residues in fresh apples and products. Food Additives and Contaminants A, London, v.22, n.12, 1231-1242, 2005. Disponivel em: <http: / / www.informaworld.com/smpp/section?content=a727751821\&fullte $\mathrm{xt}=713240928>$. Acesso em: 17 mar. 2009.

UNIVERSIDADE DE SÃO PAULO. FACULDADE DE CIÊNCIAS FARMACÊUTICAS - USP/FCF. Departamento de Alimentos e Nutrição Experimental. Tabela brasileira de composição de alimentos. Projeto integrado de composição de alimentos. 2008. Disponivel em: <http: / / www.fcf.usp.br/tabela/resultado.asp?IDLetter=B\&IDNumber=659>. Acesso em: 02 abr. 2009.

USDA. Foreign Agricultural Service. Brazil Tomatoes and products. Annual Report 2008. Washington, 2008. Disponivel em: <http://www.fas. usda.gov/gainfiles/200805/146294775.pdf>. Acesso em: 02 abr. 2009.

ZROSTLÝKOVA, J.; HAJSLOVA, J.; GODULA M.; MASTOVSKA, K. Performance of programmed temperature vaporizer, pulsed splitless and oncolumn injection techniques in analysis of pesticide residues in plant matrices. Journal of Chromatography A, Amsterdam, v.937, p.73-86, 2001. 
APÊNDICE A 


\section{Acefato}

O acefato (O,S-dimethyl acetylphosphoramidothioate) de fórmula química $\mathrm{C}_{4} \mathrm{H}_{10} \mathrm{NO}_{3} \mathrm{PS}$, número $\mathrm{CAS}$ 30560-19-1 pertence a classe toxicológica III (ANVISA, 2009), possui aplicação foliar na cultura de tomate e é empregado como inseticida e acaricida. Pertence ao grupo químico dos organofosforados e possui LMR estabelecido pela legislação brasileira na cultura de tomate de $0,5 \mathrm{mg} / \mathrm{kg}$, intervalo de segurança de 7 dias e ingestão diária aceitável (IDA) de 0,03 $\mathrm{mg} / \mathrm{kg}$ de peso corpóreo (BRASIL, 2003b). O LMR proposto pelo Codex foi revogado para a cultura do tomate (FAO, 2009a).

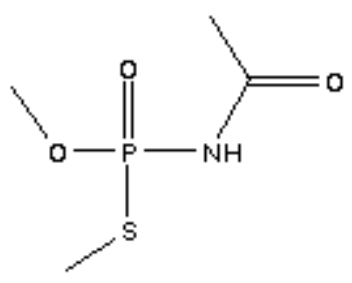

Fonte: NIST, 2005

Figura 13 - Fórmula estrutural do acefato

\section{Buprofezina}

A buprofezina (2-tert-butylimino-3-isopropyl-5-phenyl-1,3,5thiadiazinan-4-one) de fórmula química $\mathrm{C}_{16} \mathrm{H}_{23} \mathrm{~N}_{3} \mathrm{OS}$, número CAS 6932776-0 pertence a classe toxicológica IV (ANVISA, 2009), possui aplicação foliar na cultura de tomate e é empregado como inseticida e acaricida. Pertence ao grupo químico das tiadiazinonas e possui LMR estabelecido pela legislação brasileira na cultura de tomate de $0,5 \mathrm{mg} / \mathrm{kg}$ e pelo Codex de $1,0 \mathrm{mg} / \mathrm{kg}$, intervalo de segurança de 7 dias e IDA de $0,01 \mathrm{mg} / \mathrm{kg}$ de peso corpóreo (BRASIL, 2003b; FAO, 2009a). 


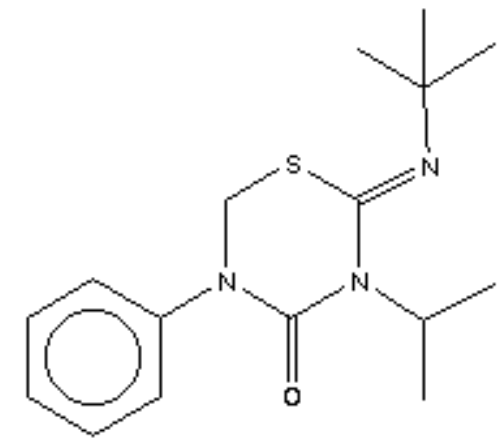

Fonte: NIST, 2005

Figura 14 - Fórmula estrutural da buprofezina

\section{Carbofurano}

O carbofurano (2,3-dihydro-2,2-dimethylbenzofuran-7-ylmethyl carbamate) de fórmula química $\mathrm{C}_{12} \mathrm{H}_{15} \mathrm{NO}_{3}$, número CAS 1563-66-2 pertence a classe toxicológica I (ANVISA, 2009), possui aplicação no solo na cultura de tomate e é empregado como inseticida, cupinicida, acaricida e nematicida. Pertence ao grupo químico do metilcarbamato de benzofuranila e possui LMR estabelecido pela legislação brasileira na cultura de tomate de 0,1 $\mathrm{mg} / \mathrm{kg}$, intervalo de segurança de 60 dias e IDA de $0,002 \mathrm{mg} / \mathrm{kg}$ de peso corpóreo (BRASIL, 2003b). O LMR proposto pelo Codex foi revogado para a cultura do tomate (FAO, 2009a). 


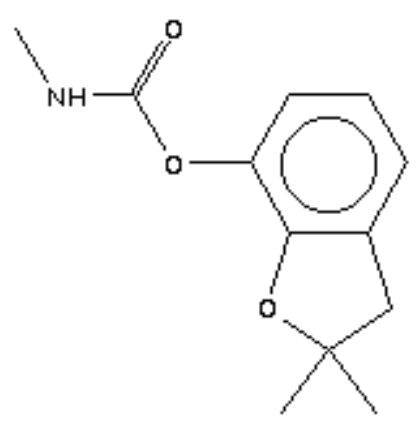

Fonte: NIST, 2005

Figura 15 - Fórmula estrutural do carbofurano

\section{Deltametrina}

A deltametrina [(S)-a-cyano-3-phenoxybenzyl (1R,3R)-3-(2,2dibromovinyl)- 2,2-dimethylcyclopropanecarboxylate] de fórmula química $\mathrm{C}_{22} \mathrm{H}_{19} \mathrm{Br}_{2} \mathrm{NO}_{3}$, número CAS 52918-63-5 pertence a classe toxicológica III (ANVISA, 2009), possui aplicação foliar na cultura de tomate e é empregado como inseticida e formicida. Pertence ao grupo químico dos piretróides e possui LMR estabelecido pela legislação brasileira na cultura de tomate de $0,03 \mathrm{mg} / \mathrm{kg}$ e pelo Codex de 0,3 $\mathrm{mg} / \mathrm{Kg}$, intervalo de segurança de 3 dias e IDA de 0,01 mg/kg de peso corpóreo (BRASIL, 2003b; FAO, 2009a).

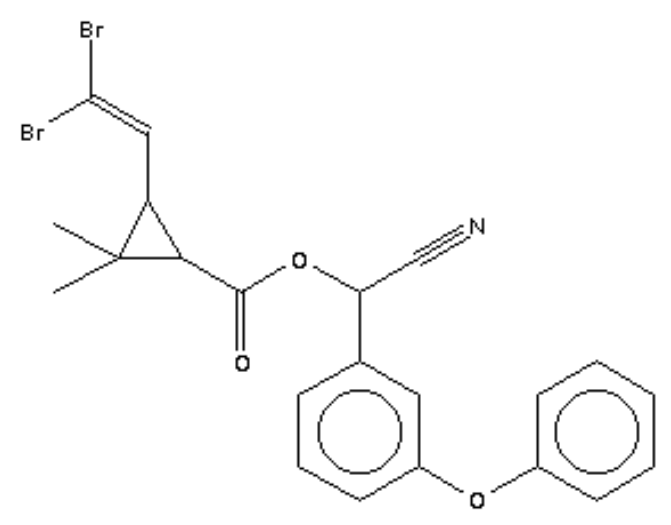

Fonte: NIST, 2005

Figura 16 - Fórmula estrutural da deltametrina 


\section{Difenoconazol}

O difenoconazol (cis-trans-3-chloro-4-[4-methyl-2-(1H-1,2,4-triazol-1ylmethyl)-1,3-dioxolan-2-yl]phenyl 4-chlorophenyl ether) de fórmula química $\mathrm{C}_{19} \mathrm{H}_{17} \mathrm{Cl}_{2} \mathrm{~N}_{3} \mathrm{O}_{3}$, número CAS $119446-68-3$ pertence a classe toxicológica I (ANVISA, 2009), possui aplicação foliar na cultura de tomate e é empregado como fungicida. Pertence ao grupo químico do triazol e possui LMR estabelecido pela legislação brasileira na cultura de tomate de $0,1 \mathrm{mg} / \mathrm{kg}$ e pelo Codex de 0,5 mg/Kg, intervalo de segurança de 14 dias e IDA de 0,6 $\mathrm{mg} / \mathrm{kg}$ de peso corpóreo (BRASIL, 2003b; FAO, 2009a).

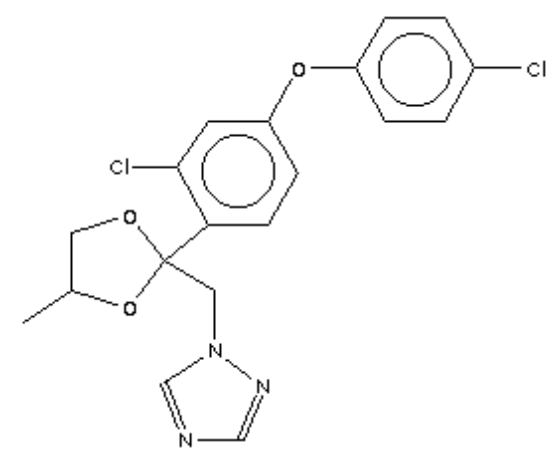

Fonte: NIST, 2005

Figura 17 - Fórmula estrutural do difenoconazol

\section{Endossulfam ( $\alpha, \beta$ e sulfato)}

O endossulfam $[(1,4,5,6,7,7$-hexachloro-8,9,10-trinorborn-5-en-2,3ylenebis methylene) sulfite] de fórmula química $\mathrm{C}_{9} \mathrm{H}_{6} \mathrm{Cl}_{6} \mathrm{O}_{3} \mathrm{~S}$ (soma de $\alpha, \beta$ endossulfam) número CAS 115-29-7 e o sulfato de endossulfam de fórmula química $\mathrm{C}_{9} \mathrm{H}_{6} \mathrm{Cl}_{6} \mathrm{O}_{4} \mathrm{~S}$ e número CAS 1031-07-8, pertence a classe toxicológica I (ANVISA, 2009), possui uso indevido na cultura de tomate e é empregado como acaricida, inseticida e formicida nas culturas de algodão, cacau, café, cana-de-açúcar e soja. O produto técnico é composto pelos isômeros $\alpha$ e $\beta$ 
endossulfam e o sulfato de endossulfam é produto de degradação. Pertence ao grupo químico do ciclodienoclorado e possui LMR estabelecido pela legislação brasileira somente para as culturas de cacau e cana-de-açúcar de $0,01 \mathrm{mg} / \mathrm{kg}$, intervalo de segurança de 30 dias e IDA de $0,006 \mathrm{mg} / \mathrm{kg}$ de peso corpóreo (BRASIL, 2003b). O LMR proposto pelo Codex foi revogado para a cultura do tomate (FAO, 2009a).

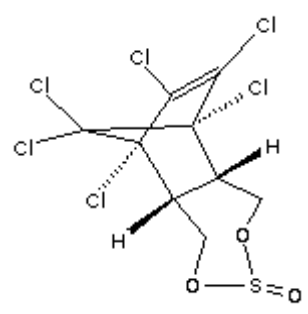

$\alpha$-endossulfam

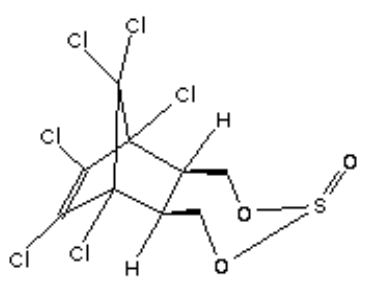

$\beta$-endossulfam

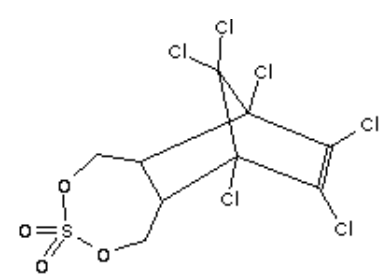

endossulfam Sulfato

Fonte: NIST, 2005

Figura 18 - Fórmula estrutural do $\alpha, \beta$ endossulfam e endossulfam sulfato

\section{Fenpropatrina}

A fenpropatrina [(RS)-alfa-cyano-3-phenoxybenzyl 2,2,3,3tetramethylcyclopropanecarboxylate] de fórmula química $\mathrm{C}_{22} \mathrm{H}_{23} \mathrm{NO}_{3}$, número CAS 39515-41-8 pertence a classe toxicológica II (ANVISA, 2009), possui aplicação foliar na cultura de tomate e é empregado como inseticida e acaricida. Pertence ao grupo químico dos piretróides e possui LMR estabelecido pela legislação brasileira na cultura de tomate de $0,2 \mathrm{mg} / \mathrm{kg}$ e pelo Codex de $1 \mathrm{mg} / \mathrm{Kg}$, intervalo de segurança de 3 dias e IDA de 0,03 mg/kg de peso corpóreo (BRASIL, 2003b; FAO, 2009a). 


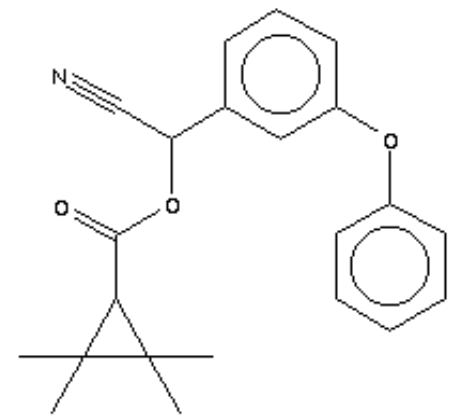

Fonte: NIST, 2005

Figura 19 - Fórmula estrutural da fenpropatrina

\section{Monocrotofós}

O monocrotofós [dimethyl (E)-1-methyl-2-(methylcarbamoyl)vinyl phosphate)] de fórmula química $\mathrm{C}_{7} \mathrm{H}_{14} \mathrm{NO}_{5} \mathrm{P}$, número CAS 6923-22-4 era empregado como inseticida e acaricida, mas segundo Ofício $\mathrm{n}^{\circ}$ 008/06/GENAV de 06 de fevereiro de 2006, ficou estabelecido a data de 15 de março de 2006, como limite para comercialização de agrotóxicos a base de monocrotofós, sendo proibido a partir desta data. Pertence ao grupo químico dos organofosforado e não possui LMR estabelecido pela legislação brasileira e pelo Codex para nenhuma cultura (BRASIL, 2003b; FAO, 2009a).

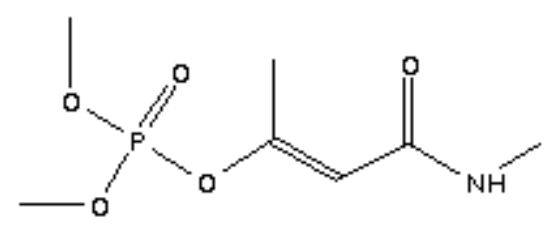

Fonte: NIST, 2005

Figura 20 - Fórmula estrutural do monocrotofós 